
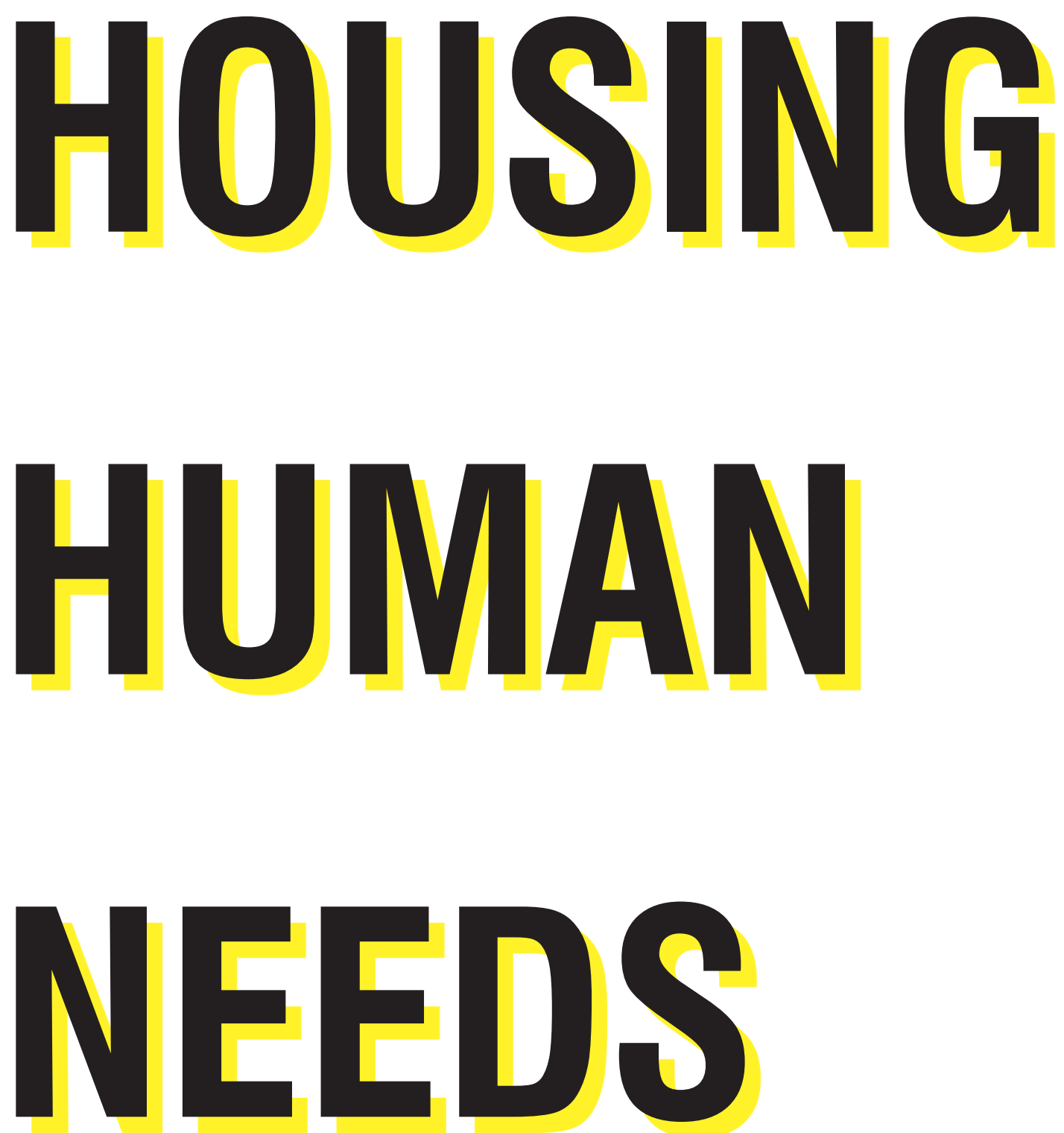

\section{ADDRESSING THE} PSYCHOLOGICAL

NEEDS OF OCCUPANTS THROUGH

MEDIUM-DENSITY HOUSING 
HOUSING HUMAN NEEDS: ADDRESSING THE PSYCHOLOGICAL NEEDS OF OCCUPANTS

THROUGH MEDIUM-DENSITY HOUSING

BY

\section{SASKIA SIMPSON}

A 120 point thesis submitted to the Victoria University of Wellington

in fulfilment of the requirements for the degree of

Master of Architecture (Professional)

Victoria University of Wellington

(2020) 
ACKNOWLEDGEMENTS

ABSTRACT

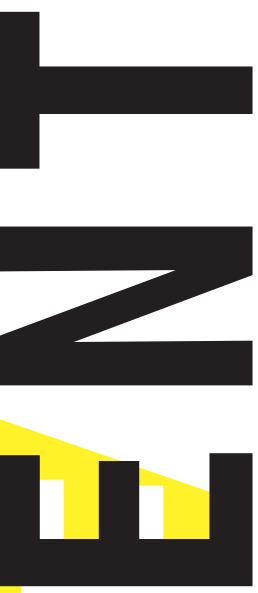

\subsection{RESEARCH AGENDA}

1.1 INTRODUCTION

1.2 RESEARCH QUESTION

1.3 AIM + OBJECTIVES

1.4 METHODOLOGY

1.5 OVERVIEW OF RESEARCH PORTFOLIO

\subsection{CONTEXT}

2.1 LITERATURE REVIEW: HOUSING AND PSYCHOLOGY

2.2 SITE INTRODUCTION

2.3 DESIGN FRAMEWORK

2.4 CASE STUDIES

\subsection{DESIGN PROCESS}

3.1 SITE SELECTION + ANALYSIS

3.2 INTRODUCTION OF DESIGN EXPERIMENTS

3.3 MASTER PLANNING

3.4 LICHFIELD STREET

3.5 HEREFORD STREET

3.6 CASHEL STREET

3.7 SUMMARY OF DESIGN

\subsection{REFLECTION}

4.1 REFLECTIONS

4.2 CONCLUSION

BIBLIOGRAPHY

LIST OF FIGURES 

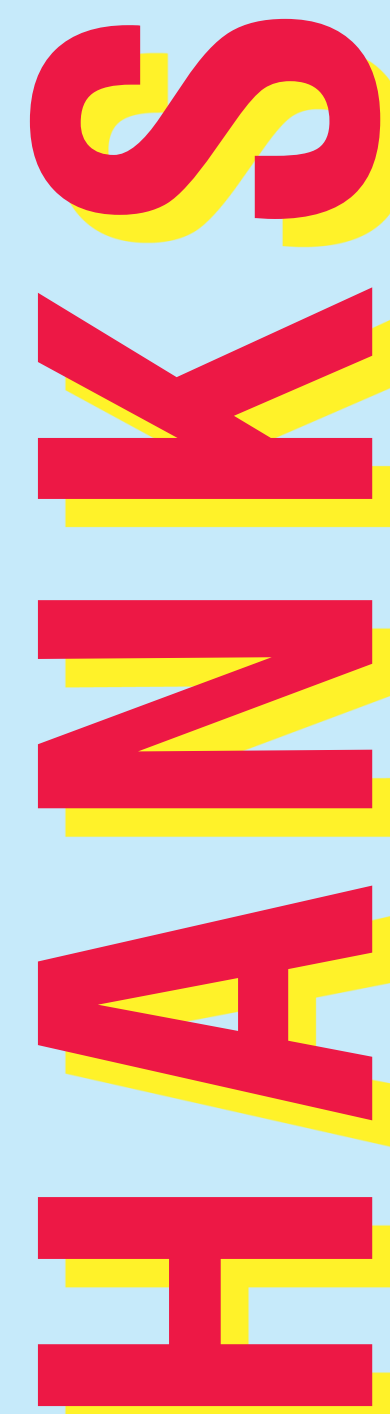

My sincere gratitude goes out to you all.

Thank you, Morten Gjerde, my supervisor, for your guidance throughout the year and for sharing your expertise in the urban and housing domains.

Thank you to all those who helped me along during the last five years at the School of Architecture. My time here would not have been possible without the love and support I received from my family and friends from near and far. 
An ever-increasing population calls for more housing at higher densities. New Zealand is struggling to keep up with the demand for housing, and consequently, the country is experiencing a housing crisis. In addressing this demand, developer-led projects are becoming more frequent. However, the focus of developer-led construction is often on costs and profits, not its future occupants' well-being. Many studies have shown that the physical environment, especially the quality of housing, affects the human psyche. New Zealand's current situation offers the opportunity to alter the way housing is designed to benefit society. This design-led research portfolio informs architects and designers of human psychological needs and the importance of facilitating them through the design of housing. The study develops a framework based on Maslow's Hierarchy of Human Needs, which assists architects and designers in creating housing at higher densities, more holistically. Finally, the introduction of a specific site allows the framework to be tested and evaluated through an iterative process of architectural design in an appropriate situation; Christchurch, New Zealand. 


\subsection{RESEARCH AGENDA}

1.1 INTRODUCTION

1.2 RESEARCH QUESTION

1.3 AIM + OBJECTIVES

1.4 METHODOLOGY

1.5 OVERVIEW OF RESEARCH PORTFOLIO 


\subsection{INTRODUCTION}

New Zealand is currently in the midst of a housing crisis. There is a shortfall of housing, and it is growing each month (Johnson et al., 2018). In addressing this need, the focus has been on numbers; however, in meeting the demand, there is also an opportunity to address quality issues. Can housing, particularly when created at scale, also address people's well-being?

This thesis sets out to provide an approach to combating the housing crisis while simultaneously addressing the quality of life of the occupants of the housing.

To begin, a literature review discusses the current state of housing and well-being in New Zealand and justifies the argument that housing affects one's well-being. The literature review introduces the psychologist Abraham Maslow and his Theory of Human
Motivation (1943). Maslow's Hierarchy of Needs is a well-known model in psychology and is referenced in many other fields. This research grounds the hierarchy in architectural design for housing. The hierarchy informs a framework for design, consisting of six criteria based upon the top three needs of the pyramid. The six criteria bridge the gap between the more abstract Hierarchy of Needs and pragmatic needs for architectural design. They are devised to encourage and give direction to designers to facilitate the psychological needs of occupants through the design of their housing. A site in Christchurch, New Zealand, is selected to evaluate the potential for this framework to support the design activity.

Before the research commences with the design, cases of existing projects are studied and evaluated next to the framework to ascertain techniques for incorporating the criteria from the framework into the design of medium-density housing.

Finally, the framework is tested through architectural design at two scales: the Masterplan of two city blocks (with a total area of $220 \mathrm{~m} \times 220 \mathrm{~m}$ ), and a smaller scale looking at three separate areas within the Masterplan, each with a cluster of dwellings on it. The criteria are tested in a variety of ways by working backwards and forwards between the two scales, and between the three sites at the smaller scale. Thus, the research tests the framework through a design research methodology. The study is undertaken in the context of research through architectural design and provides a platform for design. 


\section{RESEARCH QUESTION}

How can the design of medium-density housing support its occupants to meet their psychological needs? 


\section{RESEARCH AIM AND OBJECTIVES}

The research aims to explore how the design of the home and neighbourhood can support occupants to meet their psychological needs, based on Maslow's Hierarchy of Needs.

1. To design medium-density housing that enables its occupants to meet their social needs.

2. To design medium-density housing that encourages people to meet their esteem needs.

3. To design medium-density housing that supports residents to meet their self-actualisation needs.

4. To create a robust design framework for others to adopt and use in their future housing developments. 


\subsection{METHODOLOGY}

The study uses design-led research as the primary methodology through an exploratory and iterative design approach. The following stages inform the conceptual and developed design process

1. A literature review opens the discussion about the current states of housing and wellbeing and introduces Maslow's Hierarchy of Needs, a founding theory upon which the research is based.

2. The introduction of a site gives more context to the project and places importance on the need for better housing at higher densities. The site also helps to focus the philosophical issues that the research works with, on a physical form and space.
3. Based on the findings from the literature review and site introduction, a robust design framework interprets Maslow's Hierarchy of Needs and grounds the theory in architectural design.

4. Finally, a look into existing architectural projects give examples of how the design framework might work and actualise in the design of medium-density housing.

The most substantial weight of the research project, the design process itself, follows iterations of a Masterplan of two large city blocks and three smaller design experiments within the Masterplan. Lessons and strategies learned in the different areas of the design are transposed to other areas to qualify the design.
At the initial stages of design, a focus is placed upon hand-drawn sketches, basic digital model massing, and tracing over the digital models as a means of generating design ideas. The process of a pencil to page allows a clear thought process, as uninterrupted as possible by the medium of the computer. Later, the developed design phase employed computer software to enhance the design.

Due to the nature and diversity of human beings and architecture, no one statement or design alone can answer the research question; thus, the outcomes of the project are presented as a solution, not the solution. The study invites further research and discovery in this field. 


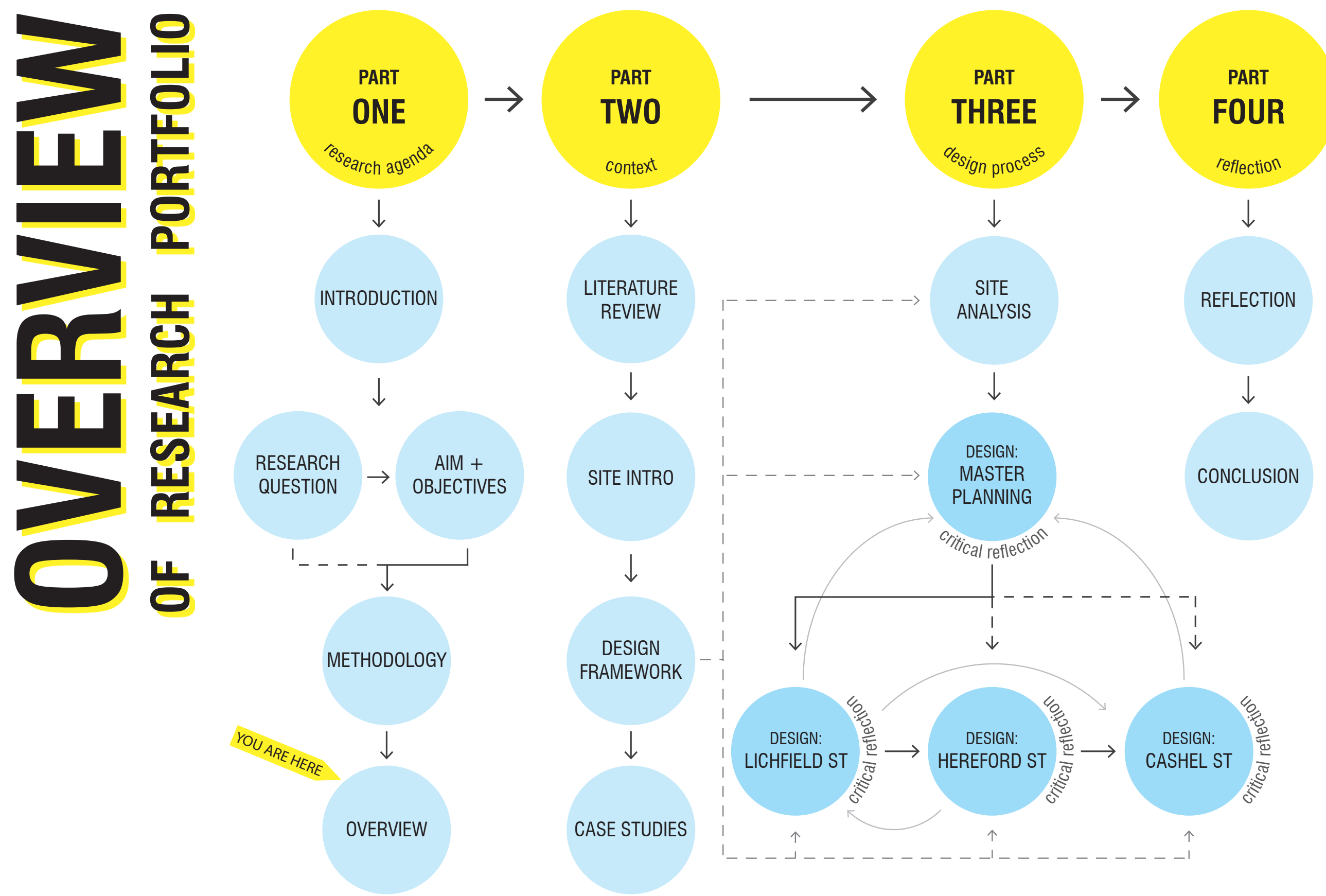




\subsection{CONTEXT}

2.1 LITERATURE REVIEW: HOUSING AND PSYCHOLOGY

2.2 SITE INTRODUCTION

2.3 DESIGN FRAMEWORK

2.4 CASE STUDIES 


\subsection{LITERATURE REVIEW: HOUSING AND PSYCHOLOGY}

\subsubsection{HOUSING CURRENTLY}

Currently, housing is being created at a mass scale to address an increasing population and demands for more homes. With the population increasing globally to an estimated 9.8 billion by 2050 ("United Nations Population Division", 2019), and in New Zealand from 4.9 million currently to between 5.3 and 7.9 million by 2068 (MacPherson, 2016), the world desperately needs more housing. Medium-density housing (MDH) developments are becoming more popular in New Zealand, as they make better use of the land resource and infrastructure systems. However, $\mathrm{MDH}$ is often developer-led, meaning that it is not the end-user that is the focal point of the project, but the costs and profits. Developer- led projects are not holistic and usually follow a one-size-fits-all notion. The housing developments are designed to meet the building code but often fall short of their potential to support occupants with their well-being. There is, however, an opportunity to develop housing to promote well-being and psychological health.

\subsubsection{WELL-BEING CURRENTLY}

Well-being is a topic currently being discussed both nationally and globally. Of the 17 Sustainable Development Goals (SDG) created by the United Nations, the third is Good Health and Well-being. The Goals were designed for all countries to protect the planet and encourage prosperity. Individuals and communities need to achieve good well- being. The UN state in their Goals, "Ensuring healthy lives and promoting well-being for all at all ages is important to building prosperous societies." It is also much easier to attain other SDGs from the platform of good well-being ("Sustainable Development Goals Report", 2019). The New Zealand Government is also turning its attention to well-being through the Local Government (Community Well-Being) Amendment Bill 2018. The Act outlines the four aspects of well-being, namely social, economic, environmental and cultural (Grimes, 2019; Morrison, 2019). Well-being is a matter that must be addressed holistically to create systems that support a healthy society. This thesis discusses the role that architecture plays in well-being. 


\subsubsection{THE PHYSICAL ENVIRONMENT'S EFFECT ON PEOPLE}

A significant factor that affects one's wellbeing is the physical conditions of the environment (Campos-Andrade et al., 2013). Evans et al. (2003) published a review of research on housing and mental health and concluded: "sufficient evidence exists to claim that housing does matter for psychological health.". The study also confirmed that there is a positive correlation between psychological well-being and housing quality. Bratt (2002) also affirms that higher psychological comfort is related to better housing quality. Thus, this thesis addresses the shortfall in both housing and mental health.

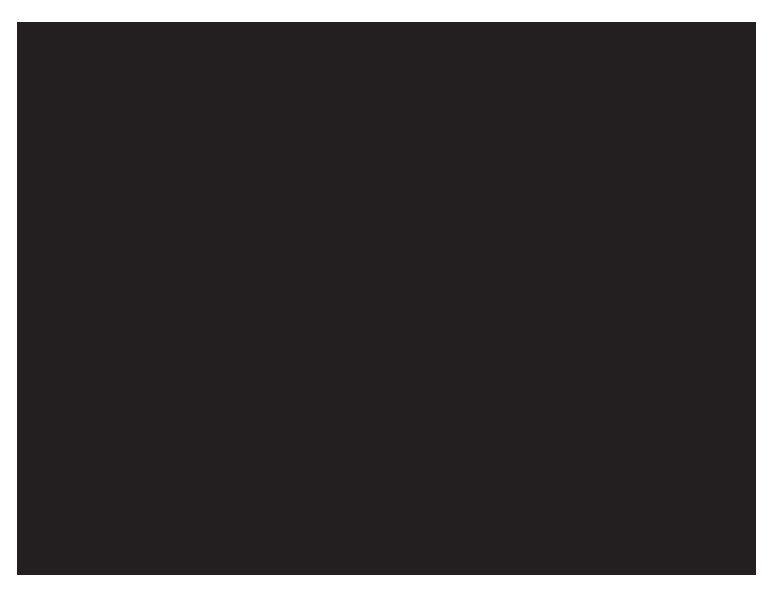

Figure 2.1. Abraham Maslow.

\subsubsection{MASLOW'S THEORY}

A crucial aspect of mental health and wellbeing is psychological. The thesis has, therefore, followed the research and teachings of psychologist Abraham Maslow (1908 1970), as a way to understand psychology and to place human needs and motivation at the forefront of the housing design. Maslow studied human motivation and the characteristics of psychologically healthy people. Later, Seligman and Csikszentmihalyi (2000) stated that much of psychology focuses on the "disease model" which studies mentally ill people. The significant strides in the prevention of such ill-being have, however, come mainly from fostering human strengths such as courage and interpersonal skills. "Positive Psychology" was the term given to this area of study, which arguably includes Maslow's studies of psychologically healthy people. In "A Theory of Human Motivation" (1943), Maslow described a way to understand the motivations of humans and their different psychological needs. In this article, he explained five levels of human needs and how a hierarchy arranges them. Maslow's Hierarchy of Human Needs consists of five levels of needs experienced by human beings (Figure 2.2). It begins with physiological needs, which are fundamental to the functioning of the human body. These are things such as food, water, shelter and warmth. Physiological needs sit at the bottom of the hierarchy as they are the 


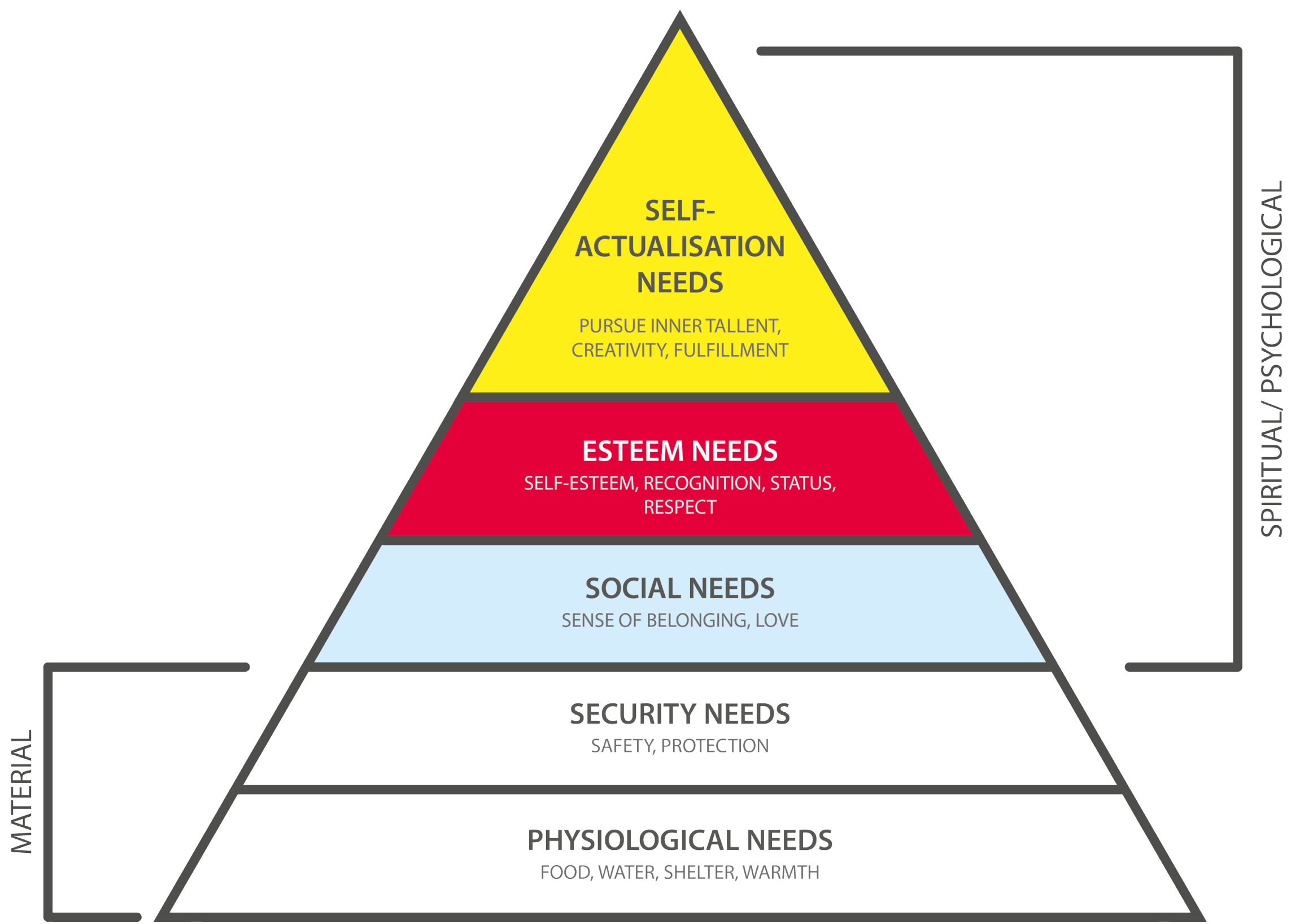

Figure 2.2. Maslow's Hierarchy of Needs. 
most fundamental. Once these needs have been satisfied, one will seek security and safety (the second tier). "Material needs" is the grouping of physiological and security needs, and currently, housing is doing its job of facilitating them. It is the higherlevel "spiritual/ psychological needs" that $\mathrm{MDH}$ developments rarely provide for well. The first tier of the spiritual/ psychological grouping and the next in the progression is social needs. When a person perpetually has enough food and water and is warm and safe, they will naturally desire love and a sense of belonging. When social needs are satisfied, the next need, esteem, emerges. There are two categories of esteem needs. These are, firstly, the want for strength, confidence and independence, and secondly, the desire for attention, appreciation, prestige, and respect from others. Satisfying these needs can make one feel worthy, confident and necessary in the world. However, not meeting this need can lead to feelings of helplessness, inferiority and weakness. The fifth and final tier is self-actualisation. To accomplish the full potential of the human experience, is the meaning of "self-actualisation".

"A musician must make music, an artist must paint, a poet must write, if he is to be ultimately happy. What a man can be, he must be. This need we may call selfactualisation" (Maslow, 1943).

As the needs are sorted by a hierarchy, for any need to be met, one must meet all preceding needs. Therefore, one who fulfils their selfactualisation needs (and thereby all other needs), is in the top percentile of human psychological health (Maslow, 1943).
Maslow studied the characteristics of such people and found some qualities that they all had in common. These are traits such as honesty, awareness, freedom and trust. Honesty refers to interpersonal relationships that are of real love, not of gratification. Awareness refers to a clear perception of reality that is not skewed, i.e. self-actualised people have strong morals, knowing right from wrong. Freedom refers to one being naturally spontaneous and creative. Finally, trust was referred to by Maslow as "autonomy" (Maslow, 1968). A self-actualised person has true autonomy. 


\subsubsection{RELATEDNESS, COMPETENCE AND AUTONOMY}

Ryan and Deci (2000) concluded that the needs for relatedness, competence and autonomy are essential for personal wellbeing. These three needs run parallel to Maslow's spiritual/ psychological needs. Ryan and Deci (2000) defined relatedness as "the need to feel belongingness and connectedness with others", or, in Maslow's terms, "social needs". Competence generally refers to the first category of esteem needs by Maslow; strength, confidence and independence. Finally, it is vital for individuals to have some autonomy, and as Maslow explained in his interview (1968), autonomy is a symptom of one who is selfactualised. Thus, the terms relatedness, competence and autonomy can be used to understand Maslow's theory further.
Housing facilitates material needs; however, people have other psychological needs to meet. When people continuously have their material needs met, the satisfaction of higher needs can be contemplated. However, lowerlevel needs must be met and kept for one to pursue higher-level.

These higher-level needs can be met by facilities that nurture occupants' needs for relatedness, competence and autonomy. "Treatment is not just fixing what is broken; it is nurturing what is best" (Seligman and Csikszentmihalyi, 2000). It is, therefore, the purpose of this research to design housing that not only supports lower-level/ material needs but higher-level/ psychological needs as well.

\subsubsection{THE PURPOSE AND POTENTIAL OF HOUSING}

Although housing provides security, shelter (protection from the elements and the public), and warmth (in most cases), it has the potential to be doing more. Housing could be supporting occupants to achieve better well-being. The meaning of home has been theorised and studied by many academics. Despres (1991) gathered the findings from studies of occupants' meanings of home and reported ten categories that the studies most commonly identified. Each of the ten categories fits into at least one of the tiers of Maslow's Hierarchy of Human Needs. For example, "Home as Security and Control" means the home facilitates security needs, "Home as Relationships with Family and Friends" means that the home facilitates social needs, and "Home as Reflection as One's Ideas and Values" means that home 
facilitates esteem and self-actualisation needs. The home can be used as a reflection of occupants' ideas and values or as an "Indicator of Personal Status" (Despres, 1991). However, people may find it challenging to do so when $\mathrm{MDH}$ is developer-led, and each dwelling constrains its occupants to conform to its form and function. Housing, or homes, at all densities, have the potential to accomplish all of these meanings of home. Therefore, it has the potential to facilitate all levels of psychological needs, based on Maslow's Pyramid. It is essential for housing to act as a vehicle or vessel for occupants to feel "at home" and thereby use it as a reflection of their ideas and values and achieve esteem and self-actualisation. To accomplish this, the occupants must have some autonomy. Therefore, this design research proposes a framework to do so.

\subsubsection{SUMMARY OF LITERATURE REVIEW}

New Zealand, and specifically Christchurch, has an opportunity to address two current crises at the same time. The first is the increasing shortage of housing, and the second is the prevalence of psychological illbeing. Although housing is being created at a mass scale to meet the demand, it often falls short in meeting its occupants' psychological needs. This research project presents a literature review, including psychologists and their theories, to bring a better understanding of psychology and well-being to the project. The main focus falls on Abraham Maslow and his Hierarchy of Human Needs. This part of the research uncovers evidence that there is a direct correlation between the physical environment and well-being and that the quality of one's home can dictate whether one's psychological well-being is healthy or poor. 
THIS PAGE IS INTENTIONALLY LEFT BLANK. 


\subsection{SITE INTRODUCTION}

\subsubsection{CHRISTCHURCH, NEW ZEALAND}

The city has had an unfortunate recent past but also stands as an excellent candidate for testing the potential for housing to meet higher-order psychological needs. The 2010 and 2011 earthquakes and aftershocks shook Christchurch City and brought down many buildings. The residential red-zone in Christchurch, 535 hectares of now greenfield land, was once filled with 7000 homes. Although the initial rush of people needing housing after the earthquakes is over, the housing crisis remains due to a combination of other factors, including the projected growth of the population.

Low-density subdivisions in the outskirts of the city and $\mathrm{MDH}$ developments in town are two current responses to the housing shortage. The sense of freedom that comes with the detached house and a quarteracre block is etched in New Zealand's postcolonial history and is attractive to many residents. However, the subdivisions that make this dream possible drive people further and further away from the city, increasing commute times and reliance upon cars, not to mention the lack of variety in housing aesthetics. MDH developments in town, on the other hand, decrease commute times and reliance on vehicles for those working in the $\mathrm{CBD}$, but rarely offer the same freedom and space that the subdivisions do. Both of these approaches have, by their nature and the building code, met the lower material needs, but lack a certain quality that supports wellbeing.

Another reason that makes Christchurch an excellent place to carry out this research upon is the results of The Quality of Life Survey
(Dudding et al., 2018). The survey measured people's perceptions of many factors that contribute to the quality of life. Of all of the cities and regions across New Zealand that the survey included, Christchurch had the largest percentage of people who disagree that Christchurch "is a great place to live" (p.13). The city had the most disagreement to the statement "I feel a sense of pride in the way looks and feels" (p.19). Regarding housing and neighbourhoods, residents of Christchurch had the most significant percentage of people who thought their neighbourhood does not suit the needs of themselves and their household (p.31). Considering that one's physical environment affects their quality of life, the results of the QOL Survey could suggest that the new housing developments in Christchurch could be better. 


\section{CHRISTCHURCH VS. REST OF NZ}

"<city/local area > is a great place to live"

"I feel a sense of pride in the way < city/local area> looks and feels"

"The general area or neighbourhood your home is in suits your needs and the needs of others in your household"

"In the last 12 months, do you feel <city/local area> has got better, worse or stayed the same as a place to live?"

SURVEY RESPONSE
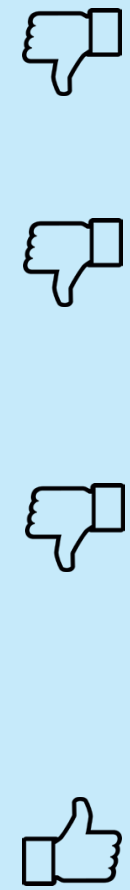

Figure 2.3. Antisocial housing 353 Cashel Street.

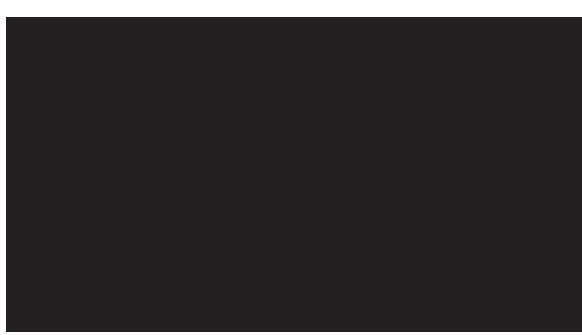

Figure 2.4. Antisocial housing 533 Cashel Street.

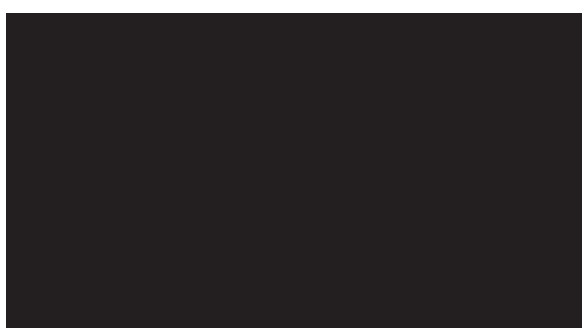

Figure 2.5. A 2017 aerial view of the residential red zone in Christchurch.

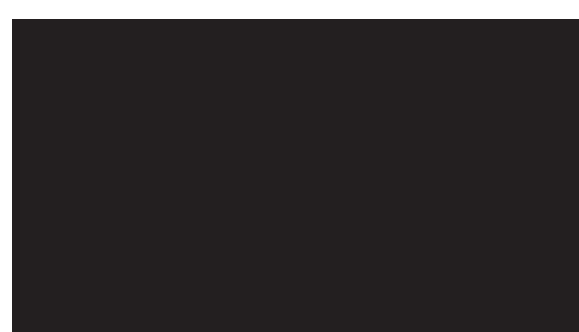

Figure 2.6. Christchurch Avon River.
Figure 2.7. Antisocial housing 491 Cashel Street.

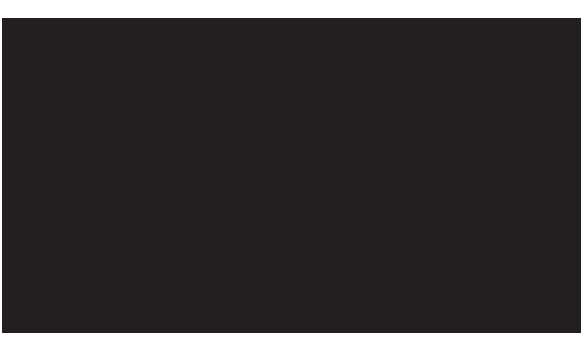

Figure 2.8. Red zone

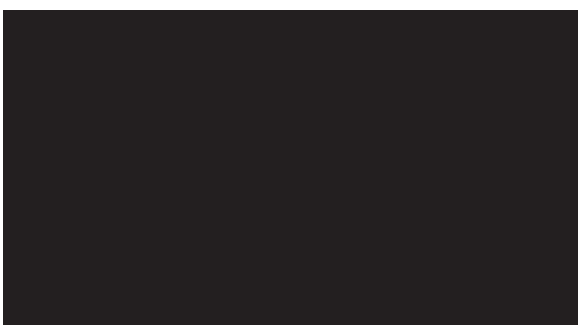

Figure 2.9. Christchurch from above 


\subsubsection{CASHEL STREET, CHRISTCHURCH}

Cashel Street in central Christchurch was selected as a more specific site for the project. It was chosen for its range of building grains and typologies, socioeconomic statuses, and land uses and vacancies along the $3.6 \mathrm{~km}$ road. Cashel Street runs from Linwood, a low-socioeconomic residential suburb at the east end, and through the $\mathrm{CBD}$ and new retail and hospitality centre. It ends in a higher socioeconomic residential area in the CBD next to the botanic gardens and hospital. Site analysis expands upon this point in section 3.1.2. Following the earthquakes in 2010 and 2011, many buildings on Cashel Street were demolished, and many sites between Linwood and the CBD remain empty. There is an opportunity to develop these vacant sites and build mixed-use and residential neighbourhoods. Designers, alongside communities, could also redevelop some of the existing housing that is only addressing some of the lower-level needs. If this is to happen, any existing housing must be sensitively redeveloped, as to displace as few people as possible. 


\subsection{DESIGN FRAMEWORK}

\subsubsection{FRAMEWORK}

\section{INTRODUCTION}

The framework addresses the top three needs on the pyramid, namely social, esteem and self-actualisation. As this framework was created for use in Christchurch, it will have specific outcomes relevant to the place. However, designers, communities and developers are encouraged to adopt and adapt the process and criteria to fit any location or housing scenario.

The framework comprises of six criteria, two for each psychological need, and each follows a four-step process to achieve a design outcome for each need.

\section{FOUR-STEP PROCESS FOR DESIGN CRITERIA}

1. Psychological need (i.e. social, esteem or self-actualisation)

2. The desired outcome for residents

3. Means to achieve the desired outcome

4. Role of the design/designer 


\section{$\Theta$ SOCLAL}

\section{CONNECTION WITH NEIGHBOURS}

\section{CONNECTION WITH THE CITY}

\subsubsection{CRITERION 1. SOCIAL:}

\section{CONNECTION WITH}

\section{NEIGHBOURS}

The first of the six criteria is that the design encourages neighbours of the development to socialise with each other. Spaces will be provided on-site for social activities and gatherings to achieve this criterion. The designer's role is to not only design specific social spaces, i.e. outdoor seating areas and community buildings but more importantly, to think of any non-private space as having the potential for neighbourly interactions and conversations. These spaces could include circulation areas such as shared stairwells. Encouraging interactions between neighbours may build relationships and a higher sense of security. Further, buildings oriented to face public areas, and more people in them, means that people will feel safer from informal surveillance, or "eyes on the street" (Jacobs, 1961). Stronger relationships within the neighbourhood and eyes on the street will naturally reinforce a sense of security, and thus, continue to facilitate lower-level needs as well.

\subsubsection{CRITERION 2. SOCIAL: CONNECTION WITH THE CITY}

A connection between the site and the city will bring about a sense of relatedness in the residents that differs from the previous criterion. The principle is similar in that it aims at facilitating social needs, but it does so at a larger scale. To accomplish this, the designer may create an invitation for the public to enter certain parts of the site. They could also make sightlines from buildings and public areas to form visual connections, i.e. to the Port Hills (south of Christchurch city), down Cashel St toward the CBD, and the Cardboard Cathedral on the northwest corner of the site. For this specific site, it will also involve creating laneways through the site that connect to other laneways on adjacent blocks. The role of the designer is to gather knowledge of the surrounding area and to fit the new development into the existing urban fabric consciously. Further, some areas must be open to the public, and others must be completely private. A distinct boundary must divide the two to enforce privacy and security (Jacobs, 1961). 


\section{- \\ ESTEEM}

\section{PRIDE}

\section{COMPETENCE}

\subsubsection{CRITERION 3. ESTEEM: PRIDE}

As discussed in the literature review in section 2.1.4, esteem needs are divided into two. The first criterion addresses respect from others, whereas the second esteem criterion addresses competence and independence in oneself.

When a building or landscape is of decent quality and is well maintained, people will naturally feel proud to call it their home. Thus, the house can facilitate a part of the occupants' esteem needs. For residents to have a sense of pride in their home over a long period, the grounds and buildings must be well maintained, and be pleasurable for the public to look at and for residents to live inside of them. The level of construction quality and maintenance are primary factors in how others view the housing development and its residents (Kearns, 2000). Spatial configuration and formal design in the hands of a capable architect/designer means that the housing will be well designed to lift the spirit through aesthetic pleasure. Additionally, the design of the communal and private areas, especially areas that are visible to the public, must be visually appealing, of high quality and appear to be maintained well.

\subsubsection{CRITERION 4. ESTEEM: COMPETENCE}

The desired outcome for this criterion is for residents and visitors to feel competent when they are on the site. A way to engender competence from the residents is to configure the site like a puzzle, without it being disorienting. Having multiple paths and directions through the site will let people create their ways of navigating the neighbourhood, and it will also create small secluded areas where children love to play (Cooper Marcus, 1983). Way-finding devices, or landmarks, and techniques can orient people to mitigate disorientation. These techniques include each building looking different from the other, and views to the Port Hills. Navigating the city was difficult after many of the prominent landmark buildings had been demolished following the earthquakes. One way of getting one's bearings was to look out to the Port Hills for a sense of direction. 


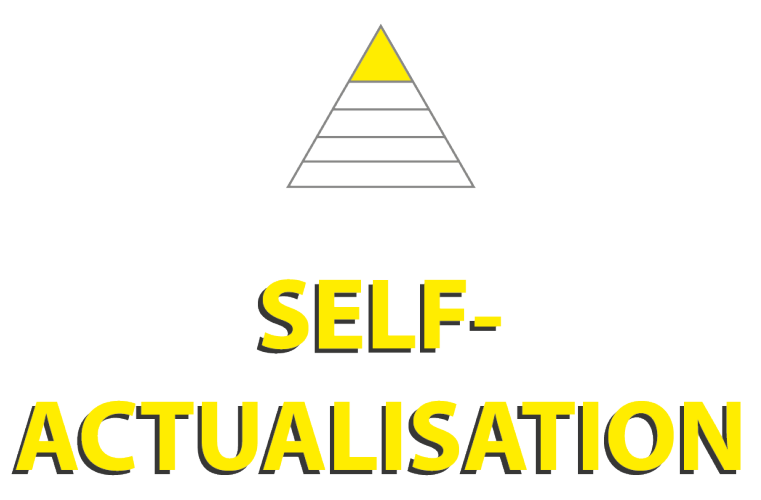

5. AUTONOMY IN DWELLING

6. AUTONOMY ON SITE

\subsubsection{CRITERION 5.}

\section{SELF-ACTUALISATION: RESIDENT AUTONOMY IN DWELLING}

Resident autonomy is the focus of both criteria regarding self-actualisation needs and both work at different scales. The first addresses resident autonomy at the individual dwelling scale. The desired outcome is for most housing units to be different from each other, and for occupants to have the power to customise and change the dwelling to suit their specific requirements. To achieve this criterion, the designer will create a diverse range of housing types and sizes, meaning that there will be a range of different options from which residents can choose. Ultimately, each dwelling will be a 'shell' or 'canvas' that the occupants can alter and customise to suit their changing needs and desires. Creating a 'canvas' may be achieved by leaving walls and floors blank and leaving kitchen and living spaces open for interpretation. The variety of housing available on each site will naturally give people more options and a better chance of finding a home that suits them. Additionally, the choice lies with the occupant of whether or not to change the dwelling itself. The framework encourages designers to leave private spaces flexible and raw to allow the occupants to finish them, however, not too unconstrained as to give occupants no starting place.

\subsubsection{CRITERION 6.}

\section{SELF-ACTUALISATION:} RESIDENT AUTONOMY ON SITE

The second scale and period in which the residents can have autonomy is the whole site and in the design stage of the housing development. The intended outcome is that residents can, if they choose, contribute to the design of the housing development as a whole and that they get the facilities they need. Achieving this outcome could lead to residents expressing the need for spaces and facilities that could support their selfactualisation. It is imperative that occupants, especially of higher-density housing, have individual control over their dwelling both at the initial design stage and in day to day living (Cooper Marcus and Sarkissian, 1986). The designer's role, therefore, is to include the community in participatory design workshops at the beginning of the project.

Natural disasters are unpredictable, and 
Christchurch has more recently been known for its earthquakes. If residents can harvest food, catch rainwater, and generate power on-site, they will have some autonomy in the case of these necessities being scarce or cut off. Therefore, another role the designer has is to design for power generation, rainwater catchment, and provision for growing food.

\subsubsection{SUMMARY OF} FRAMEWORK

To summarise, the framework abstracts each of the three psychological needs from Maslow's Pyramid into two criteria. Each criterion explains the desired outcome for residents, the means to achieve said desired outcome and the role of the design or designer. It is encouraged that each criterion is adopted and adapted to suit any housing project. 


\begin{tabular}{|c|c|c|c|}
\hline $\begin{array}{l}\text { PSYCHOLOGICAL } \\
\text { NEED }\end{array}$ & $\begin{array}{l}\text { DESIRED OUTCOME } \\
\text { FOR RESIDENTS }\end{array}$ & $\begin{array}{l}\text { MEANS TO ACHIEVE } \\
\text { DESIRED OUTCOME }\end{array}$ & $\begin{array}{c}\text { ROLE OF } \\
\text { DESIGN / DESIGNER }\end{array}$ \\
\hline & $\begin{array}{l}\text { 1. CONNECTION WITH } \\
\text { NEIGHBOURS }\end{array}$ & $\begin{array}{l}\text { Spaces on site for social activities and } \\
\text { gatherings. }\end{array}$ & $\begin{array}{l}\text { Think of any non-private space as having } \\
\text { potential for neighbourly interactions/ } \\
\text { conversations. } \\
\text { Buildings oriented to face public areas }\end{array}$ \\
\hline SOCLLA & $\begin{array}{l}\text { 2. CONNECTION } \\
\text { WITH CITY }\end{array}$ & $\begin{array}{l}\text { Invite public to enter certain parts of site } \\
\text { Sightlines from buidlings and public areas to } \\
\text { form a visual connection. }\end{array}$ & $\begin{array}{l}\text { Gather knowledge of the surrounding area and } \\
\text { to fit the new development into the existing } \\
\text { urban fabric consciously. }\end{array}$ \\
\hline & 3. PRIDE & $\begin{array}{l}\text { Grounds and buildings must be well } \\
\text { maintained. } \\
\text { Pleasurable aesthetic. }\end{array}$ & $\begin{array}{l}\text { Consider the durability, maintenance } \\
\text { requirements and aesthetic qualities when } \\
\text { selecting materials and crafting spaces. }\end{array}$ \\
\hline ESTEEM & 4. COMPETENCE & $\begin{array}{l}\text { Configure the site like a puzzle (without it } \\
\text { being disorienting). }\end{array}$ & $\begin{array}{l}\text { Multiple paths and directions through the site. } \\
\text { Way finding devices }\end{array}$ \\
\hline & $\begin{array}{l}\text { 5. AUTONOMY } \mathbb{N} \\
\text { DWELLING }\end{array}$ & $\begin{array}{l}\text { Housing units to be different from each other. } \\
\text { Occupants to have the power to customise and } \\
\text { change the dwelling to suit requirements. }\end{array}$ & $\begin{array}{l}\text { Create a diverse range of floor plans and } \\
\text { elevations. } \\
\text { Each dwelling to be a'shell' or 'canvas' that } \\
\text { occupants can customise to suit changing } \\
\text { needs and desires. }\end{array}$ \\
\hline 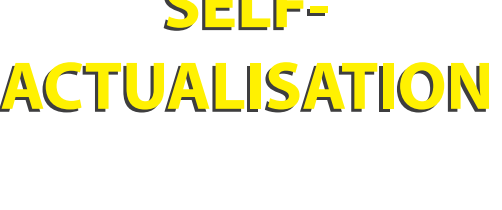 & $\begin{array}{l}\text { 6. AUTONOMY ON } \\
\text { SITE }\end{array}$ & $\begin{array}{l}\text { Residents contribute to the design of the } \\
\text { housing development. }\end{array}$ & $\begin{array}{l}\text { Include the community in participatory design } \\
\text { workshops at the beginning of the project. } \\
\text { Design for power generation, rainwater } \\
\text { catchment, and provision for growing food. }\end{array}$ \\
\hline
\end{tabular}




\subsection{CASE STUDIES}

\subsubsection{CASE STUDIES}

INTRODUCTION

A series of projects informed the design. These projects were sourced through a systematic review of design literature, compared against the design framework, and were used as inspiration in this design research. 


\subsubsection{HABITAT 67}

Designer: Moshe Safdie

Location: Montreal, Canada

Year: 1967

Dwellings: 148

Habitat 67 cleverly marries together high-rise living and individual dwellings: the perceived density is much lower than the reality. Moshe Safdie originally designed Habitat 67 as his master's thesis project. It was later presented at the 1967 World Expo in Montreal as a "high-rise village". It provides medium-high density living in the city while offering individual dwellings rather than "cells" in an apartment block ("Habitat 67", 2015).

The staggering effect of the boxes means that there are virtually unlimited configurations to make up a range of different houses with the option for double-height spaces and mezzanine floors. This effect also means that each dwelling has access to at least one terrace on the roof of adjacent dwellings. This effect helps to achieve social needs within the neighbourhood (criterion 1 from the research's design framework). The configuration of terraces gives a sense of privacy, while at the same time, passive surveillance and provision for social interactions. They give residents the autonomy to live how they choose. As presented in the design framework section of this thesis, providing an extensive range of dwelling sizes and types will help residents to achieve self-actualisation, as they are given choice and autonomy. 


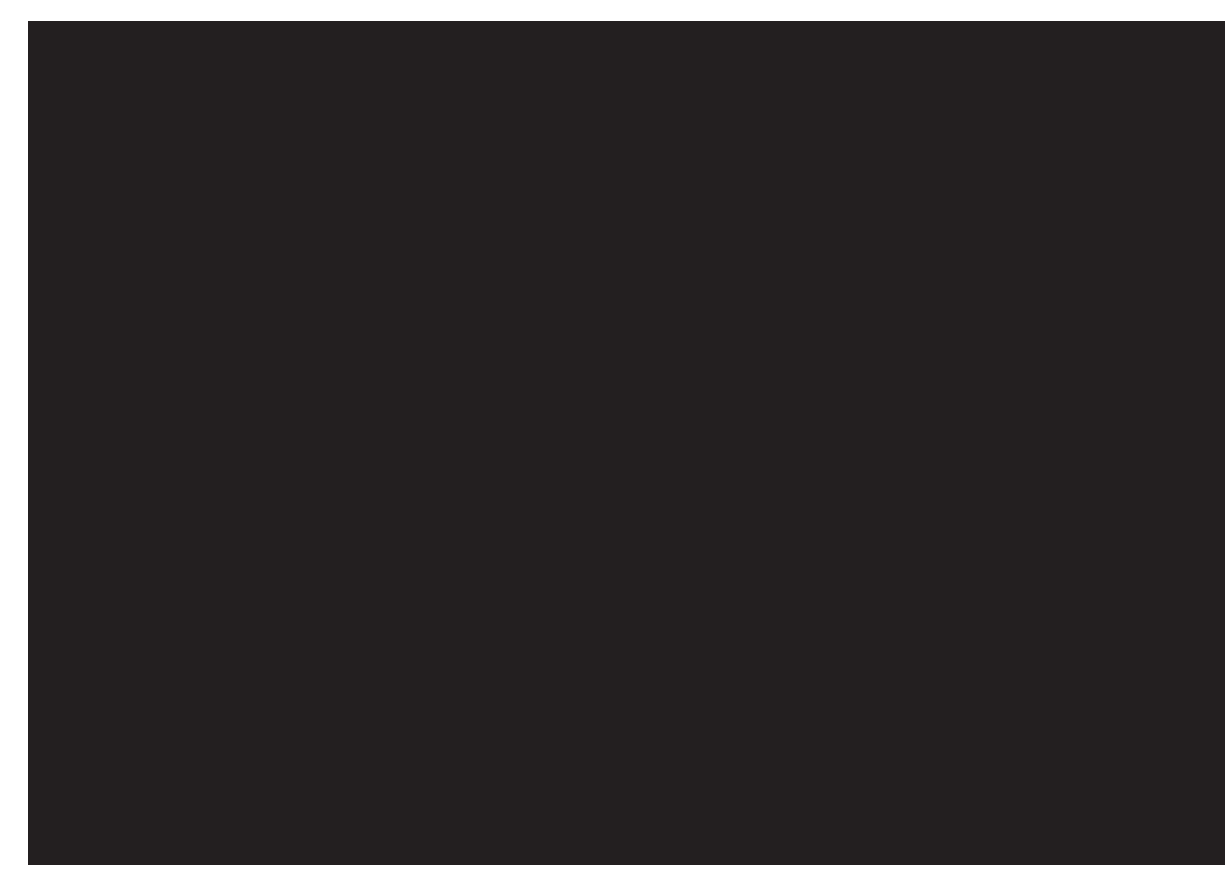

Figure 2.12. Architect Moshe Safdie with the model for Habitat 67.
Three things from Habitat 67 that this research seeks to develop:

1. Shared circulation space and how this can be pushed to facilitate social interactions further.

2. A modular box size and various combinations of boxes keep construction costs down. Because there are many variations, no two dwellings will be identical. The variation allows people to choose a home that suits them, rather than having to adapt to something generic. This also supports esteem needs, as no two are the same.

3. Terraces provide a privacy buffer to interior spaces and opportunities for social interactions with neighbours. There is a potential here to achieve the competence and autonomy criteria, as the terraces could be used for growing vegetables or beehives, for example. 


\subsubsection{PARK MEWS}

Designer: Roger Walker

Location: Hataitai, Wellington, NZ

Year: 1974

Dwellings: 32

Roger Walker was commissioned by property developer Campbell Homes to design Park Mews: the 32 units that were completed in 1974. Each unit has a private outdoor garden or private roof deck attached to it (Walker, 2018).

Park Mews has its own identity in its context, and the residents are fond of it. Not only is each floor plan different, but each dwelling is distinguishable from the outside. Walker said in an interview with Hickey (2019),

"People can look up and say 'well that little quirky corner up there that's my place'. Whereas in an apartment block they'll say my place is the third window from the left, two floors down from the roof. It's not enough. It's not individual enough for the New Zealand character".

Everyone has a very individual dwelling. This individuality can satisfy esteem needs by residents feeling proud of their own home. Walker achieved successful private outdoor spaces despite the compactness of the design. The dwellings are in high demand, and people are proud to live there (Hickey, 2019). 

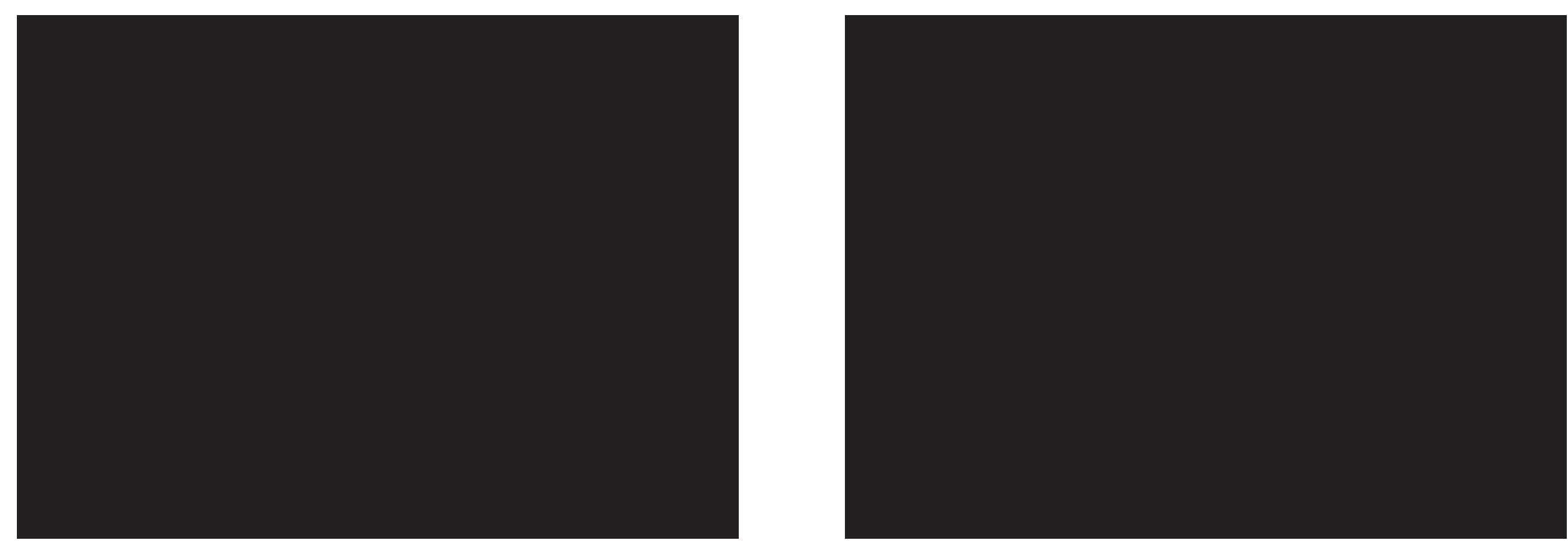



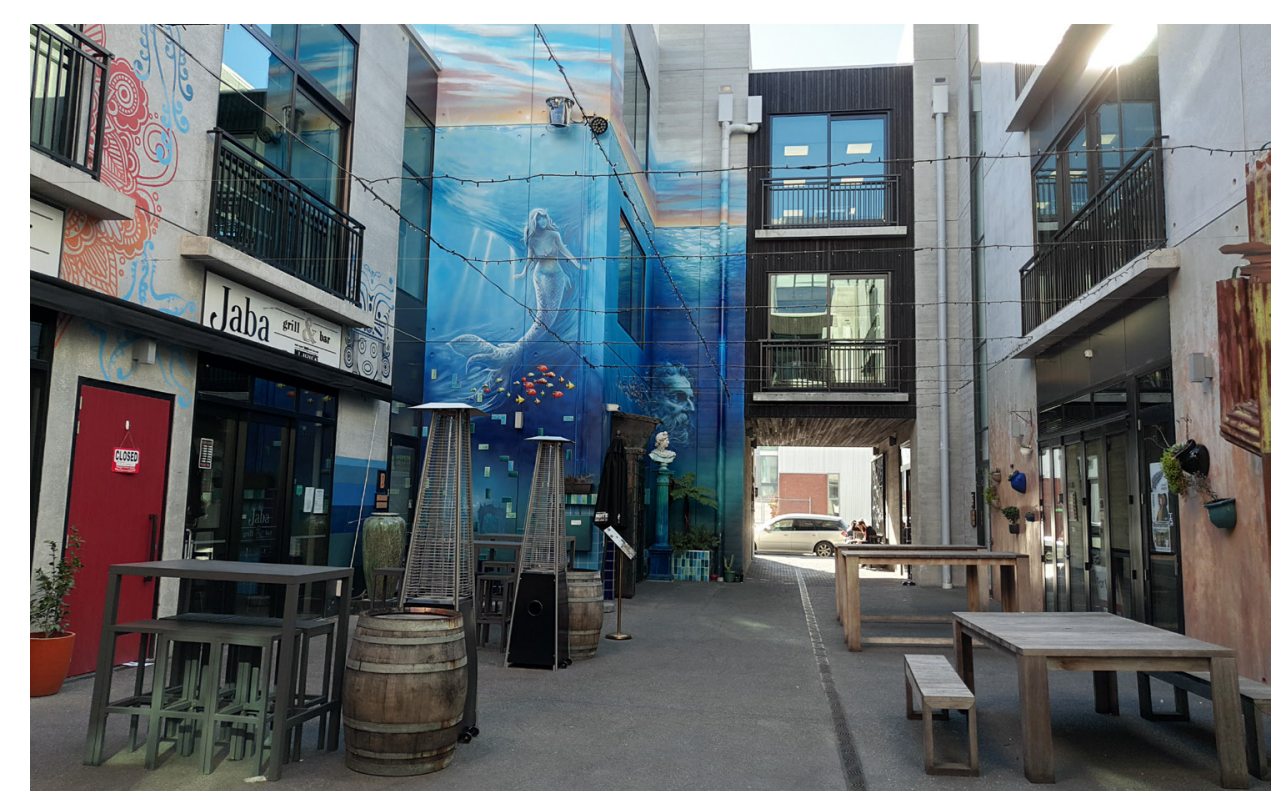

Figure 2.18. Lichfield Courtyard.

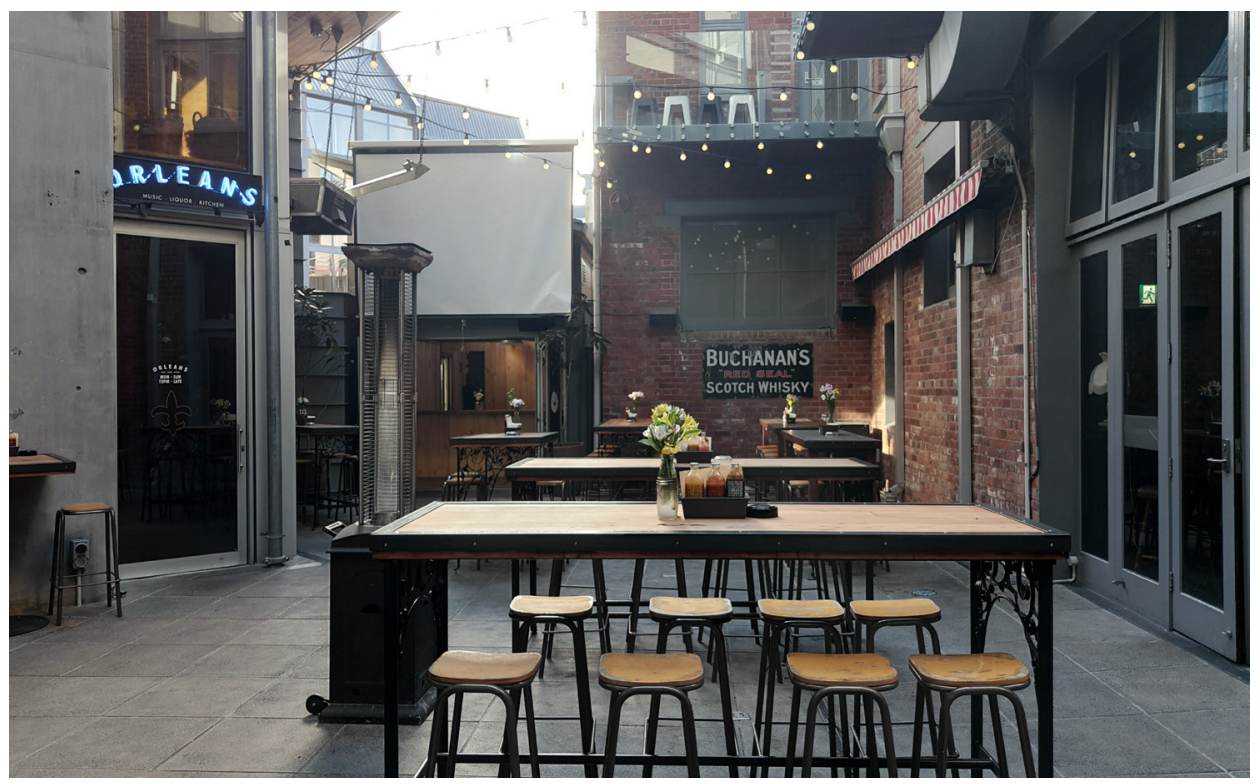

Figure 2.19. Stranges Lane.

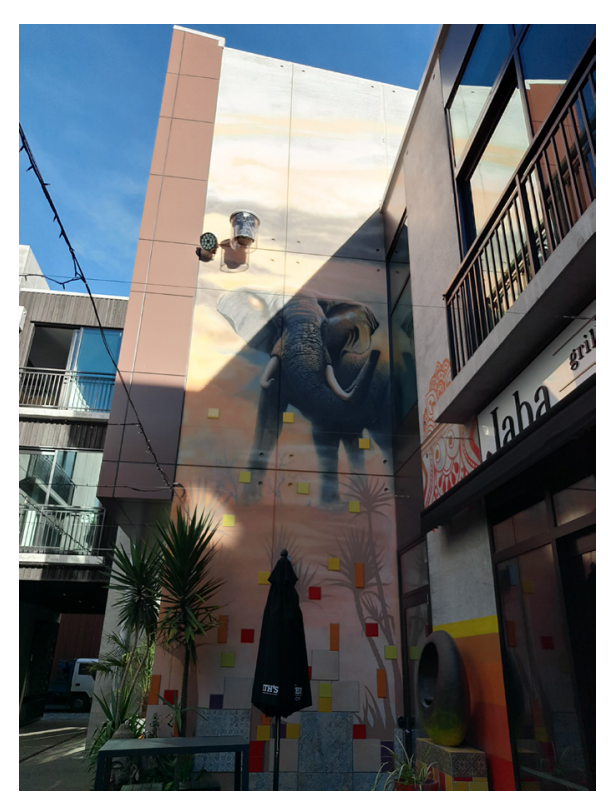

Figure 2.20. Lichfield Courtyard.

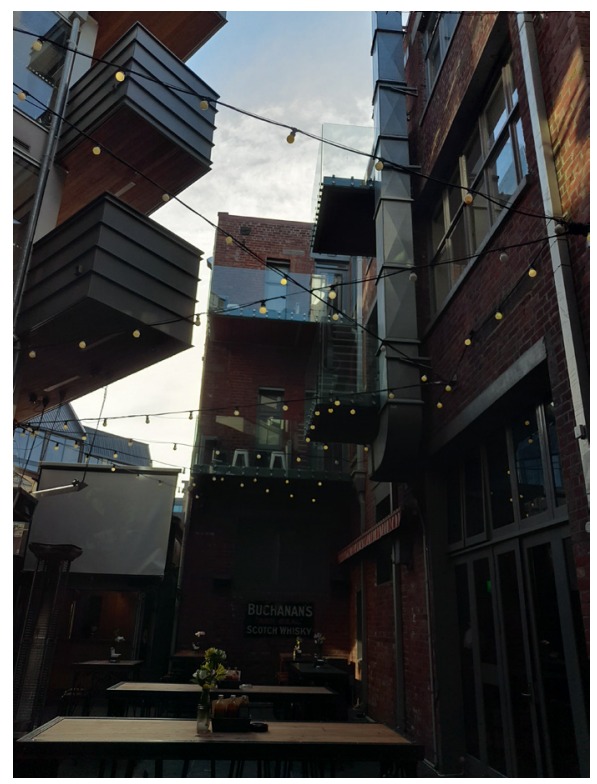

Figure 2.21. Stranges Lane.

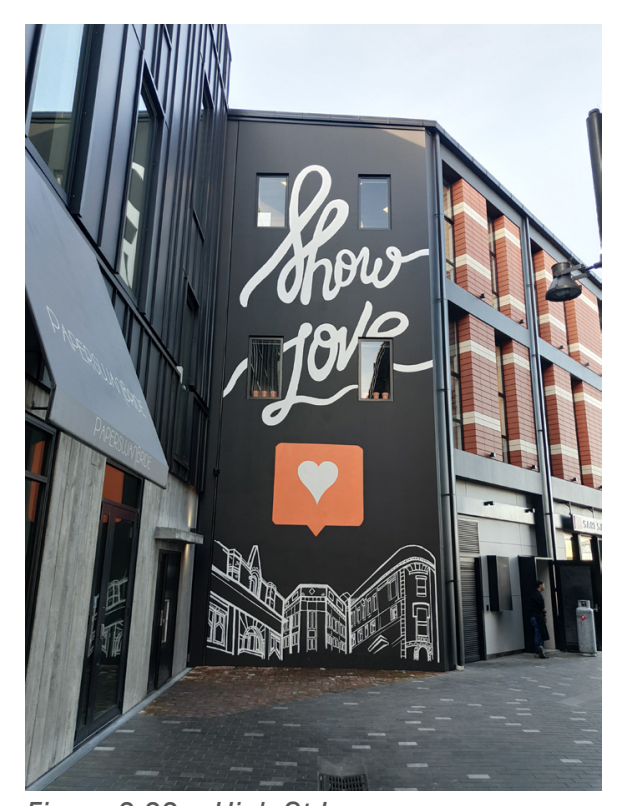

Figure 2.22. High St Laneway.

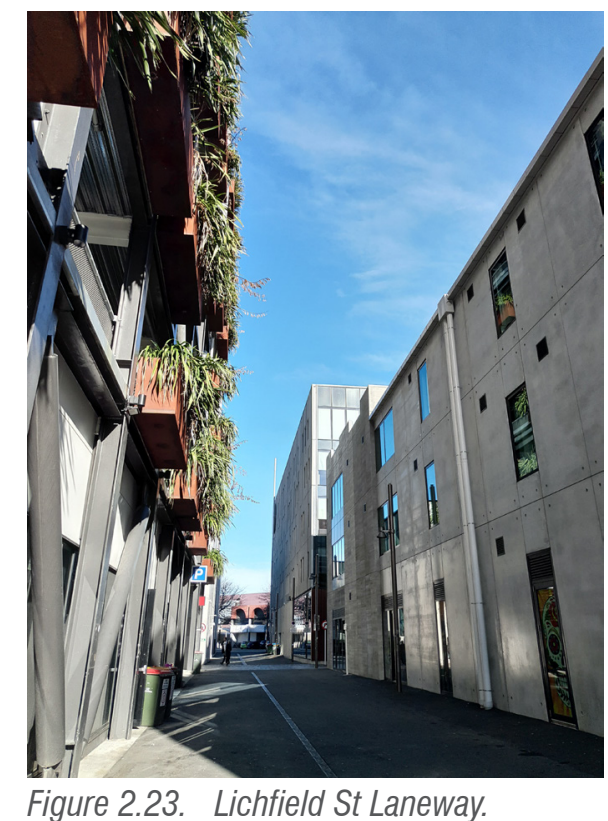

Figure 2.23. Lichfield St Laneway. 


\subsubsection{SUMMARY OF FINDINGS FROM CASE STUDIES}

The two examples of housing developments (Habitat 67 and Park Mews) have similarities in the way that both offer a large variety of dwellings, both functionally and visually. This project does aim to build on the idea of having various dwelling layouts available to potential residents. However, the project placed emphasis on developing the in-between spaces. The research project tests how the in-between spaces, such as shared circulation spaces, can achieve the social criteria of the design framework.

The third case study, Christchurch CBD Laneways, like the previous two case studies, is an example of some architecture that this research project aims to emulate and implement elements from into the design. Due to the laneways being in Christchurch, this research project also aims to bring more of the laneway typology to the city, add to the existing network, and ultimately, encourage future developments to do so as well.

SUMMARIA 
THIS PAGE IS INTENTIONALLY LEFT BLANK. 


\subsection{DESIGN PROCESS}

33

3.1 SITE SELECTION + ANALYSIS

3.2 INTRODUCTION OF DESIGN EXPERIMENTS

34

3.3 MASTER PLANNING

3.4 LICHFIELD STREET

3.5 HEREFORD STREET

3.6 CASHEL STREET

3.7 SUMMARY OF DESIGN 


\section{SITE SELECTION + ANALYSIS}




\section{SITE CONTEXT}

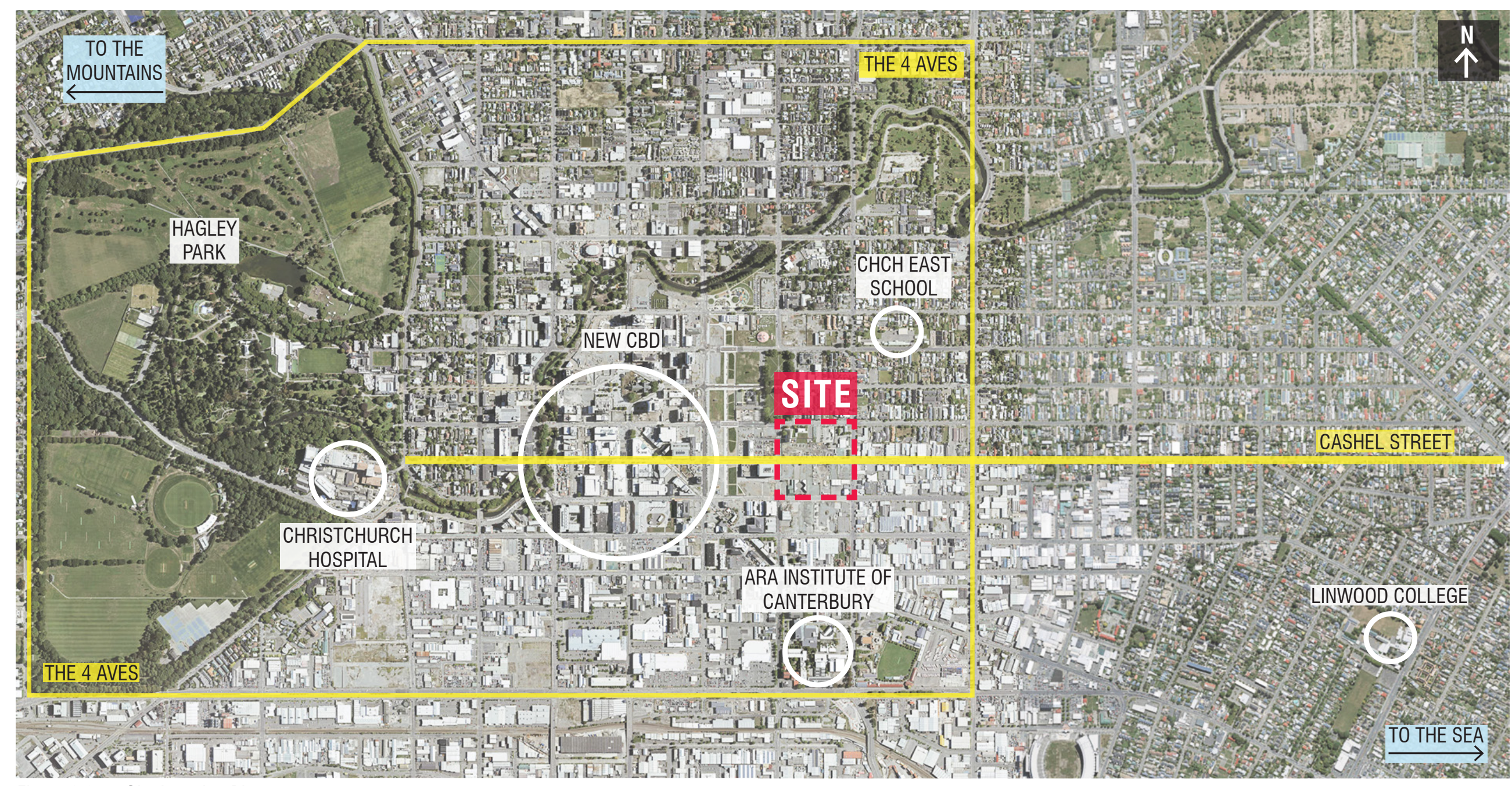

Figure 3.2. Site Location Plan. 


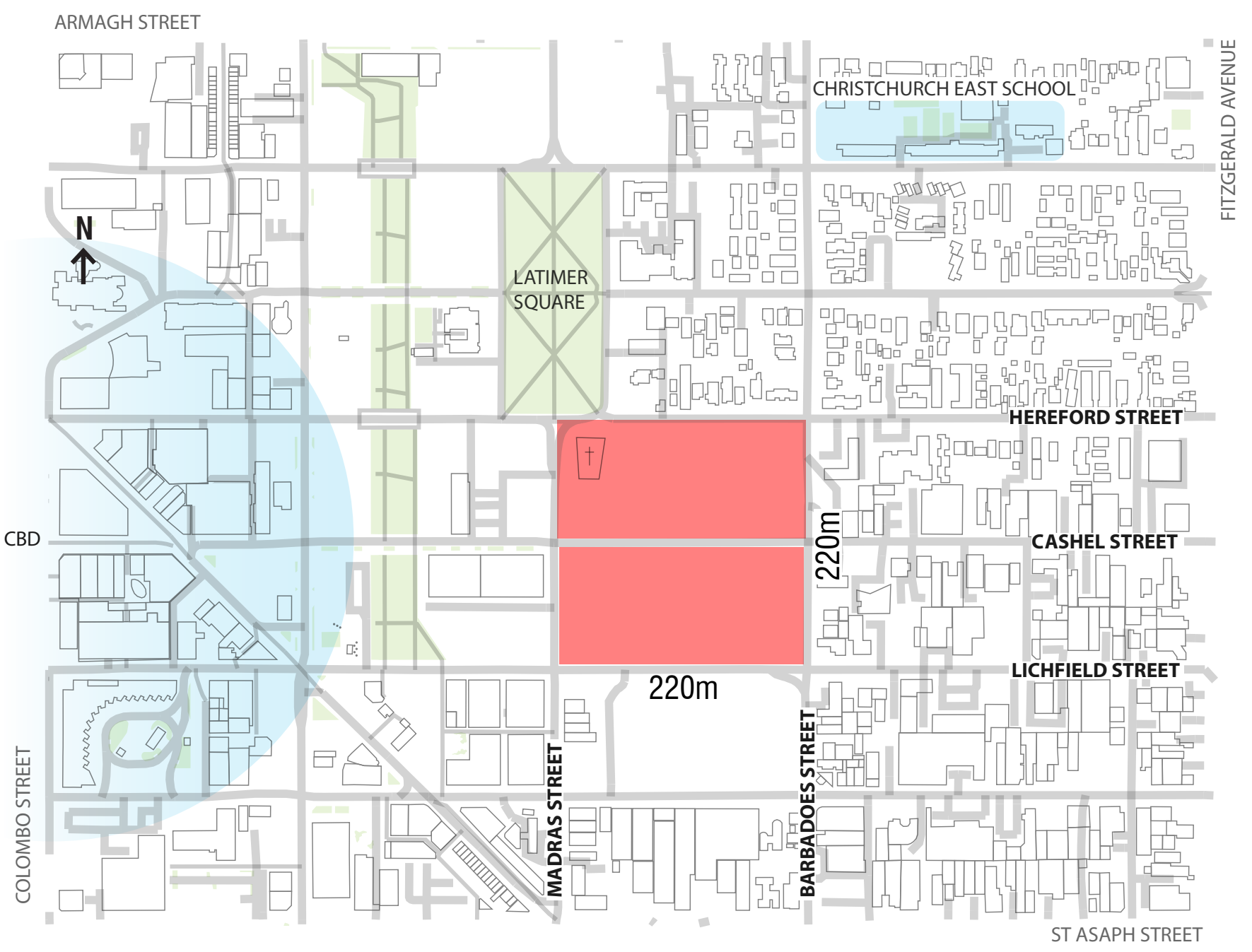

Figure 3.3. Site Location Plan 2.

\subsubsection{SITE SELECTION}

The specific site that was chosen as the test site for the research is the two blocks either side of the street, between Madras and Barbados Streets. The site was chosen as it is a large piece of land between the inner city and residential suburbs. The size $(220 \mathrm{~m} \mathrm{x}$ $220 \mathrm{~m}$ ) means that there is plenty of room to test the research at a range of scales, and it also means that the design could have a more noticeable effect on the city. Site analysis was carried out to gain a deeper understanding of the area, and to confirm that the choice of site is appropriate. Analysis of the street included the following investigations: perceived zones and thresholds along the street; speculations about what level of Maslow's Hierarchy each building facilitates; block lengths; nearby destinations; and finally, traffic volume. 


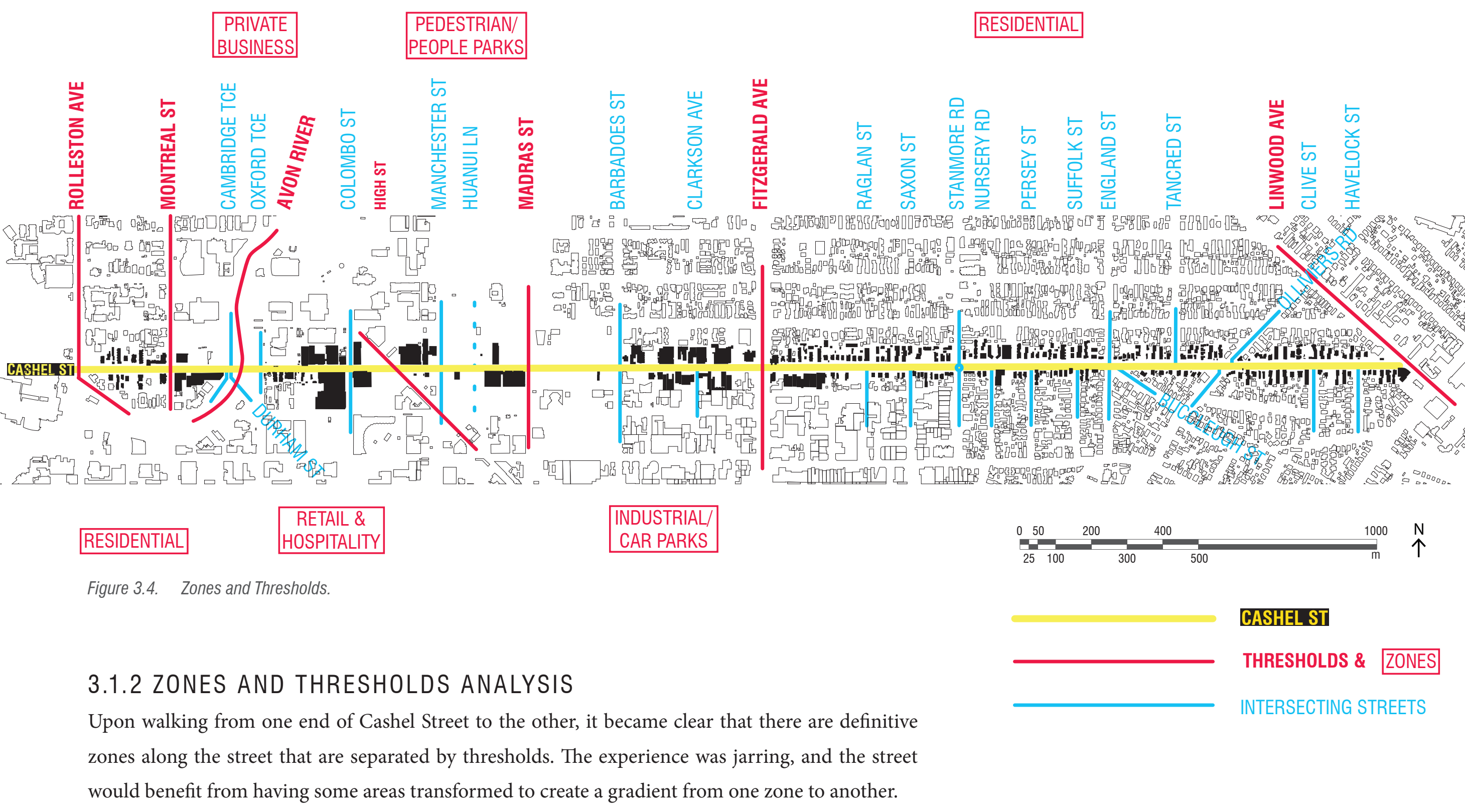




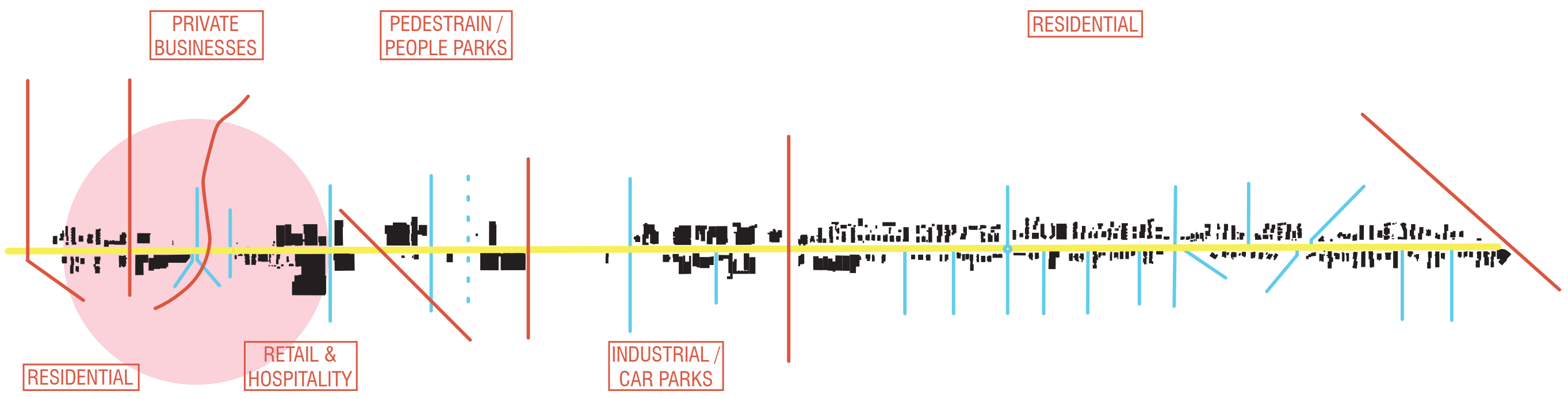

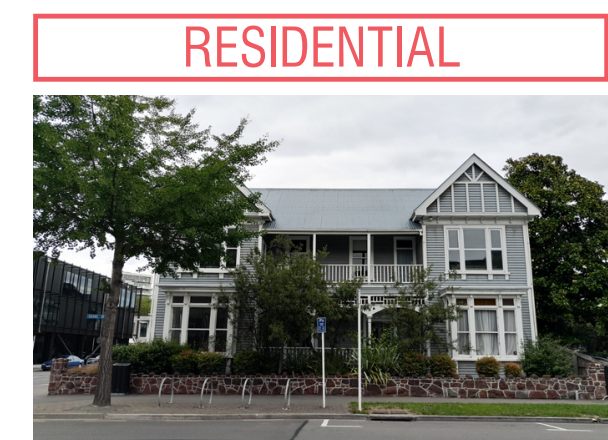

Figure 3.5. House on Cashel Street.

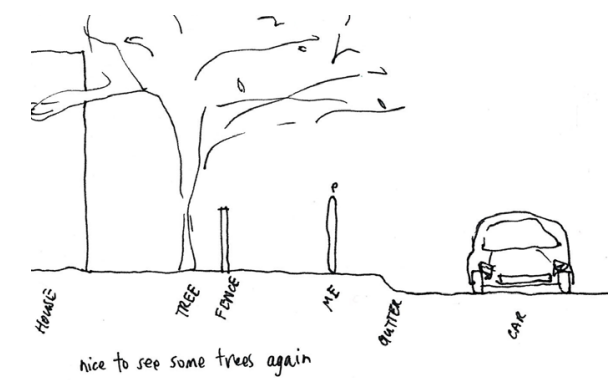

Figure 3.6. Section sketch of Cashel Street Residential Zone.

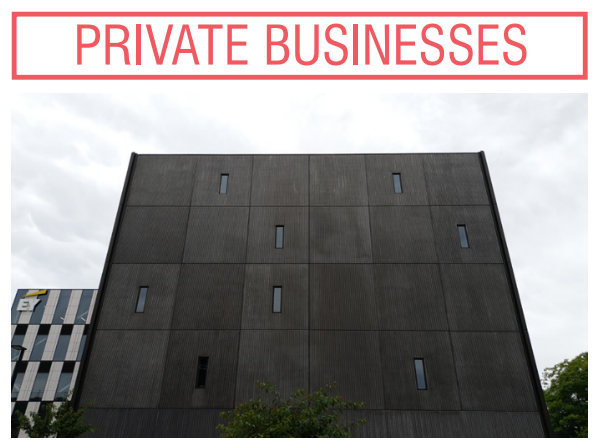

Figure 3.7. Building on Cashel Street.

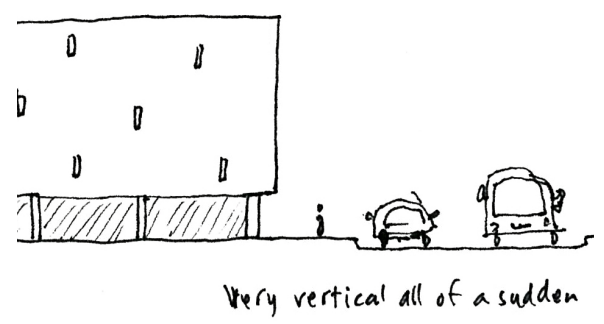

Figure 3.8. Elevation Sketch "Very tall all of a sudden".

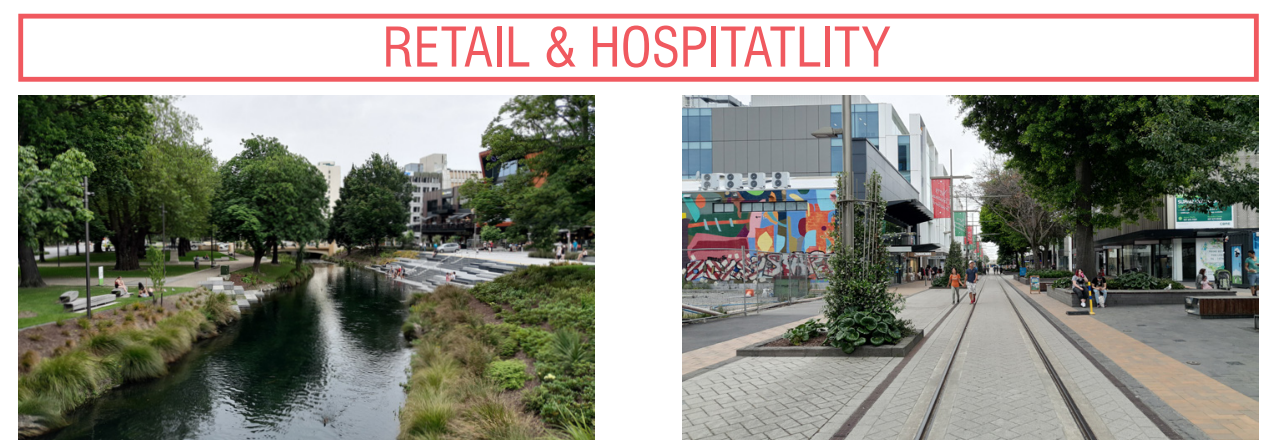

Figure 3.9. Avon River from Bridge of Remembrance.
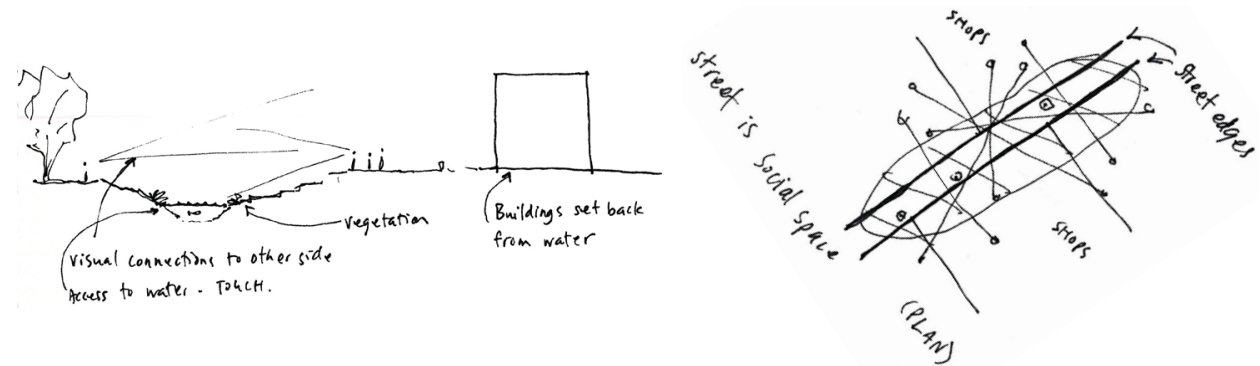

Figure 3.10. Section Sketch over Avon River.
Figure 3.12. "Street is Social Space". 


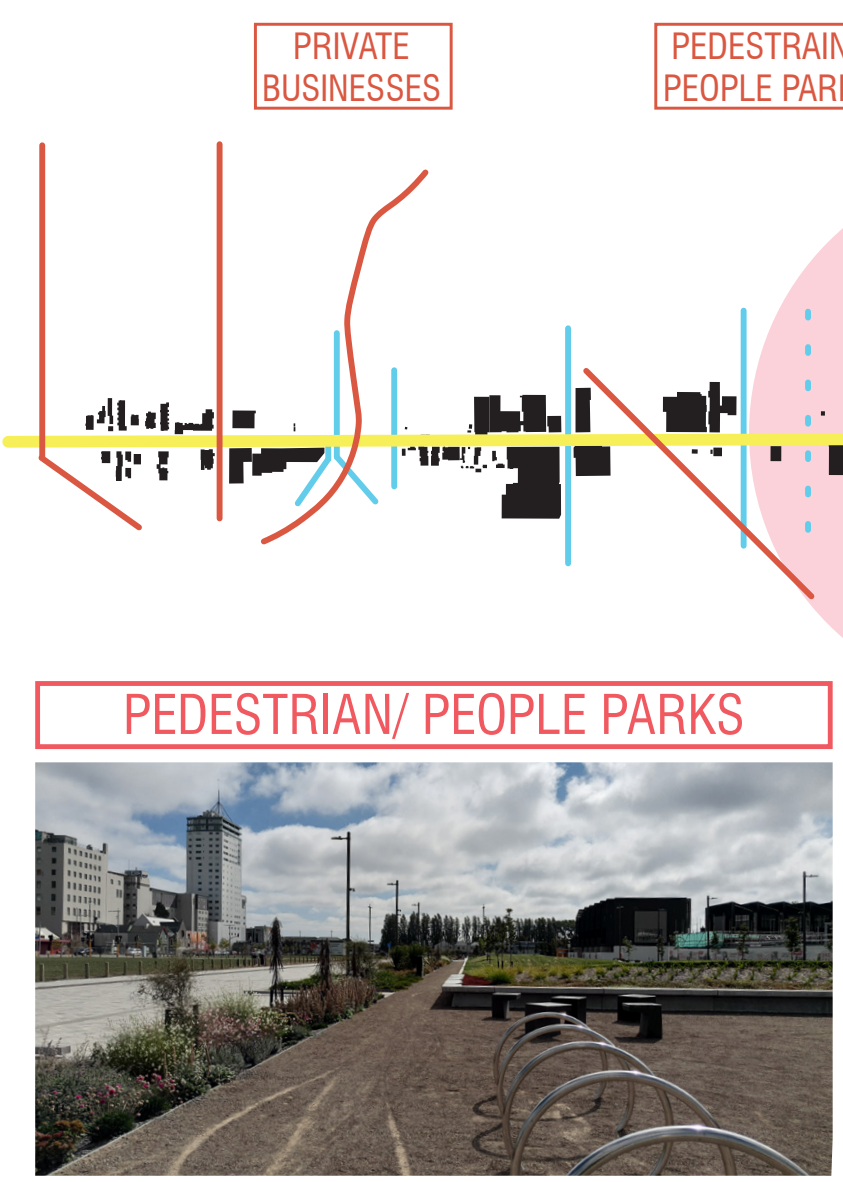

Figure 3.13. Bike Parks on Cashel.

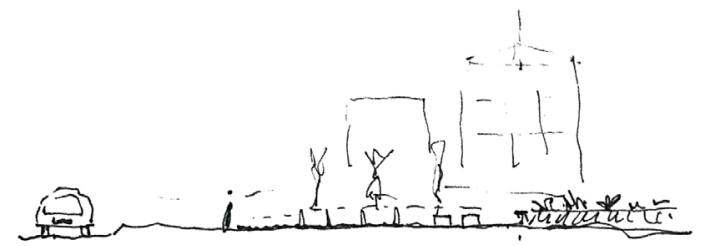

Park open + engaging.

$$
\begin{aligned}
& \text { No open? people, } \\
& \text { just bike tracks in }
\end{aligned}
$$$$
\text { Narrow road again the gravel. }
$$

Figure 3.14. Section Sketch "Park open and engaging".

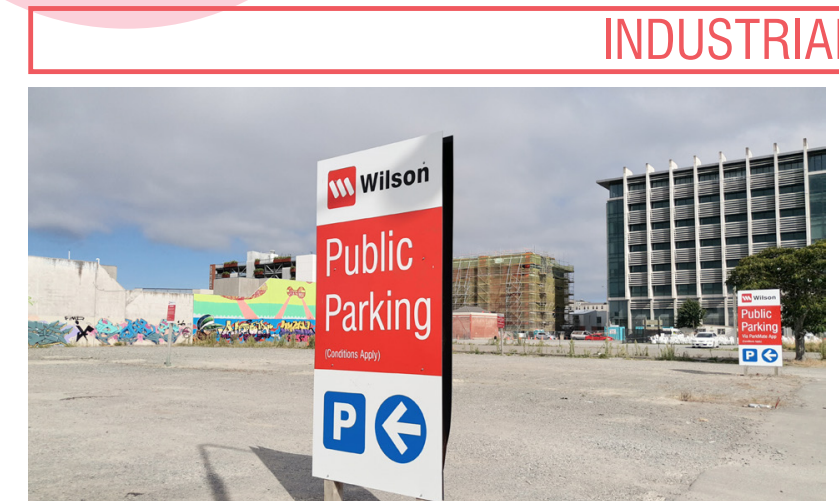

Figure 3.15. Car Parking Sign on Cashel.

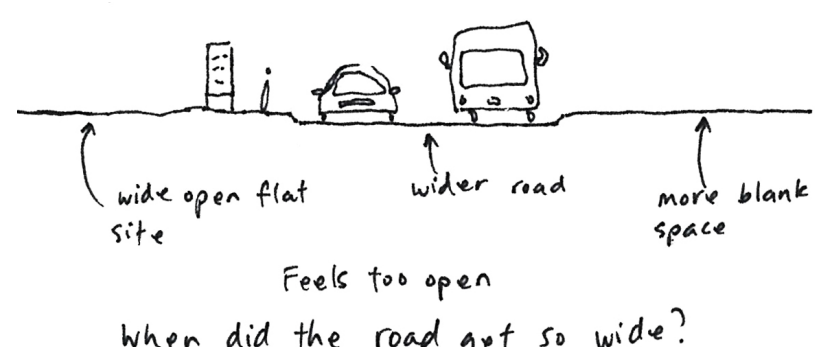

Figure 3.16. Section Sketch through barren car parking.

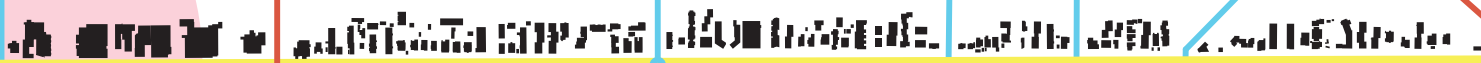

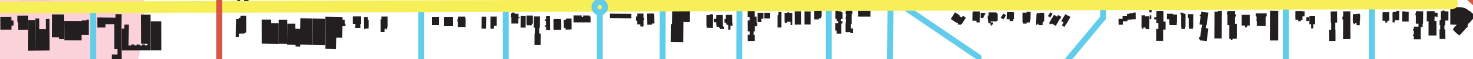
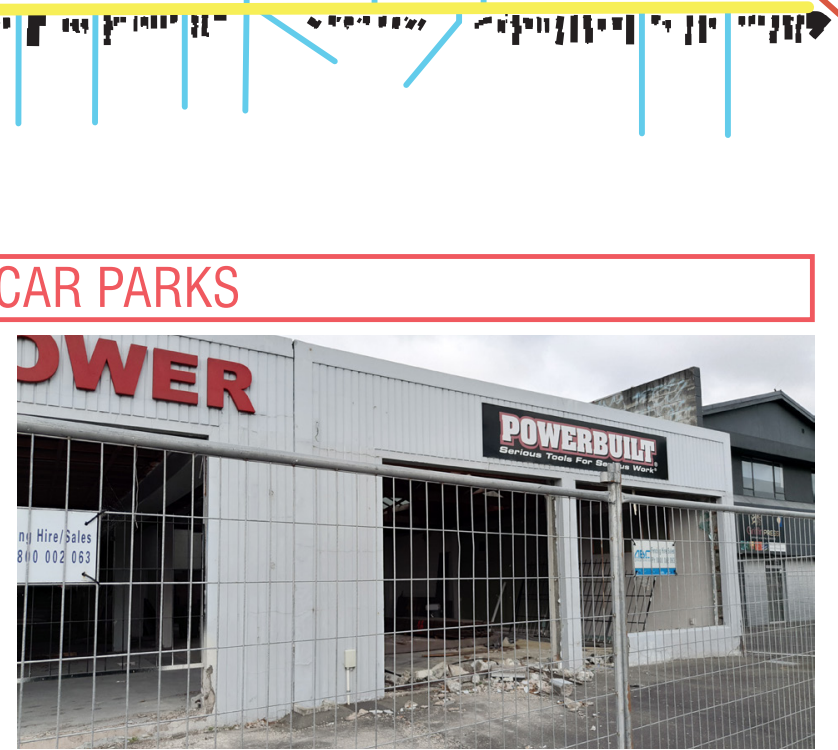

Figure 3.17. Abandoned building on Cashe/ Street.

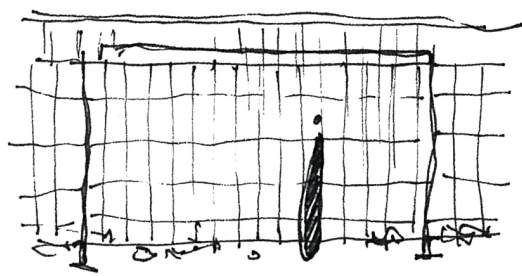

unfriendly fencing Feeling of safety lower Abandoned building - ao people

Figure 3.18. Sketch of fence abandoned building 

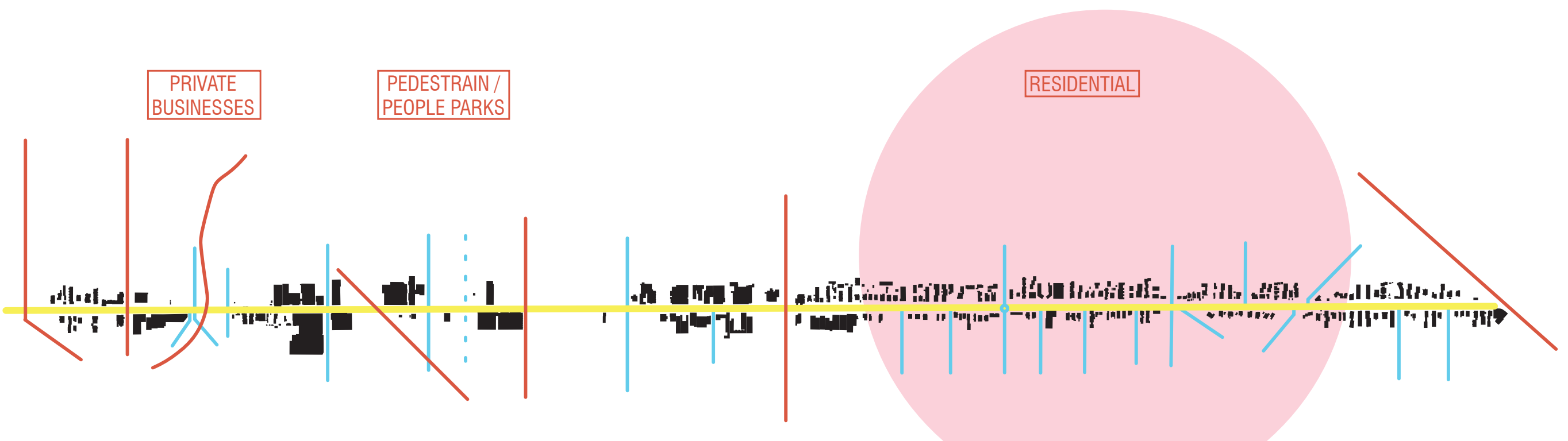

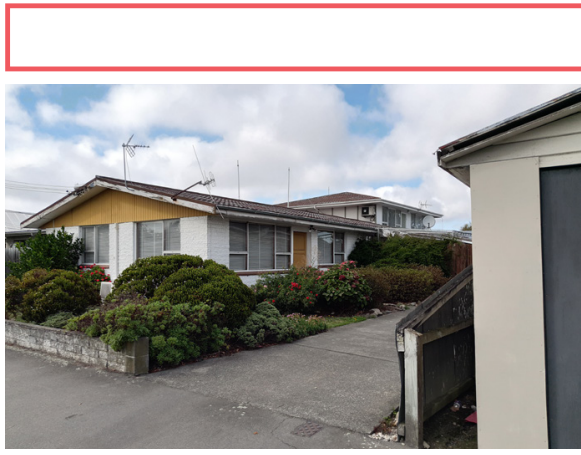

Figure 3.19. Prominent driveway.

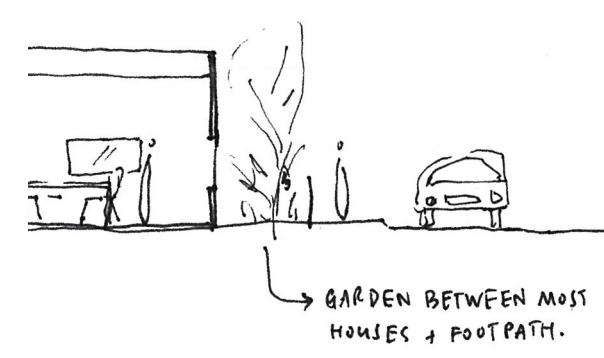

Figure 3.20. Speculative section sketch of house.

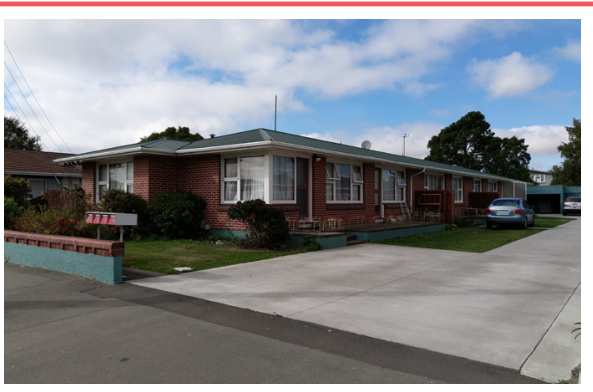

Figure 3.21. Prominent driveway 2.

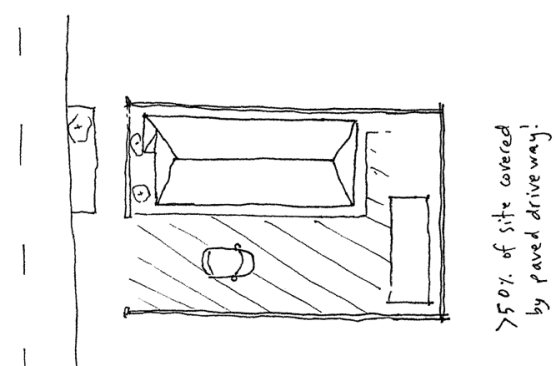

Figure 3.22. Plan sketch of house and driveway

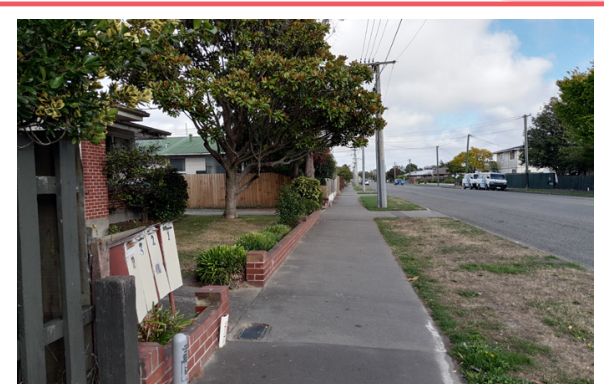

Figure 3.23. Footpath on Cashel Street.

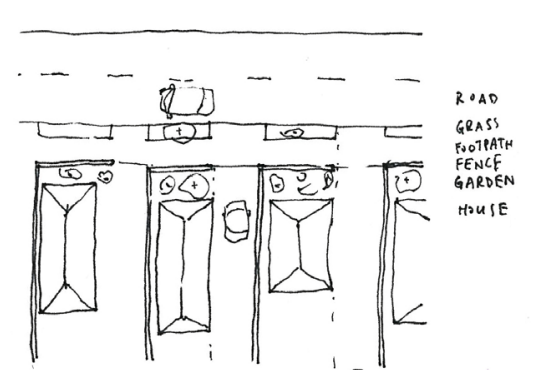

Figure 3.24. Plan sketch "Monotonous housing".

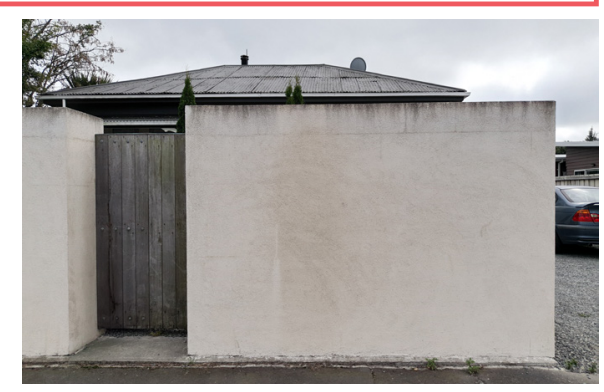

Figure 3.25. Heavy fence, missing gate.

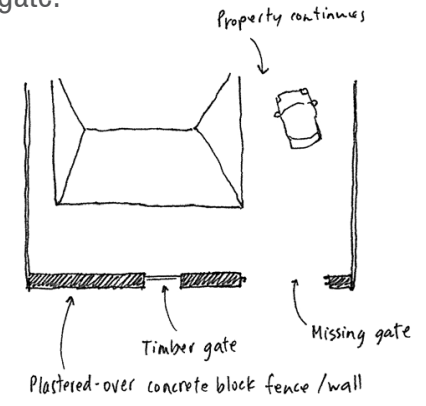

Figure 3.26. Plan Sketch "Heavy fence, missing gate". 

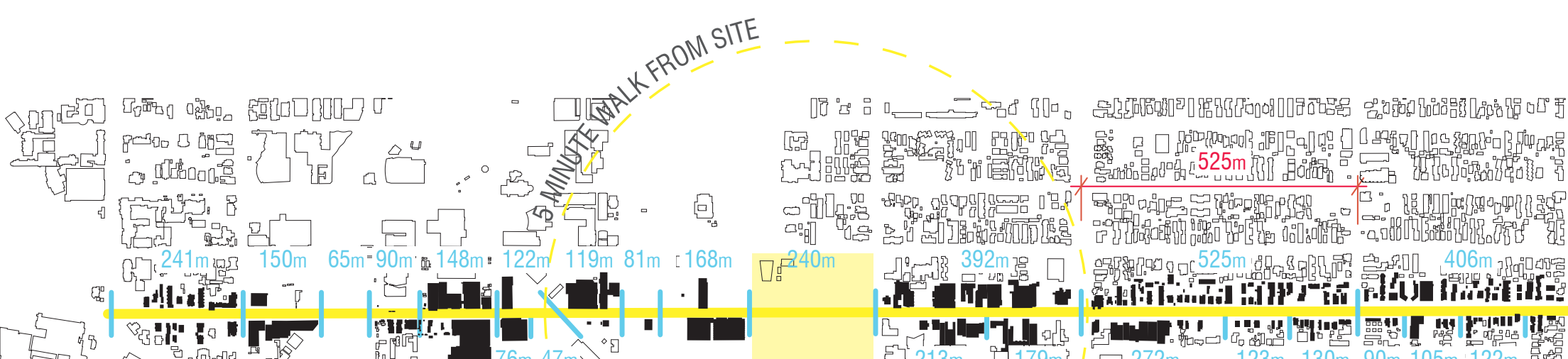

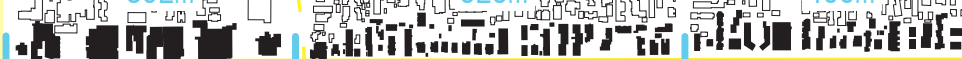
thill.

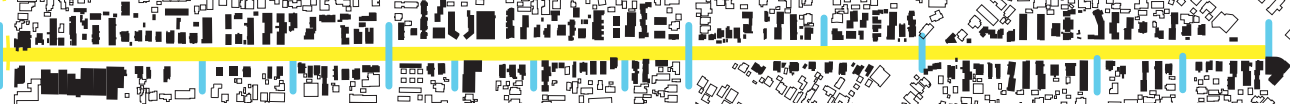

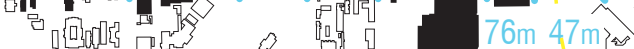
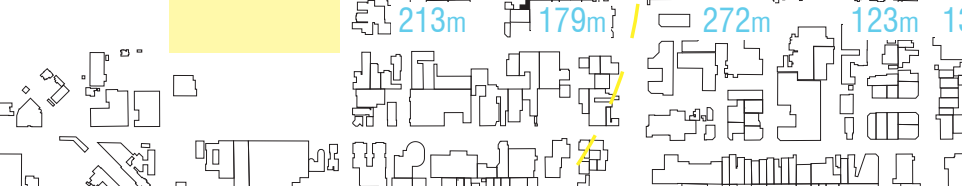

Figure 3.28. Block Lengths.

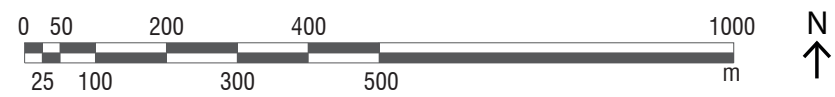

\subsubsection{BLOCK LENGTHS}

One reason why Christchurch is reliant on cars and why there are so many new car parking buildings and lots where buildings used to be, is because the block sizes are incredibly long and discourage pedestrian activity. The longest block without an intersecting street is $525 \mathrm{~m}$. This would take the average person five minutes to walk. The average block length is approximately $190 \mathrm{~m}$. From this, it was decided that the design portion of this portfolio will devise a strategy to reduce the block lengths and encourage further developments around the site to do the same. The preferred outcome is that the streets are more pedestrian-friendly and help people to support their social needs. 


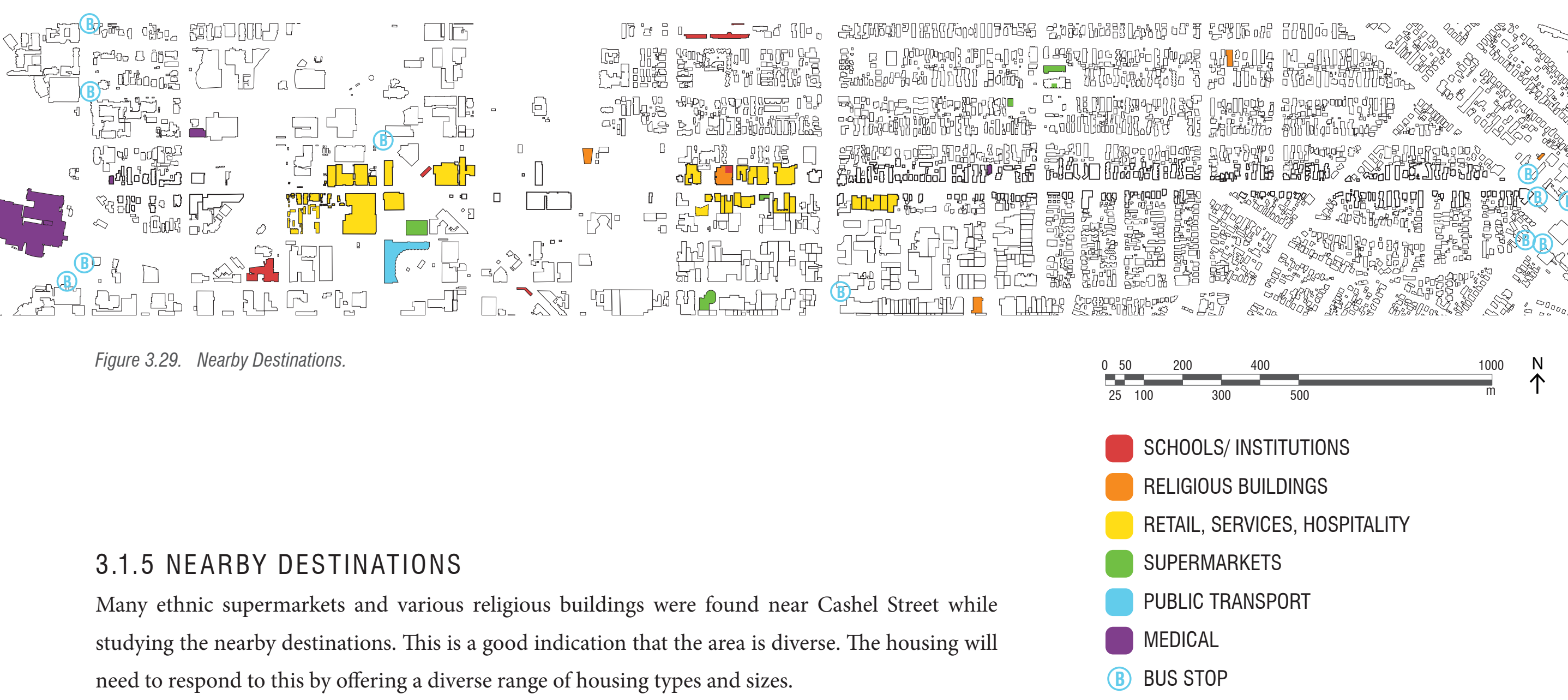




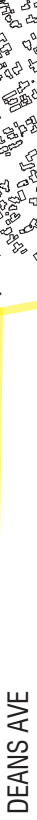

1

\section{BEALEYAAVE}

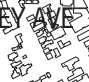

7

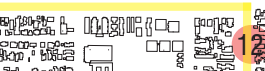

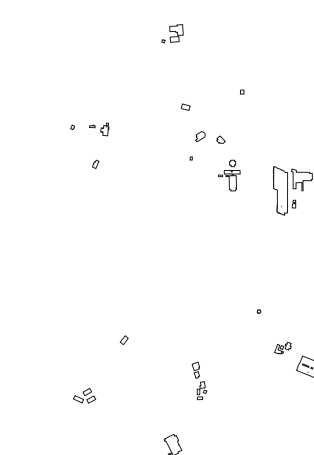

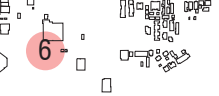

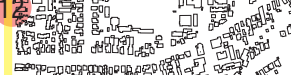

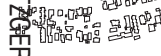
罗 㝕

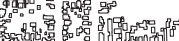

19

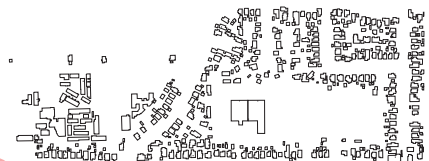

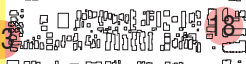

18 .

${ }^{4}$ SITE

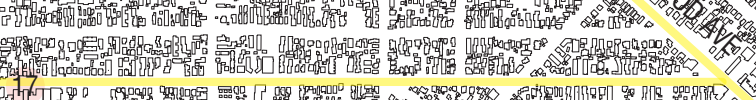

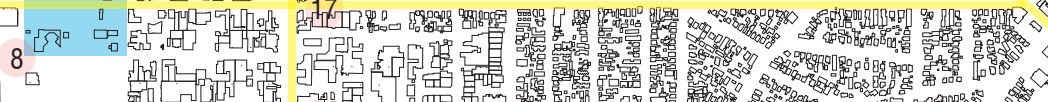

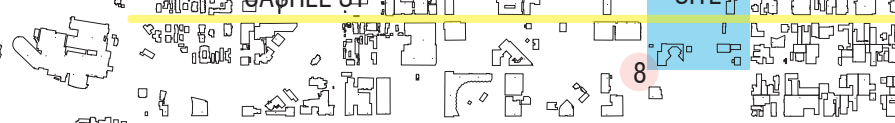
15 indunt

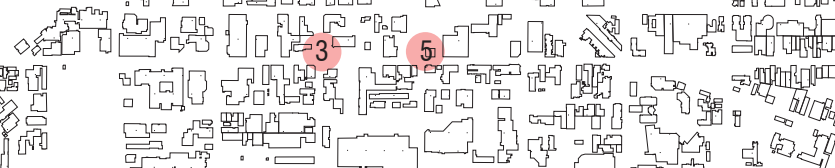

14

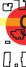

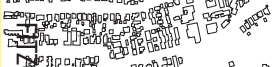

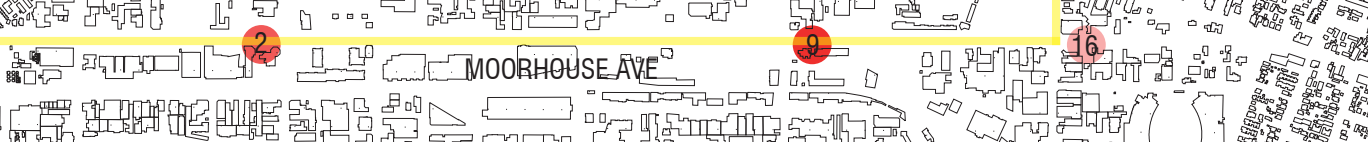
MORHOUSEAVE

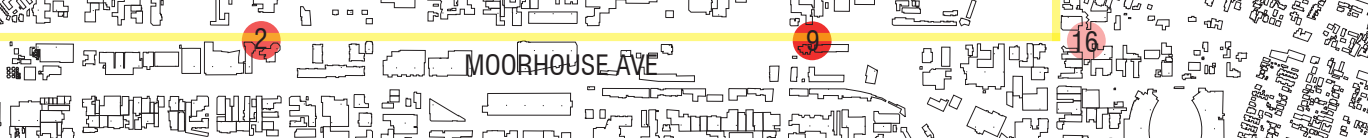

Figure 3.30. Traffic Volume.

\subsubsection{TRAFFIC VOLUME}

Based on the available statistics (Christchurch City Council, 2013), the research concludes that the area surrounding the site has low vehicular traffic which strengthens the argument to make the site pedestrianfriendly.

https://ccc govt nz/transport/transport-pro-

\section{Deans Ave (N Lester Ln) $\mathbf{1 0 , 3 4 8}$}

2. Moorhouse Ave (W Antigua St) 38,773

3. Durham St South (N St Asaph St) 17,518

\section{Colombo St (N Armagh) 10,292}

5. Colombo St (N St Asaph St) $\mathbf{1 3 , 4 2 9}$

6. Madras St (S Kilmore St) 12,903

\section{Bealey Ave (W Madras) $\mathbf{3 4 , 8 6 8}$}

8. Lichfield St (W Madras St) $\mathbf{9 , 5 4 5}$

9. Moorhouse Ave (E Madras St) 47,783

10. Kilmore St (E Colombo St) $\mathbf{1 0 , 9 6 0}$

11. Barbadoes St (S Gloucester St) $\mathbf{1 3 , 4 9 2}$

12. Fitzgerald Ave (S Bealey Ave) $\mathbf{2 7 , 8 7 2}$

13. Fitzgerald Ave (N Worcester St) 28,183

14. Fitzgerald Ave (N Ferry Rd) $\mathbf{3 2 , 4 7 3}$

15. Tuam St (E Fitzgerald Ave) 7,256

16. Moorhouse Ave (E Fitzgerald Ave) 18,274

17. Cashel St (E Fitzgerald Ave) 4,732

18. Stanmore Rd (S Gloucester St) 11,904

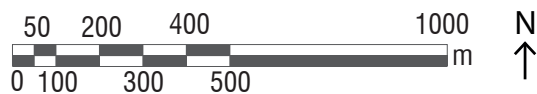

The number listed indicates the average number of vehicles over a 24 hour period. Average was calculated from a week of

data collected and compiled by CCC.

jects/traffic-count-data/intersection-count-search
19. Linwood Ave (S Woodham Rd) 10,392

0 - 9,999 vehicles / $24 \mathrm{hr}$

$10,000-19,999$ vehicles / $24 \mathrm{hr}$

$20,000-29,999$ vehicles / $24 \mathrm{hr}$

$40,000+$ vehicles / $24 \mathrm{hr}$
$30,000-39,999$ vehicles / $24 \mathrm{hr}$ 


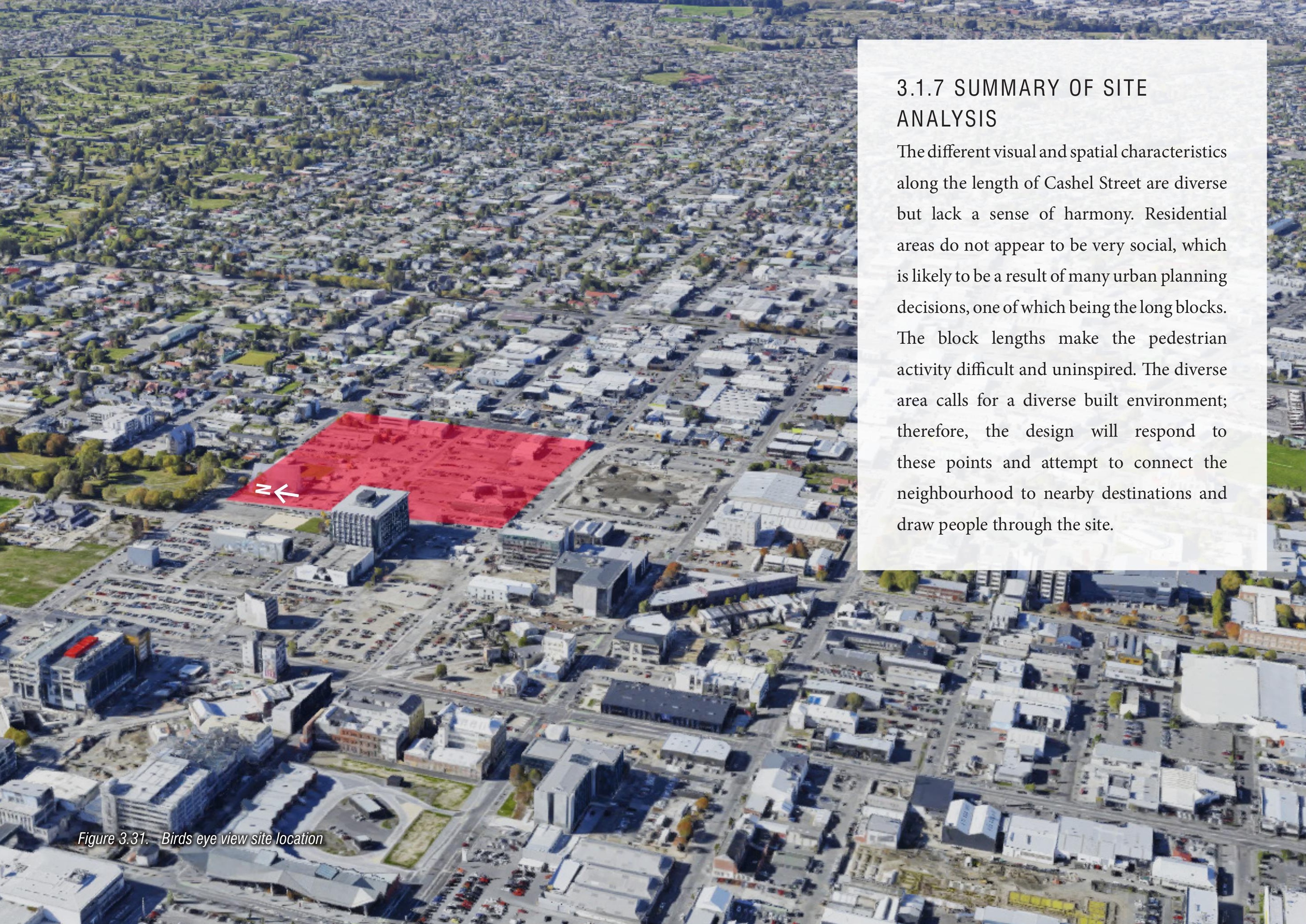


THIS PAGE IS INTENTIONALLY LEFT BLANK. 


\subsection{INTRODUCTION OF DESIGN EXPERIMENTS}

The research tests the framework through a design research methodology. To investigate how the framework can inform architecture on the site, the design was developed at two scales simultaneously: the masterplan of the entire site (as outlined in section 3.3) and a smaller scale focusing on three separate areas, each with a cluster of 2-12 dwellings on it.

The outcomes from the site analysis informed a short brief for the design as follows. The design shall redevelop a site in the industrial/ car park zone between the CDB and residential area, and incorporate both commercial and residential spaces on it. The design shall develop a strategy to encourage pedestrian activity by the introduction of laneways to break up block lengths, while simultaneously providing support for people to meet their psychological needs.

The order in which the four different parts of the overall design are presented in this document reflects the chronological order that they were started in but does not reflect the fact that work between the different elements happened simultaneously. The four parts of the design are presented in order of a Masterplan of the entire site, apartments on Lichfield Street, single-detached houses on Hereford Street, and a gallery, apartments and offices/ commercial use spaces on Cashel Street.
Ideas and learnings were taken from each area of the design and applied to others as they were simultaneously designed. These shared ideas are recorded in two boxes to the side of the written descriptions in each design experiment discussion. The blue box contains the ideas that were imported from other design experiments and used to enhance the one being discussed. The yellow box contains ideas and lessons that were learned in the design area being discussed and were exported to other design experiments. 
For example, the Lichfield Street design had a necessity for careful planning to create privacy between dwellings vertically and those across from one another. These principles were then applied in the design of the single-detached houses on the Hereford Street site. The narrow lanes on the Hereford Street site propose a threat to the privacy between dwellings across from each other. The technique to create privacy that was learned in the Lichfield Street design informed Hereford.

[This information will be displayed in the blue box in the Hereford St site section, and in the yellow box under the Lichfield St site section.]

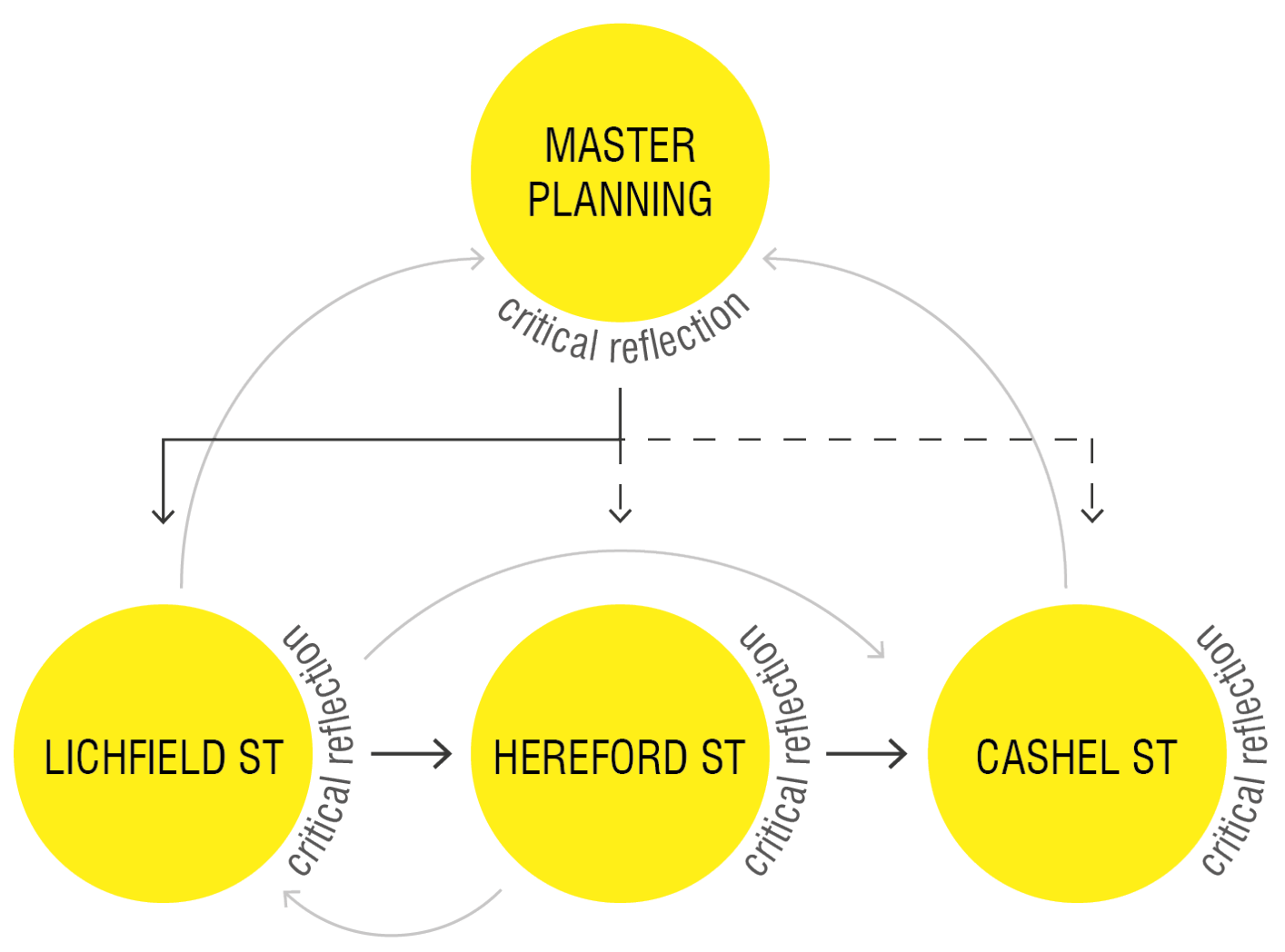




\subsection{MASTER PLANNING}

\subsubsection{INTRODUCTION}

The masterplan of the site aimed to achieve most of the criteria of the framework, as it set solid foundations for the smaller sites within it. Communal gardens intend to satisfy the first criterion, relatedness with neighbours, and the sixth criterion: autonomy on site. Desire lines and pathways through the site aim to achieve the second criteria: connection to the city, and the fourth criteria: competence, by providing choices of how to get from one point to another. Finally, a large variety of housing types and designs aim to give residents the autonomy to choose a home that suits them the best.All iterations of the masterplan were started by sketching the general spaces, then generating basic digital models of the site. It was developed further by the input of the other design experiments, found in the following chapters.

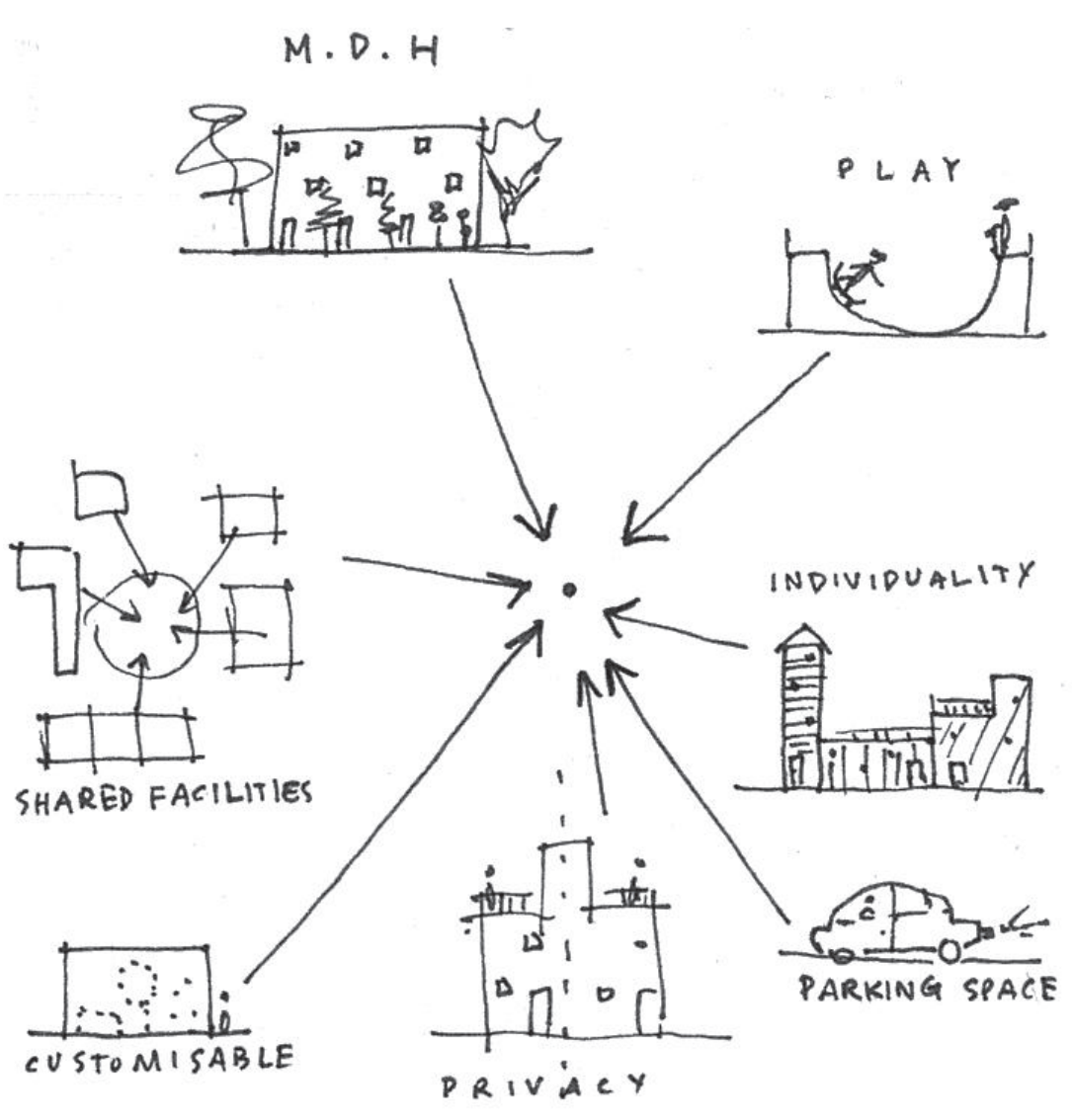

Figure 3.32. Masterplan brainstorm 
Figure 3.33. Space Outlines Masterplan Iteration 1.

Figure 3.34. Negative Space as Positive Object Masterplan Iteration 1.

Figure 3.35. Positive Space Masterplan Iteration 1.

\subsubsection{ITERATION ONE}

The first and second iterations of the Masterplan followed the same process to produce the building forms. That process was:

1. Outline the public spaces and thoroughfares

2. Make the outdoor spaces and thoroughfares into positive objects

3. Reverse the positive and negative space so that the potential building space is a positive object. 


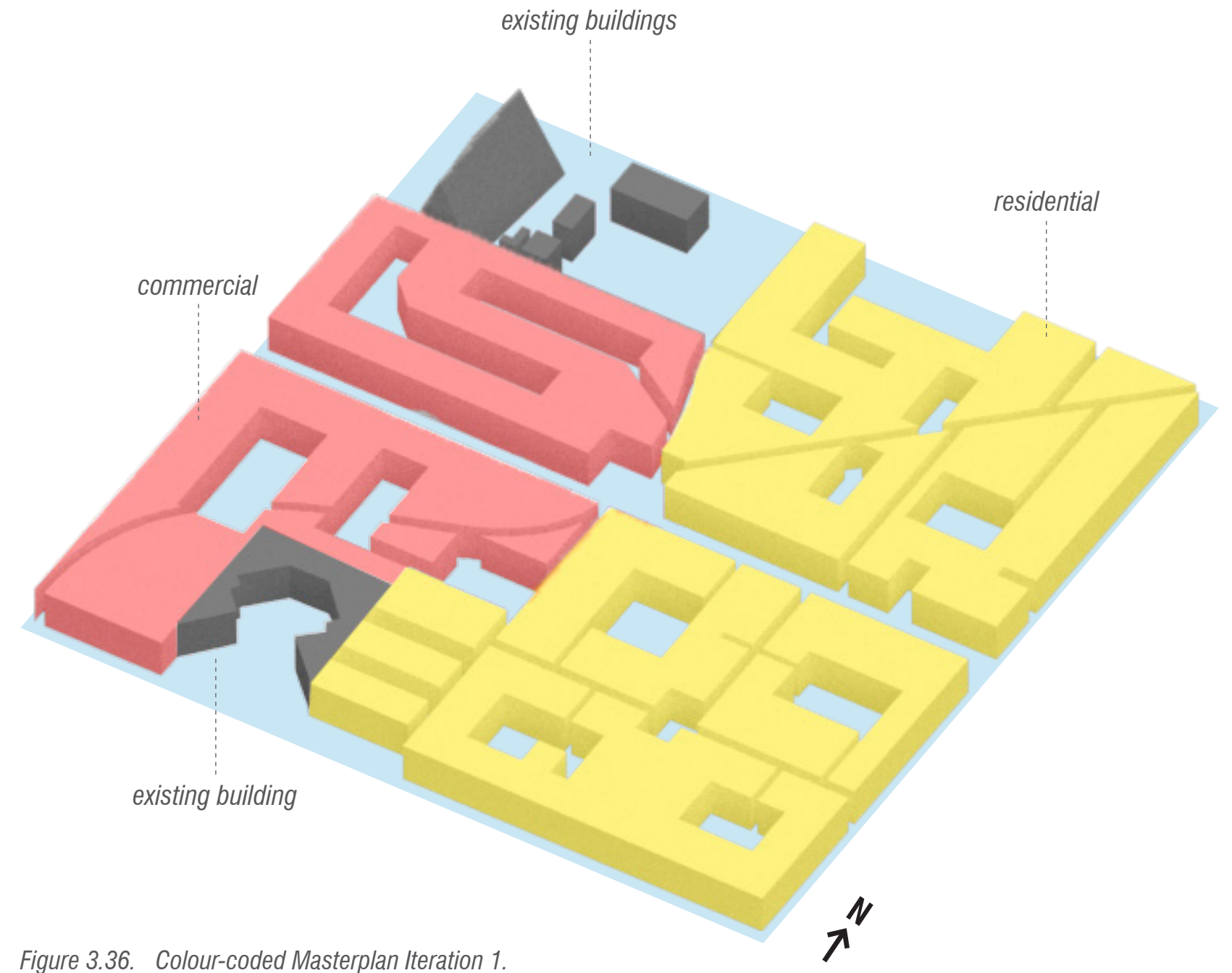

In this design, there was not enough outdoor space, and the buildings were too close together. What was learned from this iteration was that the laneways needed to be wider, or have more space either side of them. The site also needed to have more public outdoor spaces, such as parks. 


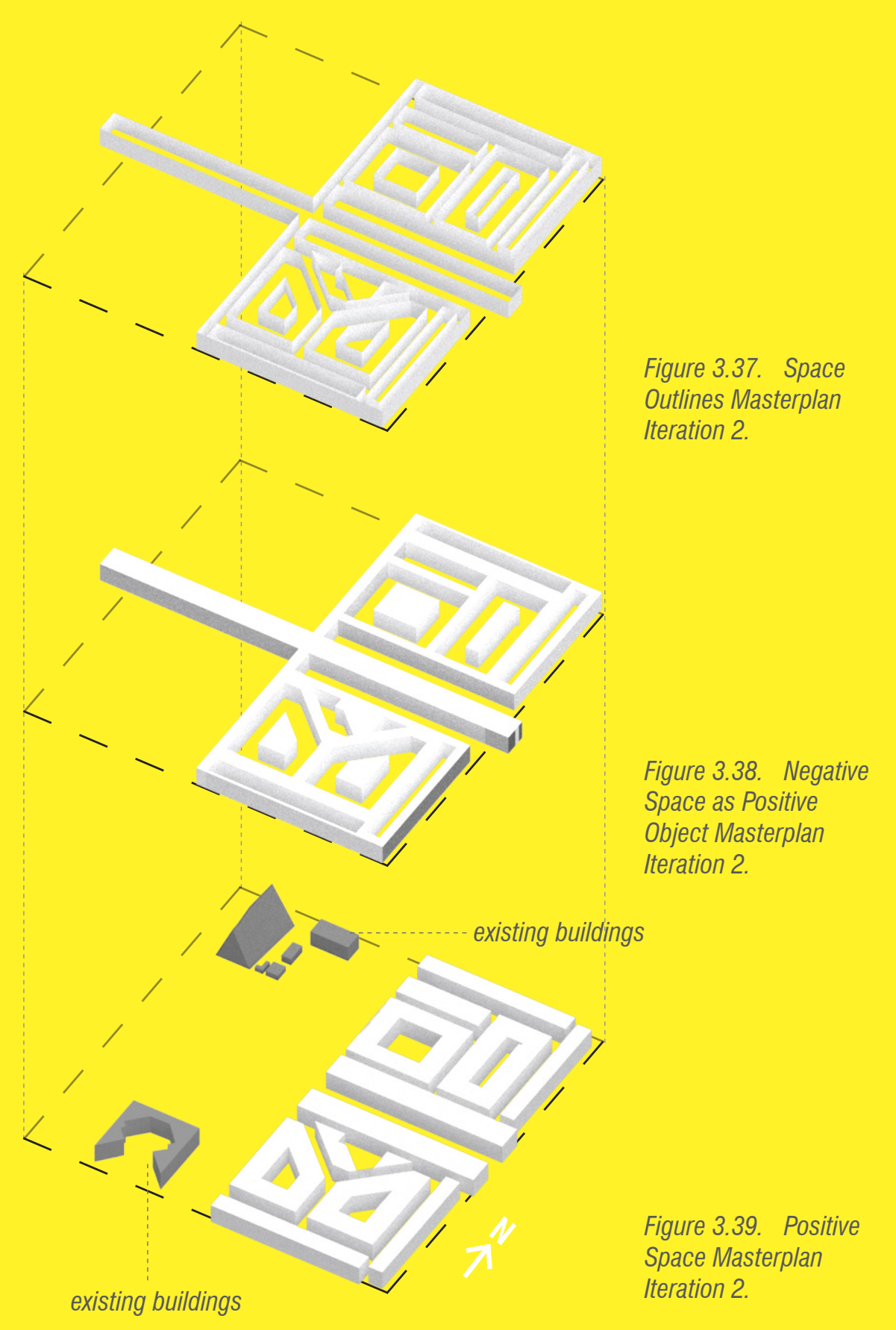

\subsubsection{ITERATION 2}

\subsubsection{Design Process}

The approach of the second iteration of the Masterplan was splitting the site in two, focusing only on the east side and making it primarily residential.

The outdoor public spaces and thoroughfares were outlined and then made into positive objects. The positive and negative spaces were then reversed, revealing the potential building forms. From there, the forms were printed and traced over. Single-detached houses, duplex houses, apartments above commercial spaces, and terraced houses were organised into various parts of the site to determine where each housing type might work best. Many of the houses face in toward a communal garden, and some others have private outdoor space. The apartments above the commercial spaces on the south side of Cashel Street are missing to allow sunlight into the south half of the site in the winter. Public pathways through the site allow people to cut across the block rather than having to walk around the perimeter. The paths are also a place in which children can play. 


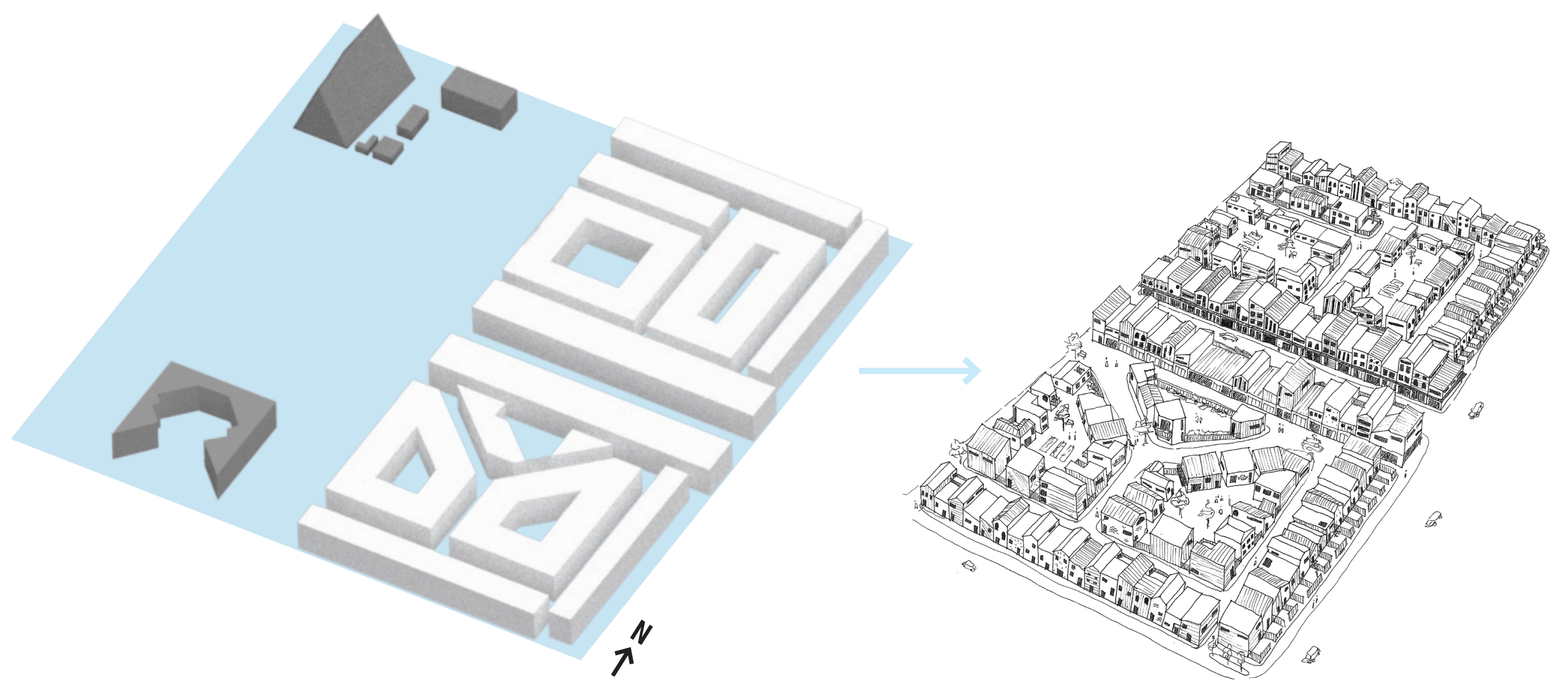

Figure 3.40. Digital Model of Masterplan Iteration 2.

Figure 3.41. Masterplan Iteration 2 sketch. 


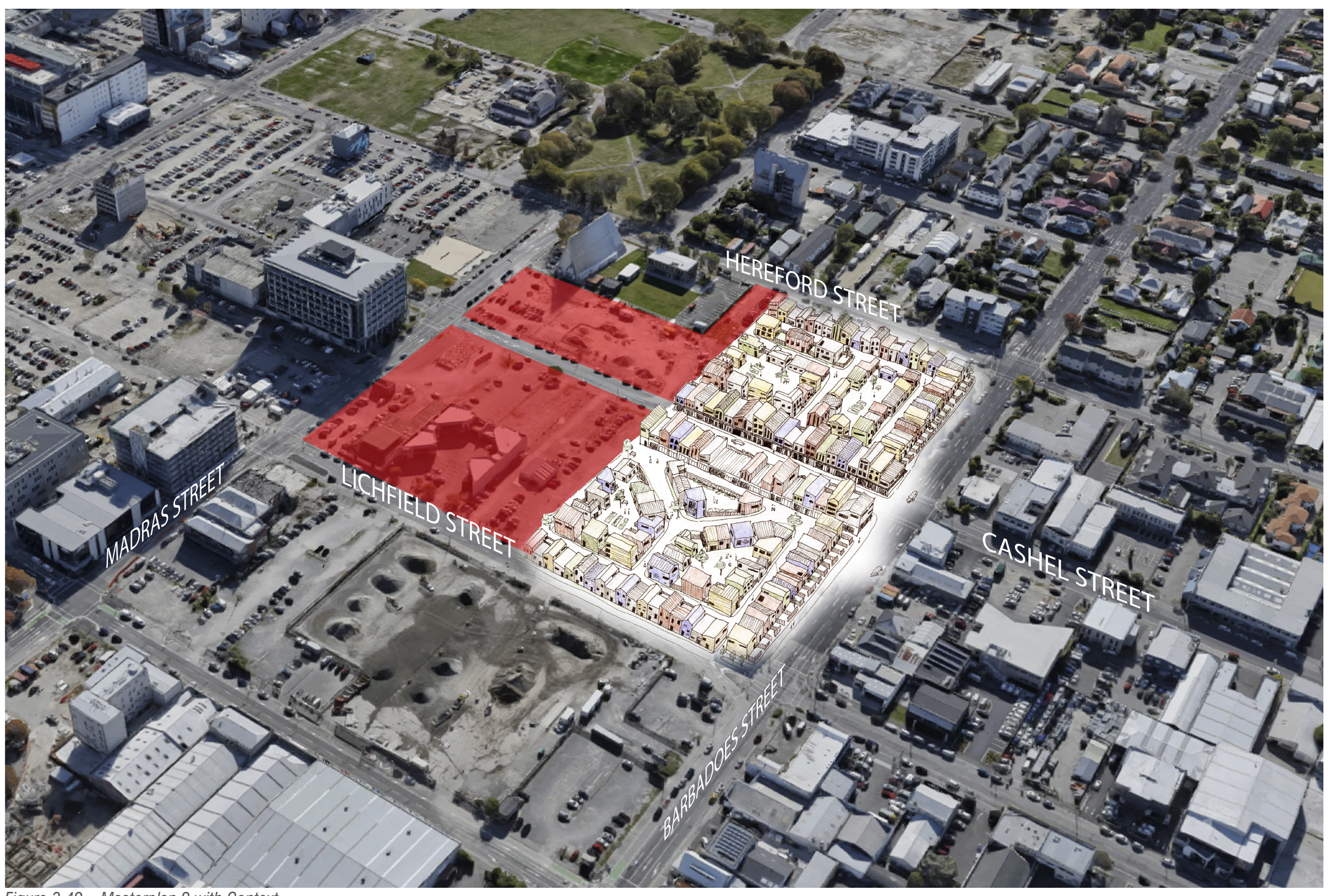

Figure 3.42. Masterplan 2 with Context. 


\subsubsection{Reflection}

Pathways through the site aimed to connect the site to the city and communal gardens aimed to encourage neighbours to connect with each other. However, considering that the pathways through the neighbourhood were narrow and surrounded by private housing, a conclusion was made that the public will feel discouraged from using the pathways as they were intended to be used. The site began to achieve a connection with the city via paths through the neighbourhood. However, considering that the commercial and residential zones were separated, it was not as successful as it could have been. Having the commercial and residential areas bleed into each other would strengthen a connection from the site to the rest of the city.
Although this iteration offers a variety of housing types, the site is aesthetically monotonous. Further development of the site shall increase diversity and variety housing on the site overall.

Private outdoor space is vital for $\mathrm{MDH}$ developments, and it is apparent that many dwellings in this iteration are missing it. It is also apparent in this sketch that the fronts of some houses are facing the backs of others which is an issue for the integrity of the street and laneways. Residents are not likely to feel proud of their neighbourhood if they walk out of the front of their house and directly face the back of someone else's where their rubbish and recycling bins are. A strategy to fix this issue is developed in the Cashel Street part of the design.
Some constriction of public outdoor space is helpful when working with built forms on a large site as it can give impact to the release-spaces such as public parks; however, this design iteration does not offer any public parks. The process that the first two iterations followed by determining outdoor space and paths, then creating buildings from the leftover space were too limiting. Therefore, that process was discontinued in the final iteration and development of the Masterplan. 


\subsubsection{ITERATION THREE}

Iteration three was designed with more care and with the critical reflections taken from the first two iterations.

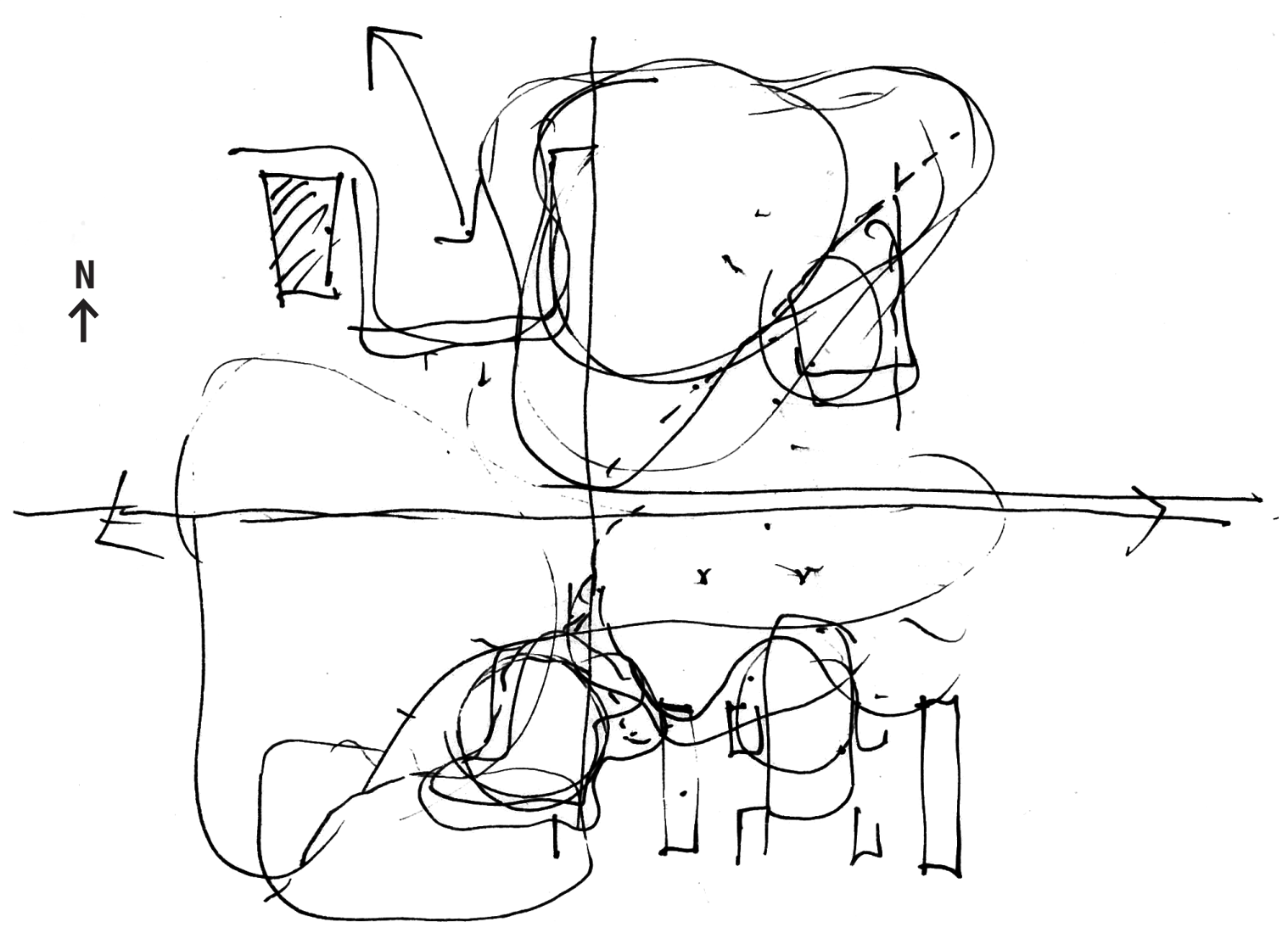

Figure 3.43. Masterplan 3 initial site plan sketch. 


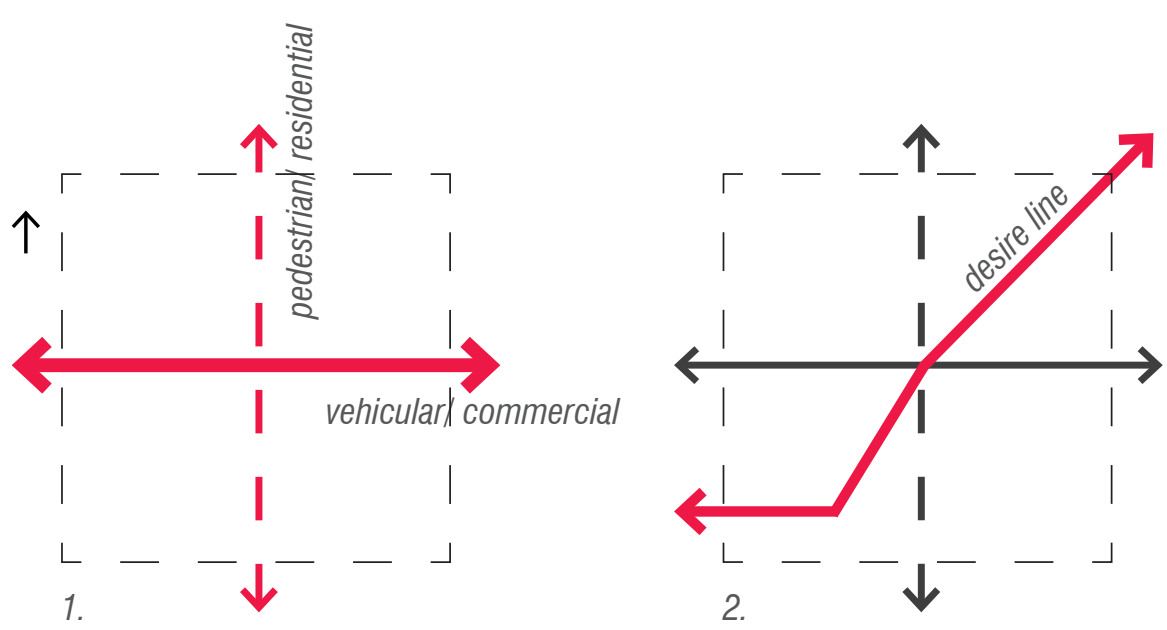

3.3.4.1 Design Process

Parti diagram 1:

Before establishing buildings and masses on the site, first, the thoroughfares and public spaces were organised according to the site analysis context and what was learned in the first two iterations. Analysis of the site, section 3.1.4, showed that the block lengths in the area are long and dissuade pedestrian activity; thus, the site was divided in two by a path running north to south through the centre. The two axes (northsouth and east-west) were then

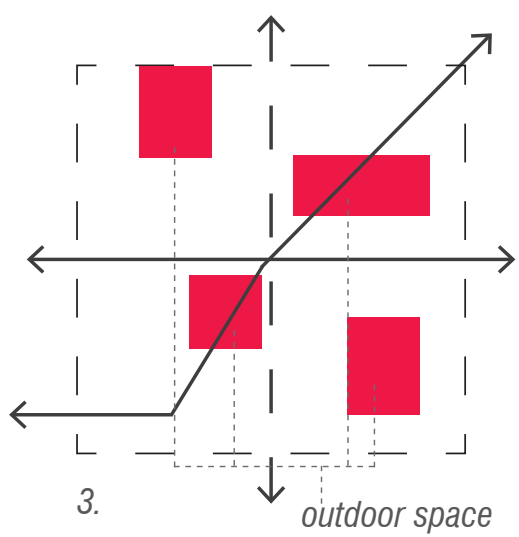

Parti diagram 3:

The north to south path plus Cashel Street divided the site into four quarters, and each quarter had an open space placed within it. The very north/west corner of the site has the Cardboard Cathedral on it, thus the open space for this quarter aimed at opening this corner up to the Cathedral and adjacent park, Latimer Square. Each of the other three open spaces were surrounded by buildings and accessed by paths.

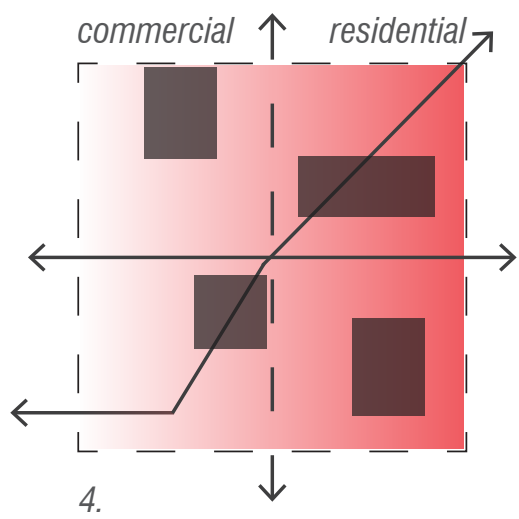

Parti diagram 4:

From west to east, the site has a gradient of commercial to residential with public outdoor spaces throughout it. The gradient was an approach to smooth out the harsh zones and thresholds along Cashel Street, as outlined in section 3.1.2, and aids the street to transition from town to suburb. This move also made good economic sense, as it spreads the development risk across different sectors and helps to increase efficiency in the use of the site. Day to night activity is enhanced. 


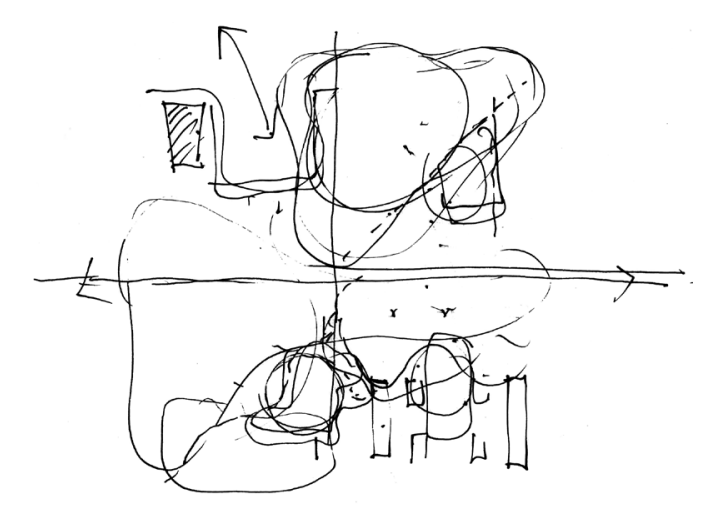

Figure 3.44. Masterplan 3 initial site plan sketch.

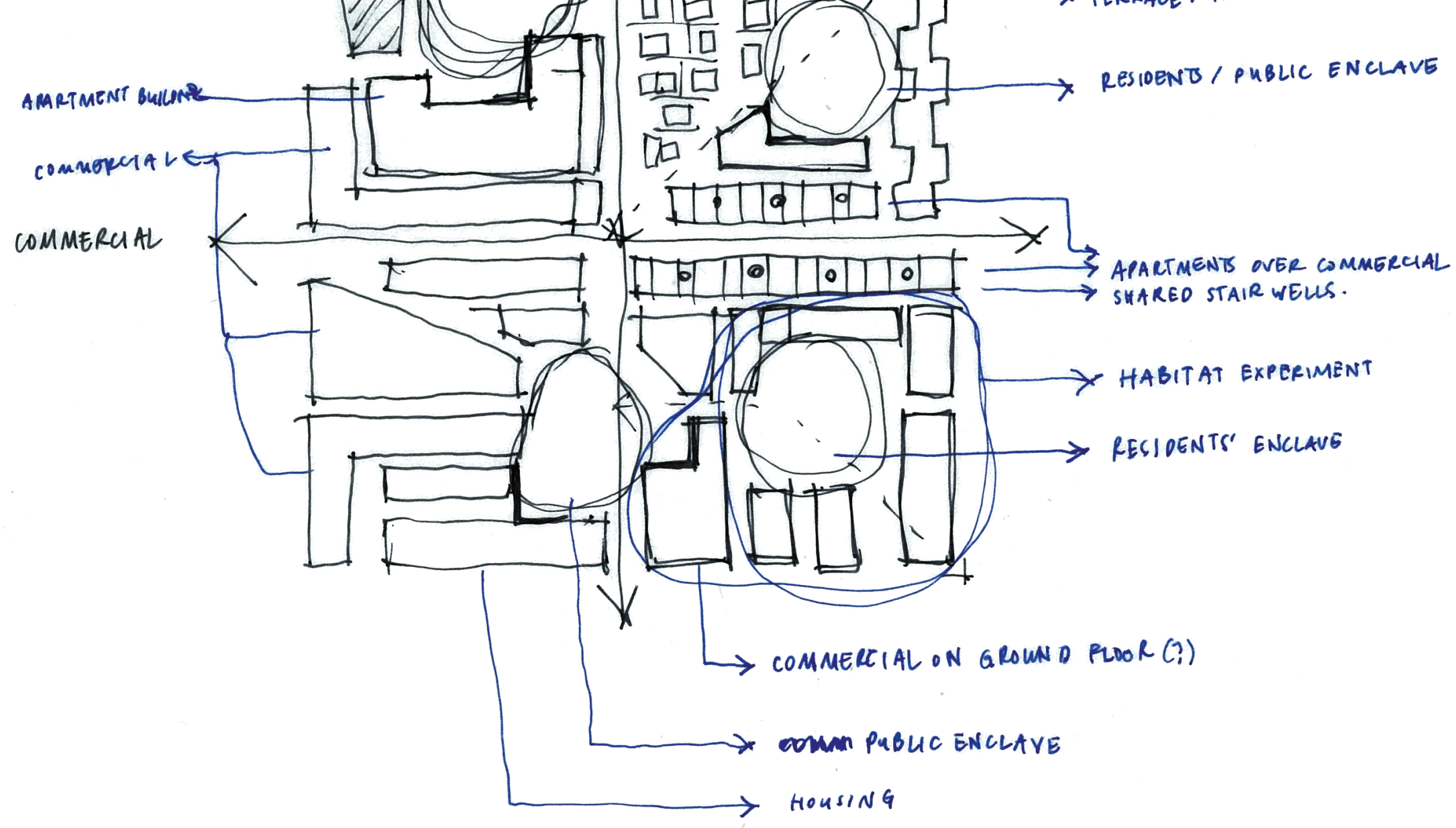

Figure 3.45. Masterplan 3 refined site plan sketch. 

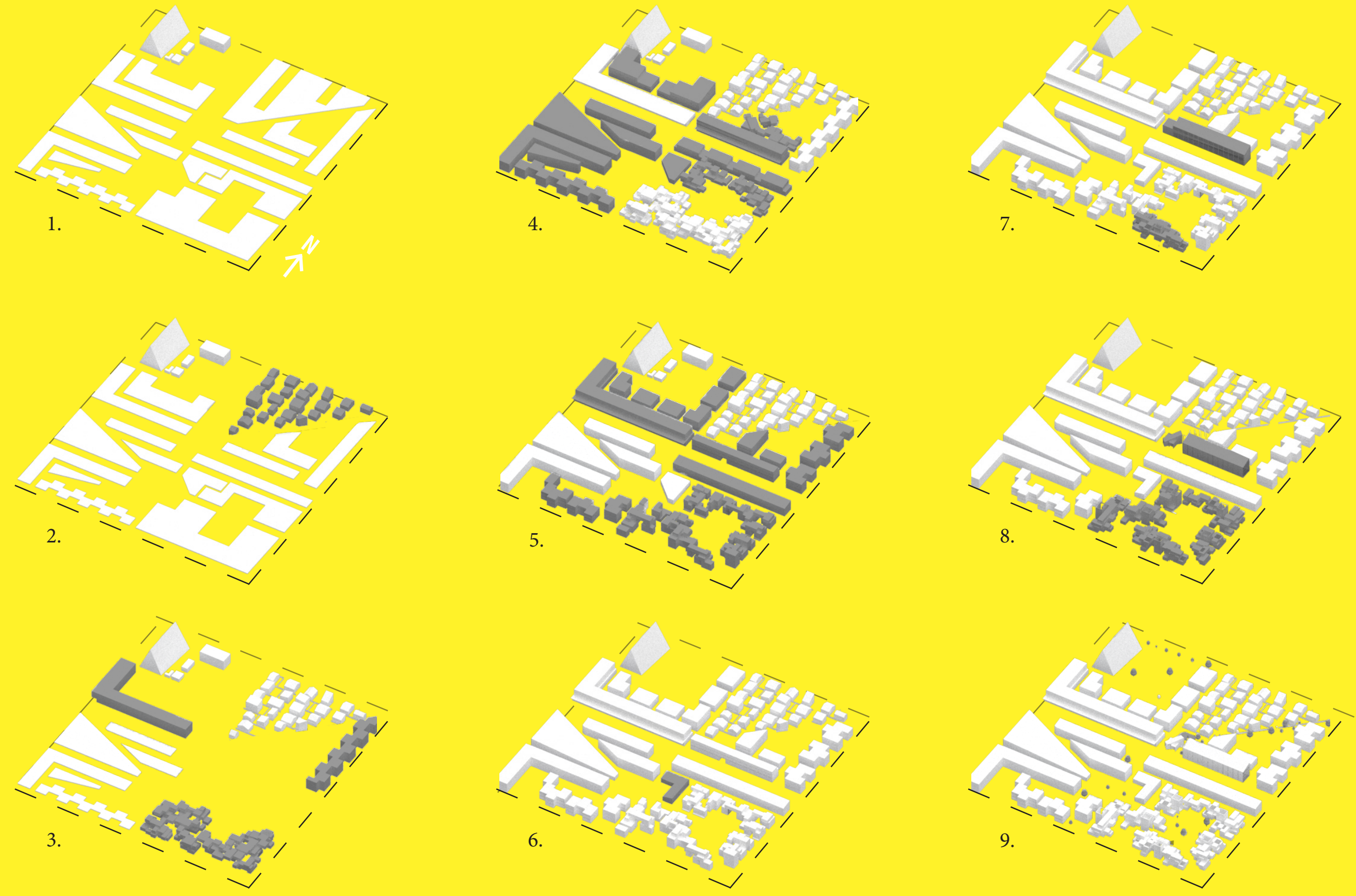


\section{Figures on previous page}

Figure 3.46. Masterplan Iteration 3 Development 1.

Figure 3.47. Masterplan Iteration 3 Development 2.

Figure 3.48. Masterplan Iteration 3 Development 3.

Figure 3.49. Masterplan Iteration 3 Development 4.

Figure 3.50. Masterplan Iteration 3 Development 5.

Figure 3.51. Masterplan Iteration 3 Development 6.

Figure 3.52. Masterplan Iteration 3 Development 7.

Figure 3.53. Masterplan Iteration 3 Development 8.

Figure 3.54. Masterplan Iteration 3 Development 9
Finally, the built form was introduced around the paths and open spaces. 3D masses were manipulated and refined to represent a variety of housing types and commercial-use spaces.

The built form of the site is five storeys at most, which was a decision made for a few reasons; the first was to not overpower the Cardboard Cathedral, a post-earthquake landmark, on the north/ west corner of the site. Another reason was not to overpower the adjacent low-rise residential context. Had the site been more than five storeys, the contrast of scale would have contradicted the criterion to connect the site to the city, as it would seem out of place and not harmonious with the city. The five-storey maximum helps the city to transition from taller buildings to houses.

The Masterplan was developed from the original diagrammatic sketch to building outlines, and finally, form. From the primary forms, the site was developed iteratively.

The four quarters of the site, and the paths between them, give pedestrians more options of ways to move through the site. The divisions also allow residents within each quarter to have a smaller, potentially more tight-knit community. They also enable efficiency in production while facilitating variety at a scale that will appeal to local residents. 


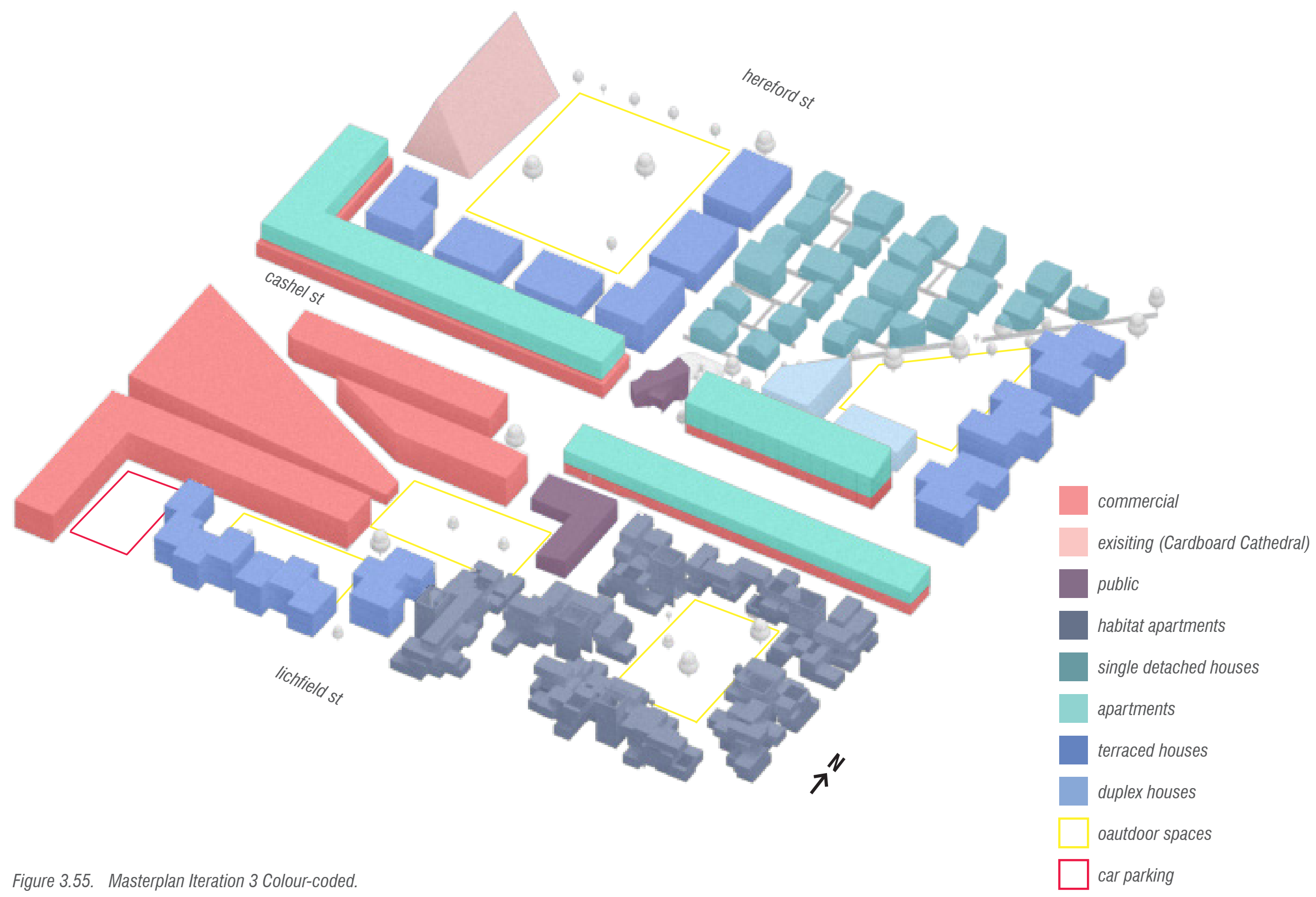




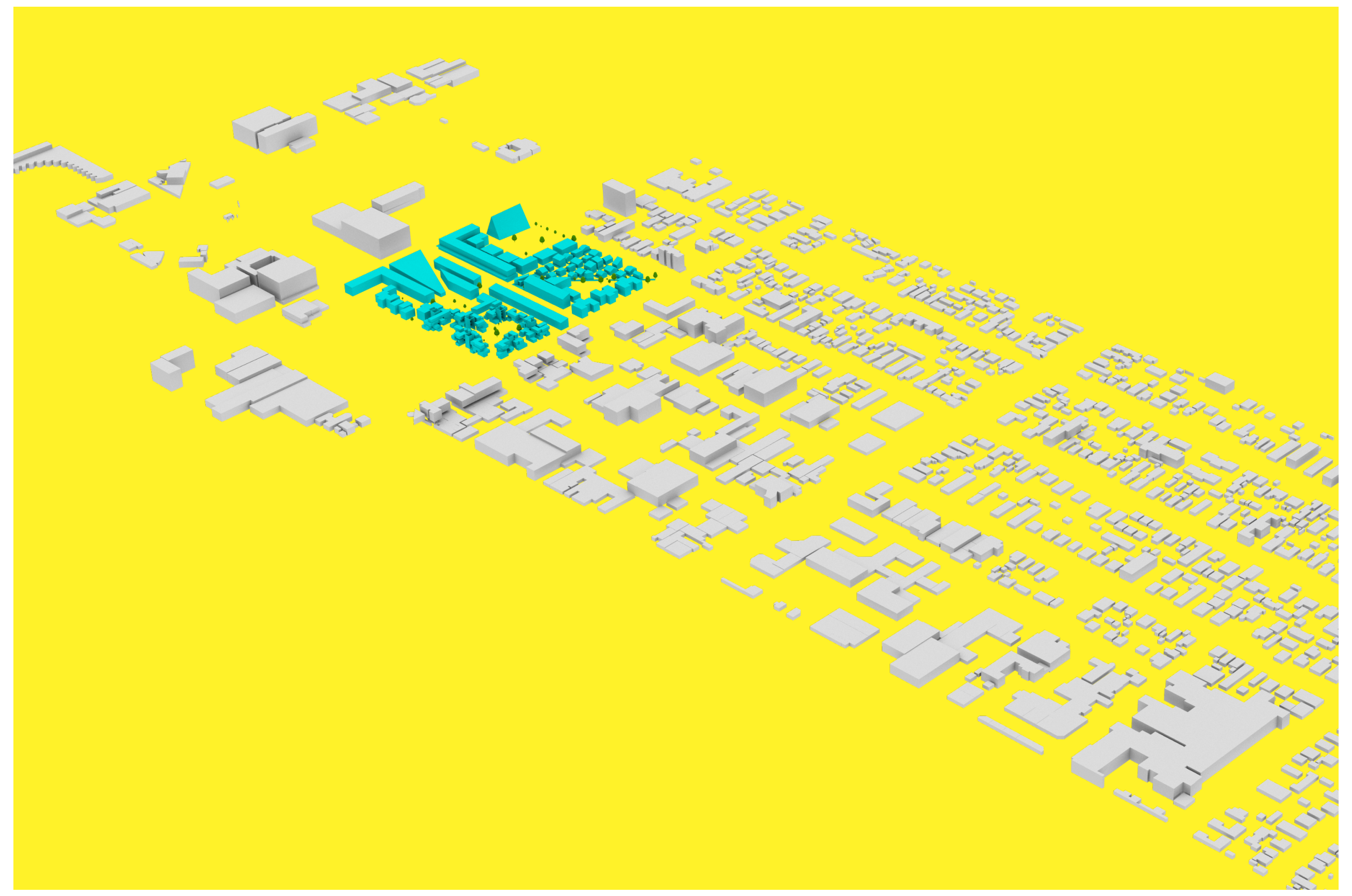




\subsubsection{REFLECTION}

Attempting to achieve so many of the criteria in the design of the Masterplan was ambitious. However, given that it is the Masterplan of the site, it was essential to endeavour to achieve as many criteria as possible.

The Masterplan achieves the first criterion, relatedness with neighbours, by providing community gardens, or a park, adjacent to or very nearby all dwellings on site. The community gardens are more prominent in this iteration than they were in previous ones.

To achieve the second criterion, connection with the city, careful planning and knowledge of the context of the site informed the placement of paths through the site that guide people to destinations beyond it. The gardens and parks also help the site to fit its context in Christchurch, which is well known as the garden city. Also, vantage points from the tops of some buildings provide residents with views toward the Port Hills and over parts of the city. The laneways worked better in the third iteration with the commercial axis and residential axis that bring order to the site.

A network of paths throughout the site provides people with choices of how to get to their destination, adding to their sense of competence while using the site.

\subsubsection{TECHNIQUES AND IDEAS IMPORTED FROM ANOTHER DESIGN EXPERIMENT TO THE MASTERPLAN}

From Lichfield: The stairwells in the Lichfield design perform best when they are accessible from both the street, or laneway, and the communal garden. This was learned through the design process of the Lichfield Street apartments. This discovery led to a better Masterplan design, as the Lichfield Street design experiment informed the placement of the stairwells.

From Cashel: Transparency around the perimeter of the site on all edges allows passers-by to get glimpses to inside the street block. This technique, making the edges transparent in parts, also has other desirable side effects. It allows light into the site as well as out onto the surrounding footpaths, particularly on Barbadoes and Lichfield Streets. This technique was developed in the Cashel Street design, where every third commercial space on the ground floor is transparent through to the other side of the building so that passers-by can see into the site. This encourages the connection between the site and the city. 
A broader range of housing types and aesthetics meets the fifth criteria, autonomy at the dwelling scale. A truly diverse range of housing also allows residents to stay within the neighbourhood when they decide to move house at different stages of their lives yet still find a home that suits their changing needs.

On the whole, the site offers residents the autonomy and freedom to use the site how they choose, for example, by growing food, creating play areas for children, or running a community building such as a gallery or a library.

\subsubsection{TECHNIQUES AND IDEAS THAT HAVE BEEN EXPORTED FROM THE MASTERPLAN}

To Cashel: In the first iteration of the Masterplan, many of the fronts of houses were facing the backs of others. This conflict not only discourages connection between neighbours but makes for a disharmonious design. A lesson learned in the third iteration of the Masterplan that addressed the fronts and backs of houses, was carried over to the Cashel Street apartments and commercial space underneath to address potential issues regarding front of house and back of the house.

To Cashel: The path travelling from the centre of the site to the north/ east corner (Hereford and Barbadoes Streets) was a key influence in the form of the gallery/ community building, as a part of the Cashel Street design. The intention is that the building and the path draw people into the site from both ends. This point is expanded on and illustrated in section 3.6.1.1. 


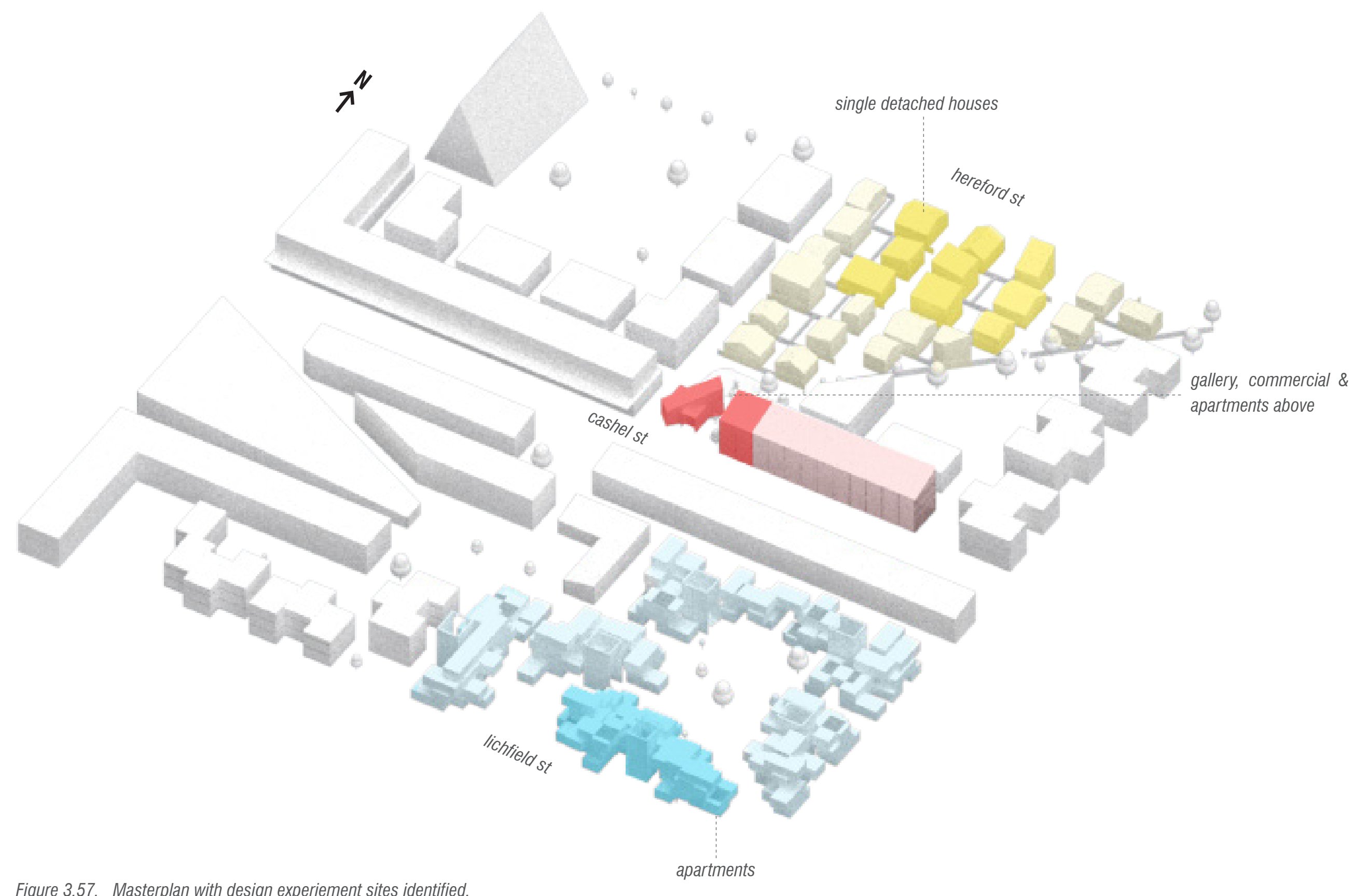

Figure 3.57. Masterplan with design experiement sites identified. 


\subsection{LICHFIELD STREET}

\subsubsection{INTRODUCTION}

The apartments on Lichfield Street aimed to achieve three criteria; 1 . Connection with neighbours; 2 . Connection with the city; and 5. Autonomy in the dwelling. The dwellings are used to achieve the criteria by testing autonomy at the dwelling scale, and a central stairwell is used to test the social criteria.

\subsubsection{DESIGN PROCESS}

3.4.2.1 The Apartments

Following on from the Masterplan, a large mass was outlined around the open space of the south/ east quarter. The adjoining street spaces were also considered in this process so as to address the public space. The Habitat 67 design approach was used to influence the shape and function of this part of the site. The design approach was also adapted to fit in the context of Christchurch's inner-city. 


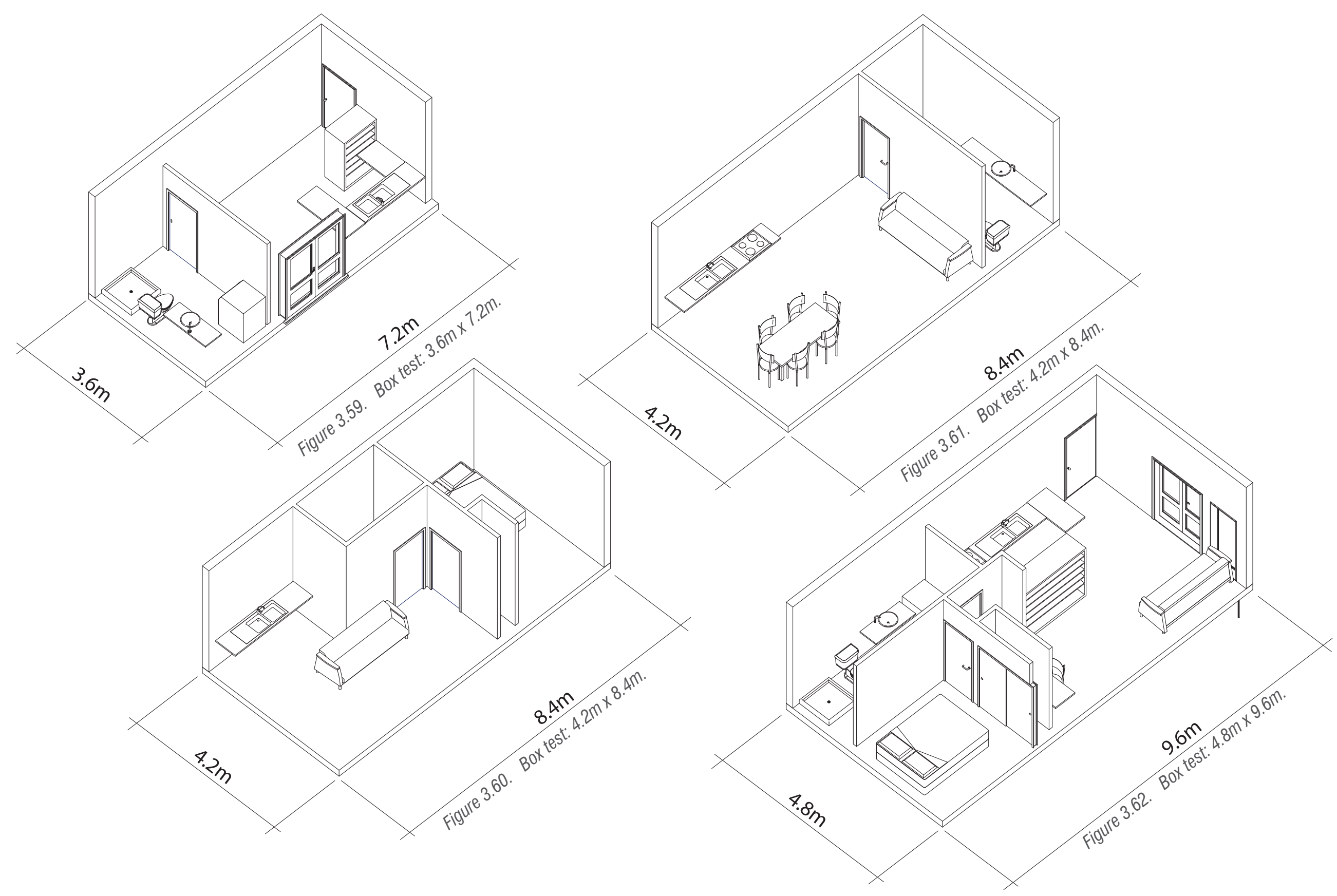




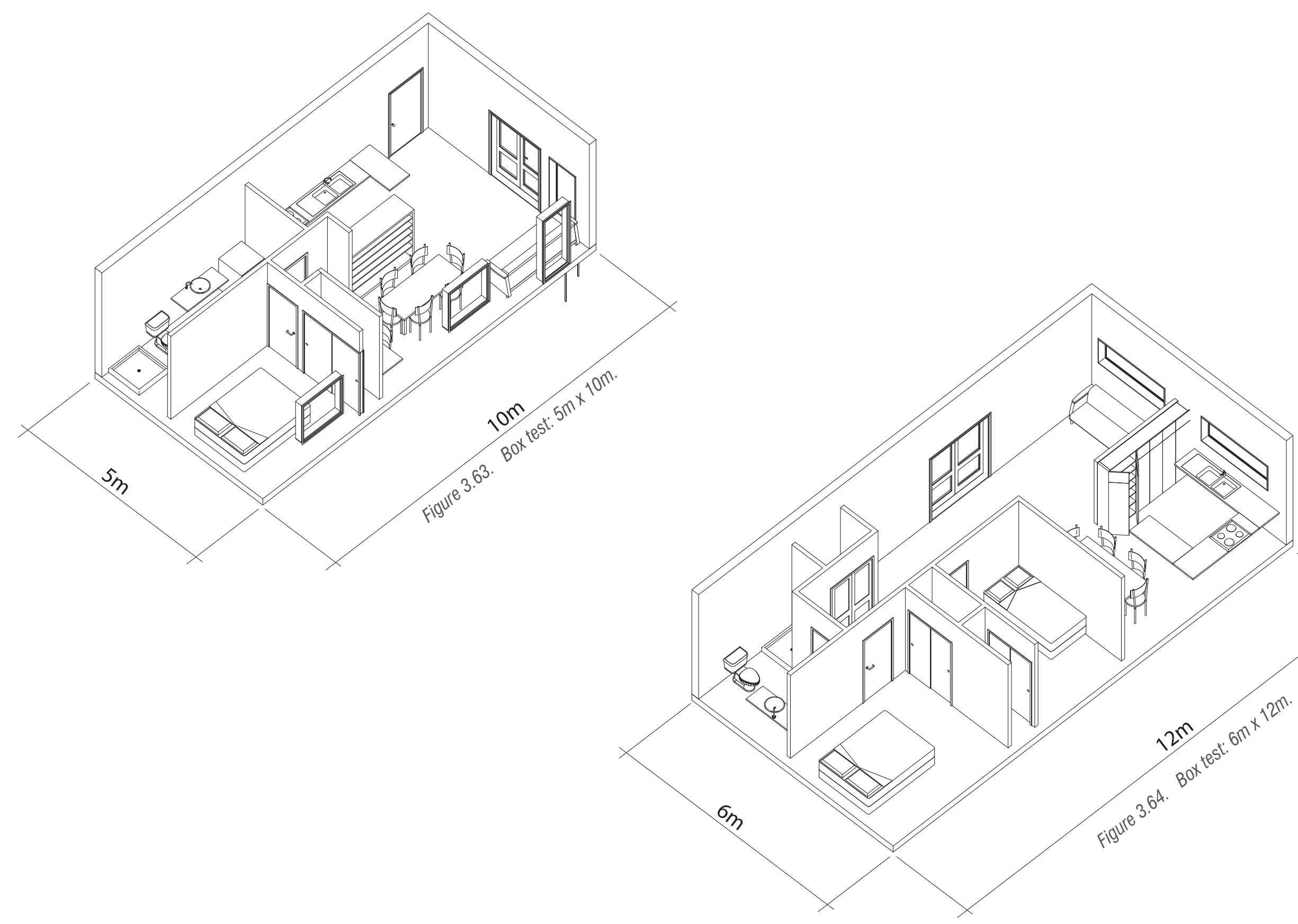




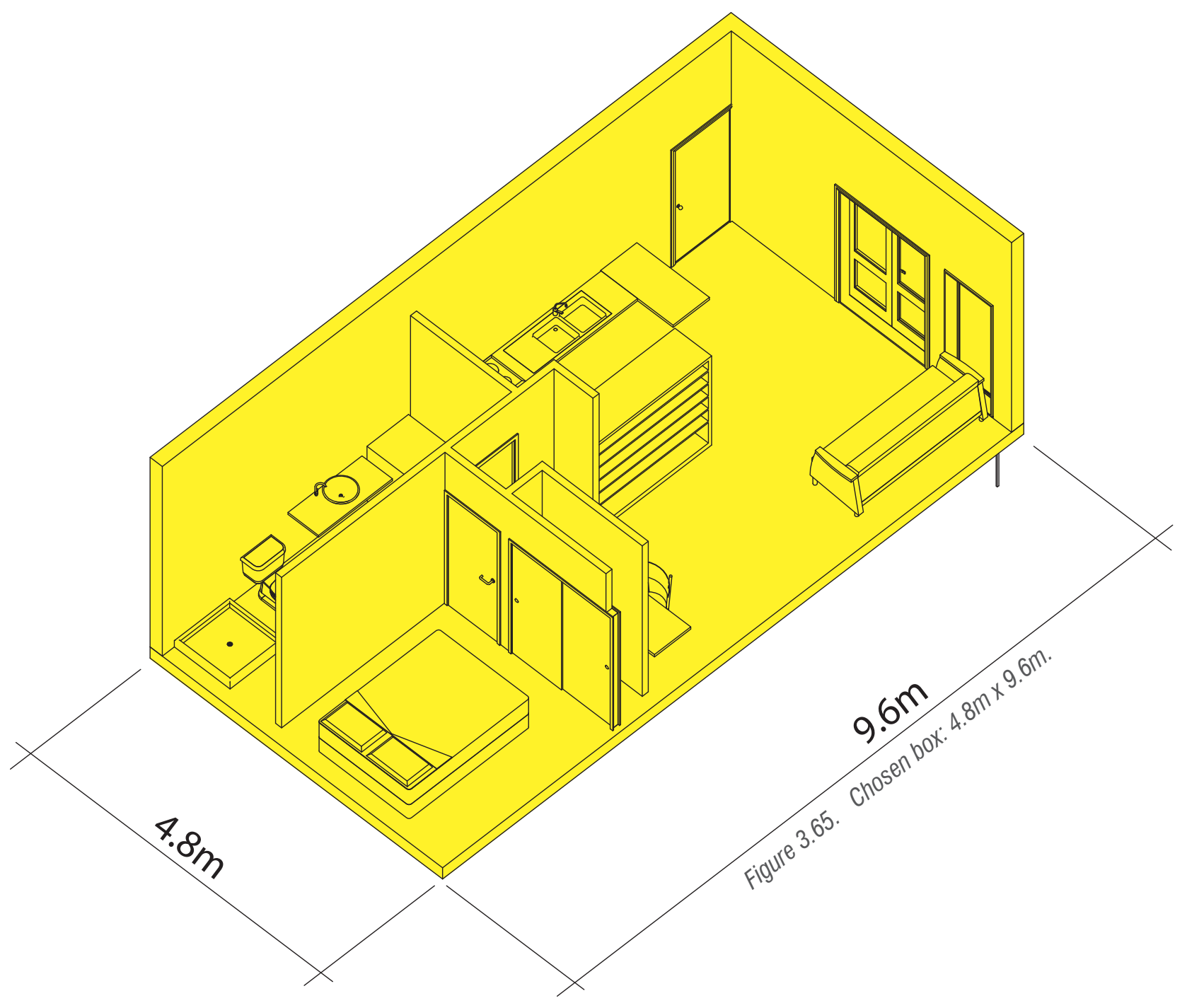

A modular box size was chosen after testing five different sizes while maintaining the 2:1 ratio in plan-view that Safdie used. After considering all of the potential sizes in terms of ergonomics, the layout of spaces and furniture to ensure comfort for the user, as well as considering standard construction material sizes to mitigate waste, the $4.8 \mathrm{~m}$ $\mathrm{x} 9.6 \mathrm{~m}$ modular box was selected. This test only trialled the layout of a single box, and although some dwellings will be only one box, most dwellings will have at least two connected boxes. The purpose of testing a single box, not multiple connected boxes, was to see how it could perform on its own, as it is the minimum size of a dwelling. All others will be larger, and thus able to fit more into it. 

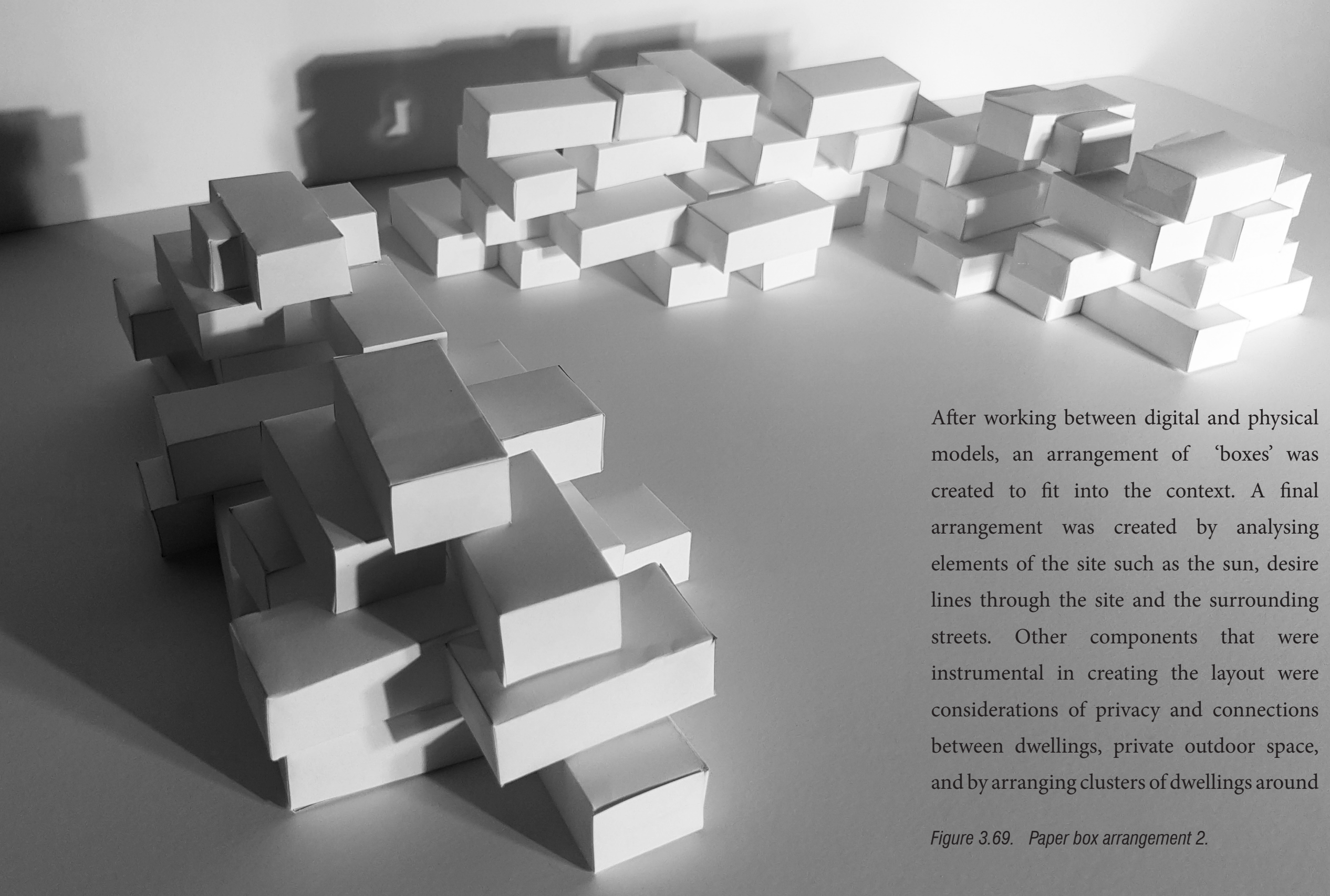
models, an arrangement of 'boxes' was created to fit into the context. A final arrangement was created by analysing elements of the site such as the sun, desire lines through the site and the surrounding streets. Other components that were instrumental in creating the layout were considerations of privacy and connections between dwellings, private outdoor space, and by arranging clusters of dwellings around Figure 3.69. Paper box arrangement 2. 
central stairwells.

A cluster of dwellings surrounding one stairwell was selected as a test site for designing the dwellings and testing the framework against them at a higher level of detail. Floor plans, private outdoor space and entrances were organised more carefully

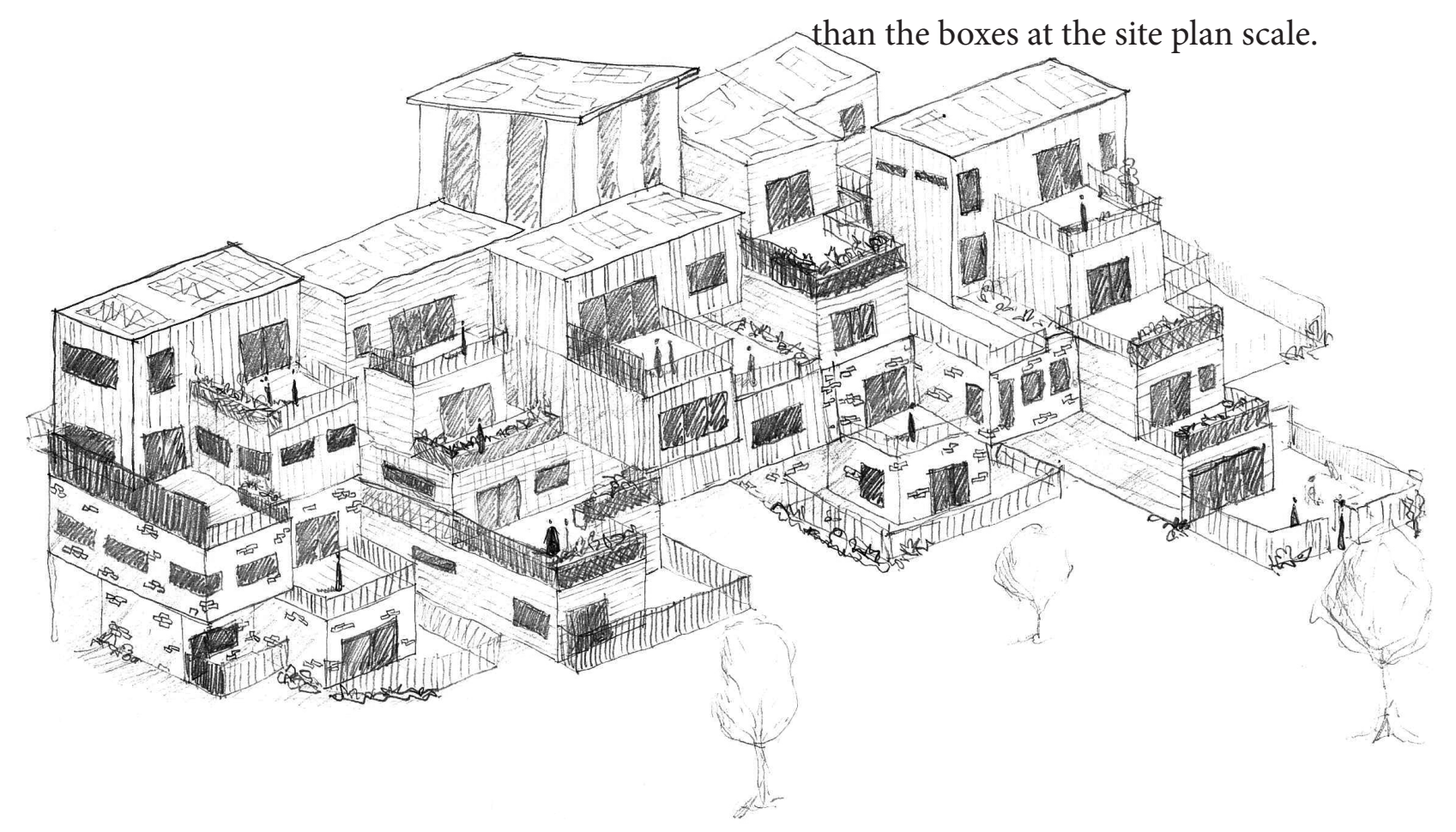

Attention was given to creating enough private outdoor space. In the feedback from one of the reviews of this project, it was noted that many houses were missing private outdoor space and that a minimum of $4 \mathrm{~m}$ $\mathrm{x} 4 \mathrm{~m}$ should be given to each dwelling. To achieve this, Safdie's technique from Habitat 67 of giving each dwelling multiple terraces by using the roofs of those below, was applied. Some houses have only one terrace, whereas others have multiple. The minimum outdoor space given to each is $16 \mathrm{~m} 2$.

As the building heights exceed three storeys, the structures fall outside the scope of NZS3604 and will, therefore, require specific structural design. Recent experience in the Christchurch context suggests that the development would require structural steel or laminated timber structural support framework.

Figure 3.70. Dwelling cluster arrangement cladding identities. 


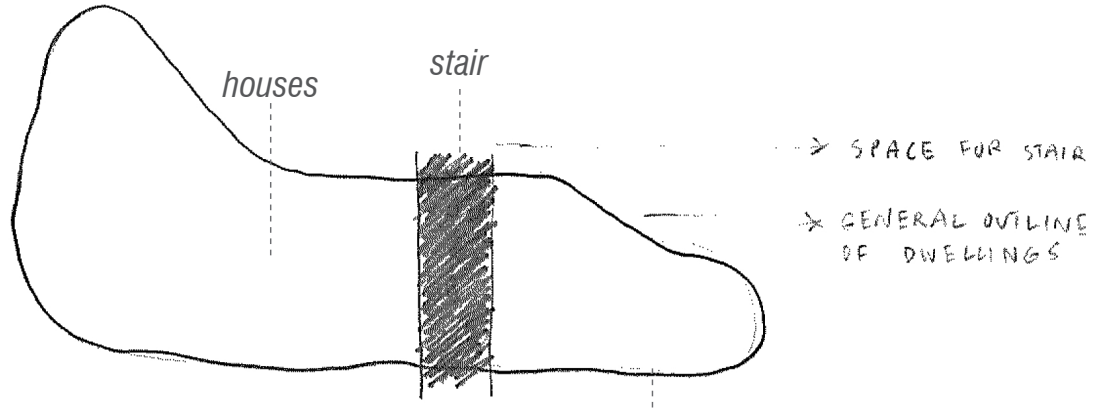

Figure 3.71. Stair parti diagram 1. houses

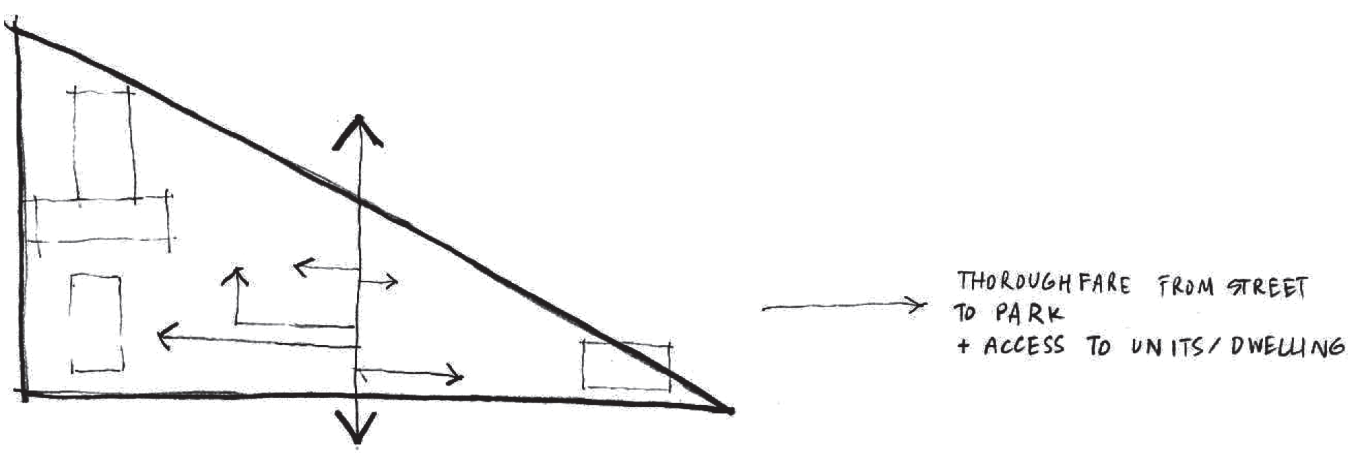

Figure 3.72. Stair parti diagram 2.

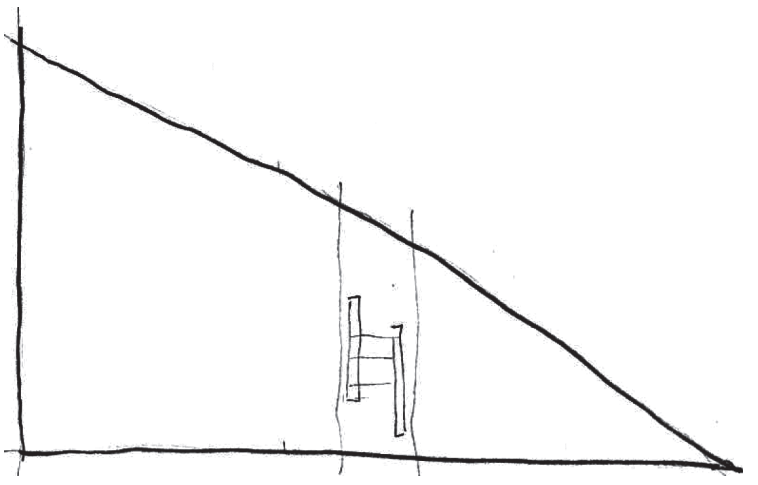

Figure 3.73. Stair parti diagram 3.

\subsubsection{The Stair}

The purpose of spending time designing a stair rather than using a generic fire escape stair was to achieve the first two criteria in the framework: connection with neighbours and connection with the city.

The design process started with parti diagrams to determine the function and general layout of the space between the dwellings. With the criteria in mind, it needed to be connected to the street/ residents' parking, and the communal garden, thus it could act as a private thoroughfare and literally connect residents to both the neighbourhood and the city. Additionally, it was important that each stairwell building was different from the others, that it had its own identity and acted as a landmark. The concept of placing landmarks on the site was discussed in section 2.3.5, the fourth criterion, to orient people. Once the function was established, concepts of the form were developed, and different qualities of stairs were tested.

Circular vs Square stair 


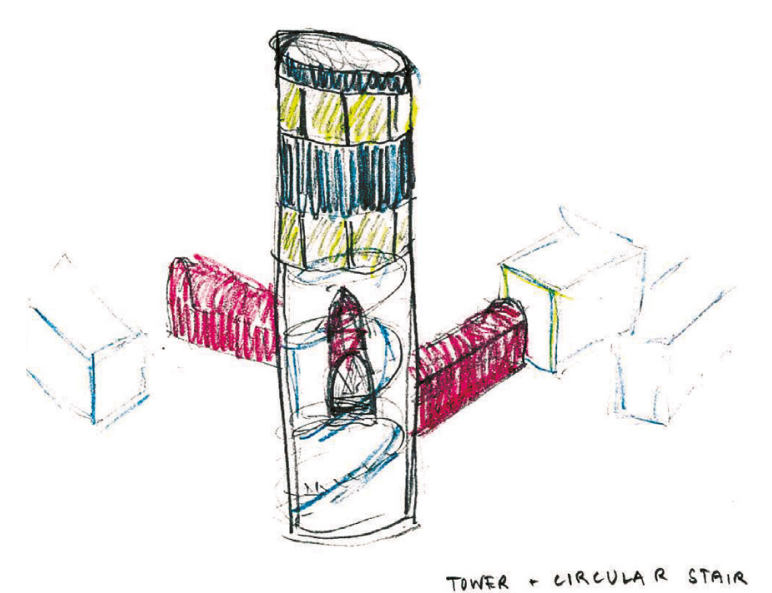

Figure 3.75. Circular stair and walkways

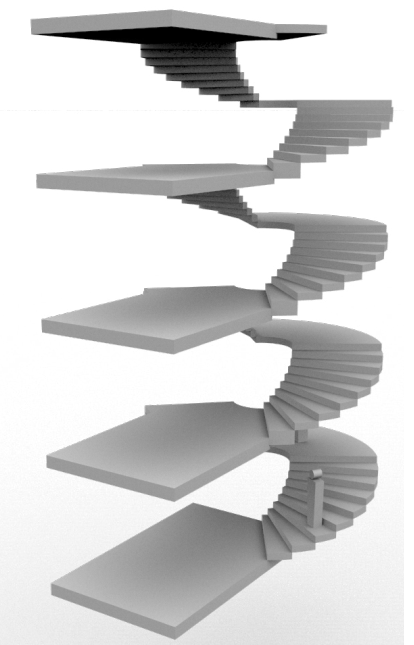

Figure 3.77. Digital model circular stair 1.

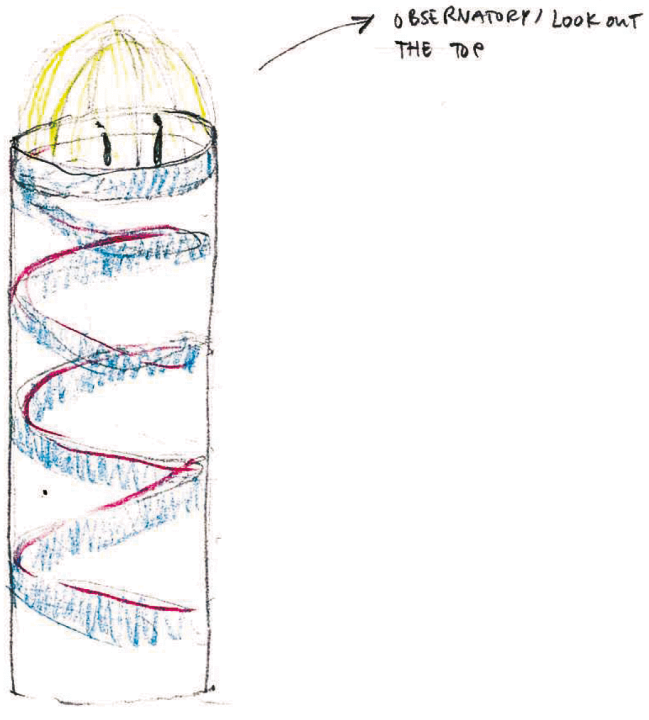

Figure 3.76. Circular stair with observatoires

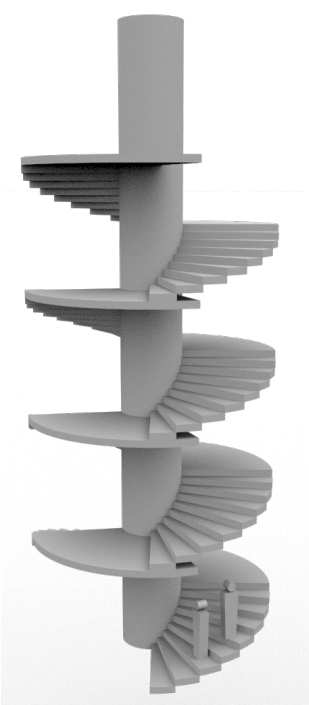

Figure 3.78. Digital model circular stair 2.
The structure of the stair itself can be square or circular. Both shapes were modelled and evaluated against the framework. Although a circular stair might look grand stretching up to four flights, and be a feature of the construction that residents could feel proud of (satisfying criterion 3), a circular stair would make it harder for residents to stop and talk to a neighbour. It is more difficult to stand next to someone on a circular stair, as the tread becomes too narrow at the centre of the stair. Therefore, the square-shaped stair was chosen.

When the basic form of the space and the

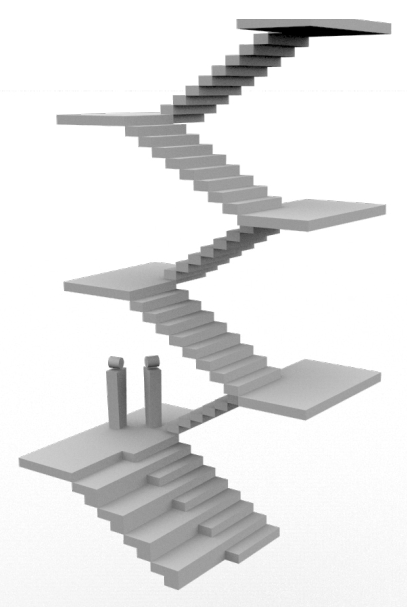

Figure 3.79. Digital model square stair. 
shape of the stair were established, other concepts were experimented with to see how the stairwell space could be further developed. It needed to have elements of attraction to persuade people to use the stair rather than the elevator. This manifested in design trials of how to attract people in terms of function, beauty, and fun.

Concept: Outdoor stair

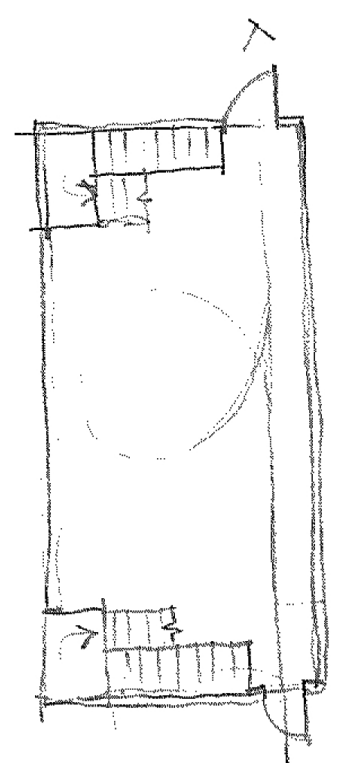

istom nology

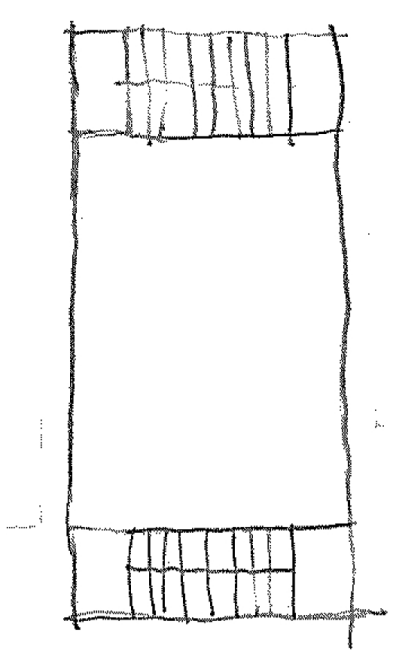

UPPER FLORE

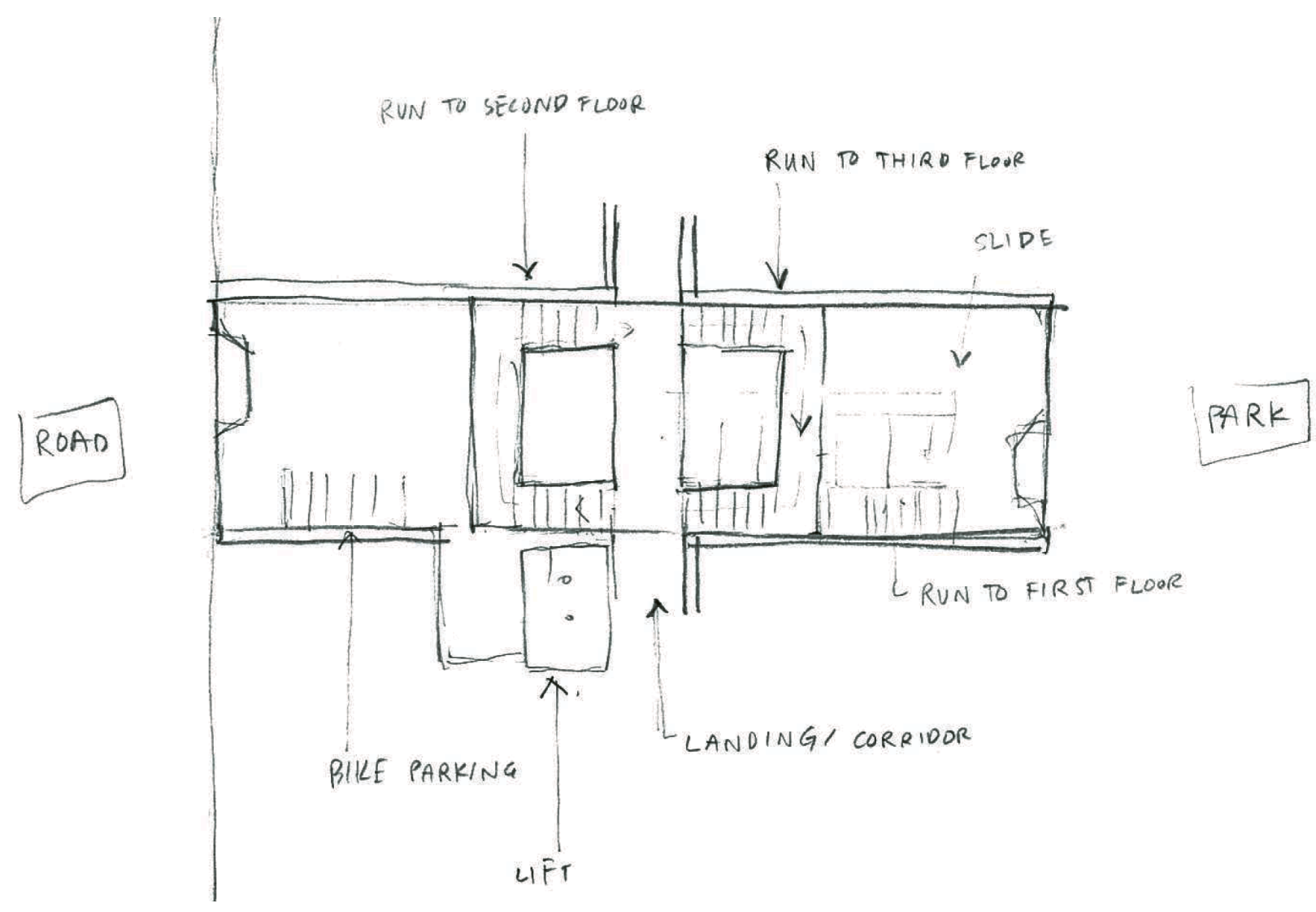

Figure 3.80. Two stairs with central lobby.

Figure 3.81. Winding stair with central landing. 


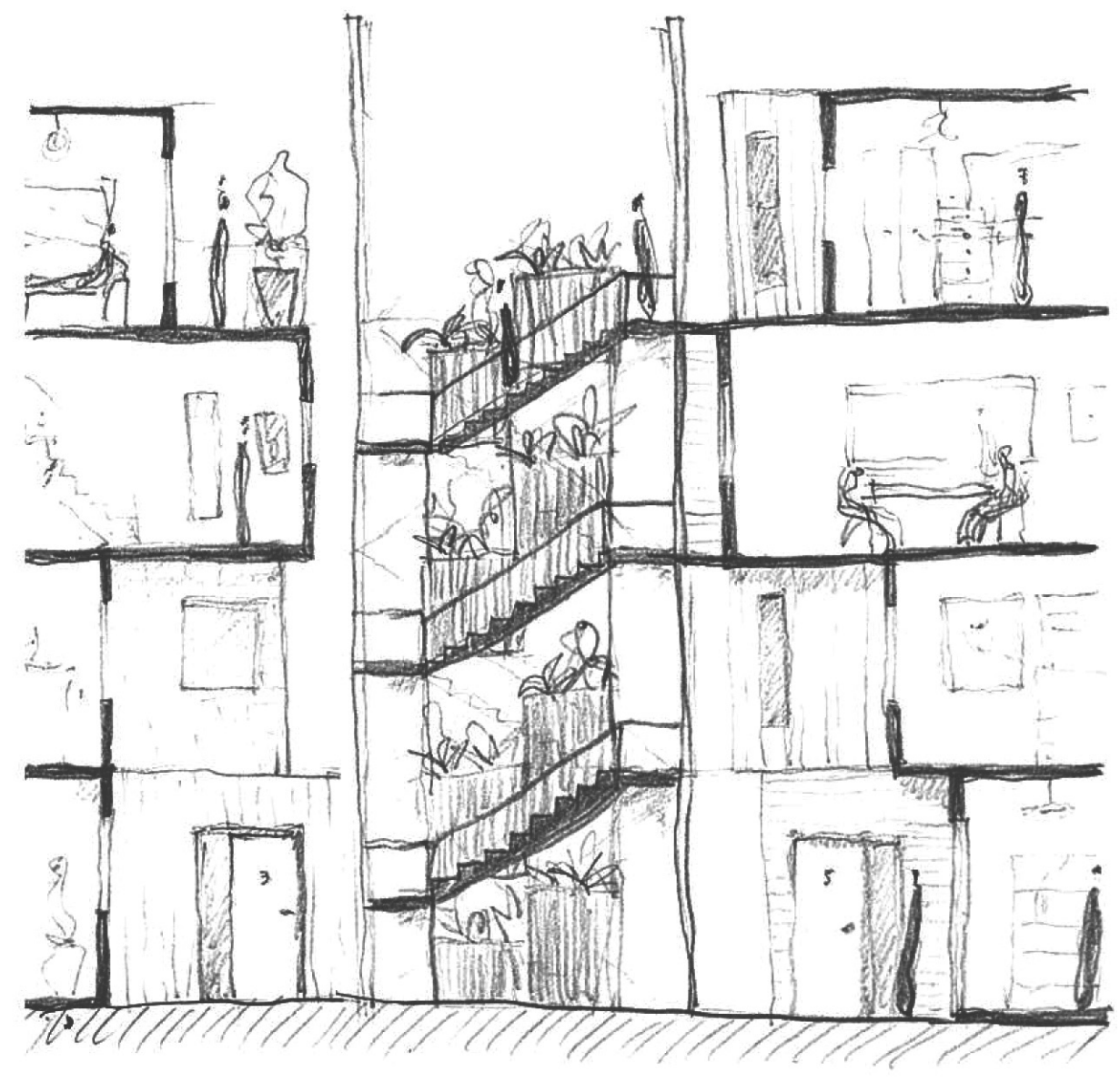

Figure 3.82. Outdoor stair elevation.

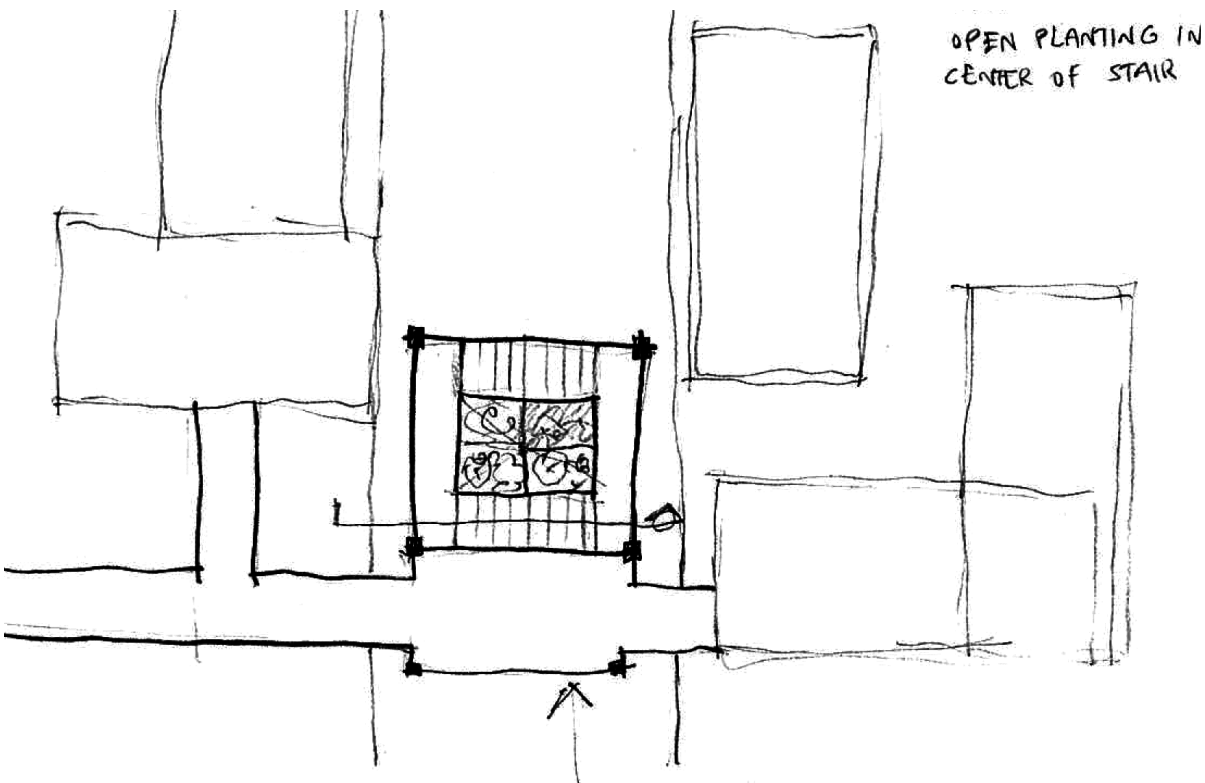

Figure 3.83. Outdoor stair plan.

The sheltered outdoor stair is a timber structure with a central void filled planted out on each floor. This concept aimed to be a stepping stone between the public space of the street, and the private indoor space inside the apartments. 
Concept: "Stairs that aren't Stairs"

Another concept looked at ways to get up and down the floors of the building, without using the stairs. This involved a slide, a fireman's pole, a ladder, a climbing wall, and a zip line/ flying fox.

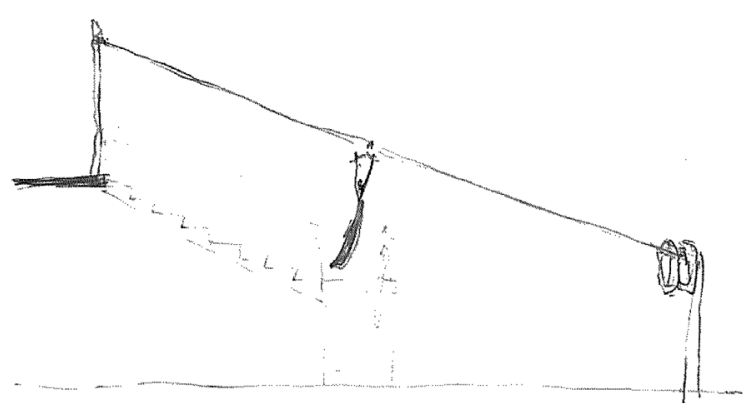

Figure 3.84. Zipline/ Flying fox.

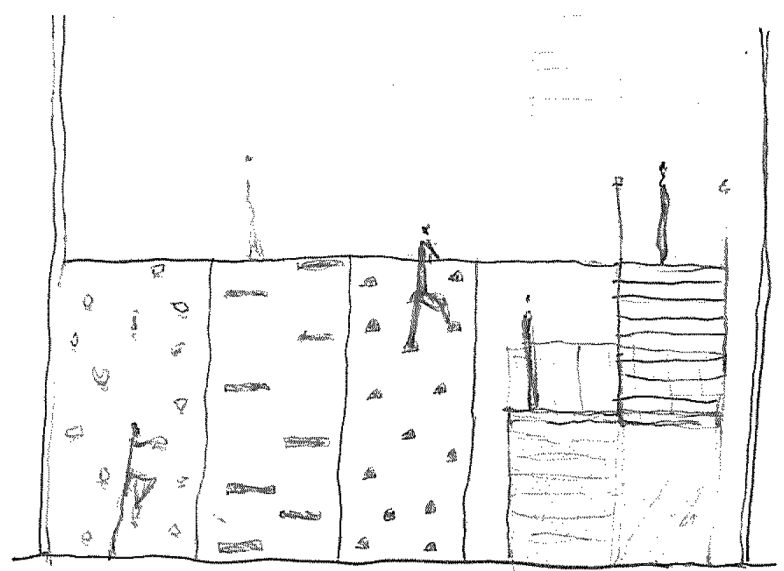

Figure 3.85. Climbing wall.

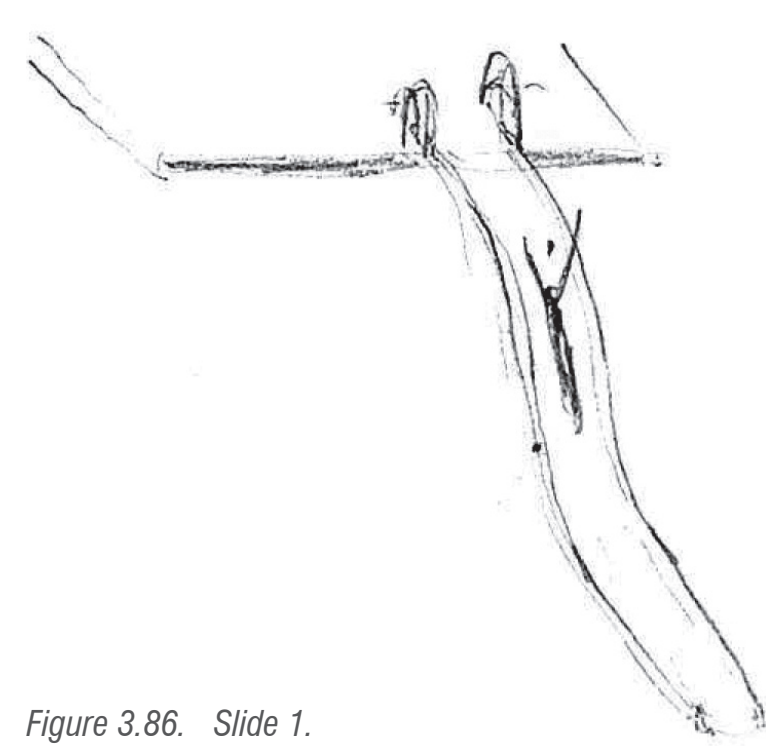

Figure 3.86. Slide 1.

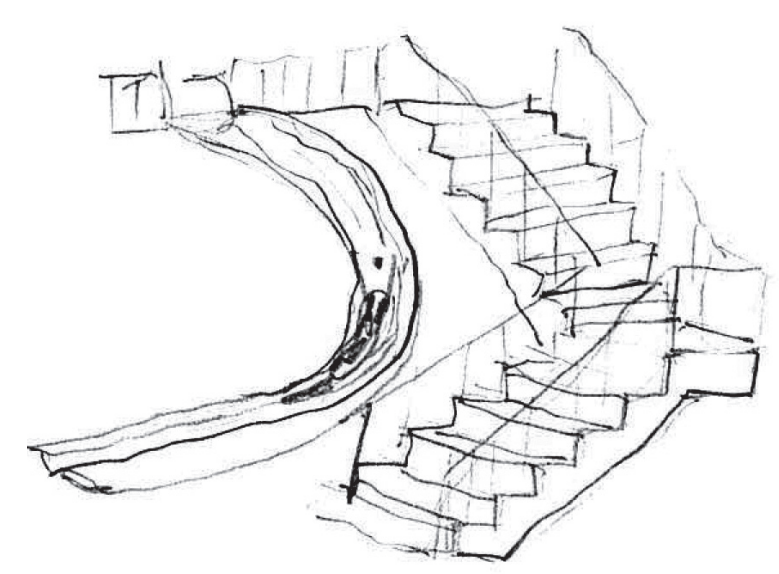

Figure 3.87. Slide 2.

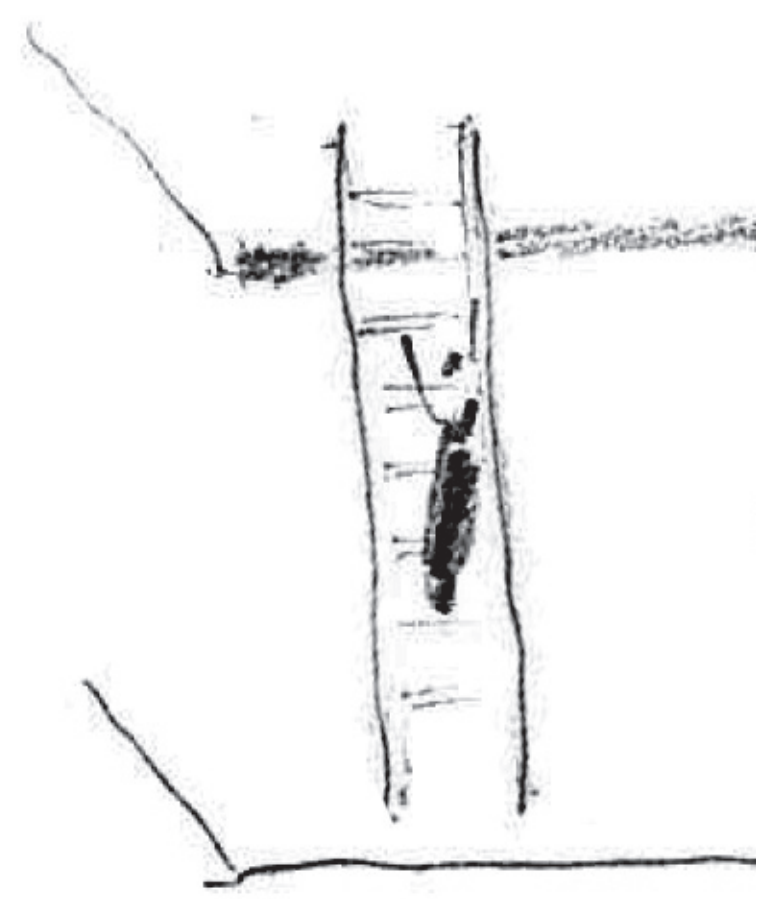

Figure 3.88. Ladder.

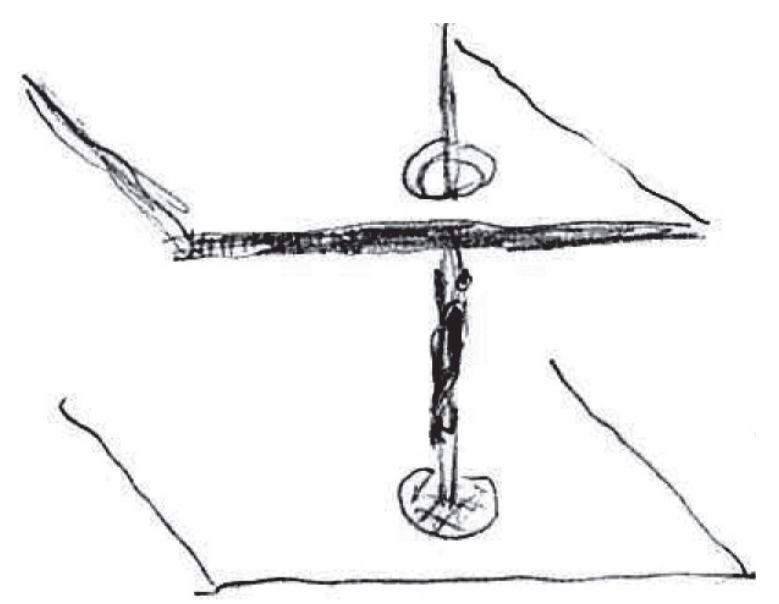

Figure 3.89. Fireman's pole. 
After the 'Stairs that aren't stairs' concepts were conceived of individually, a final design incorporated three of these ideas on the ground floor of the stairwell/ thoroughfare. The climbing wall was further developed to be transparent to let light through and to let people see from both sides, people using the play equipment.
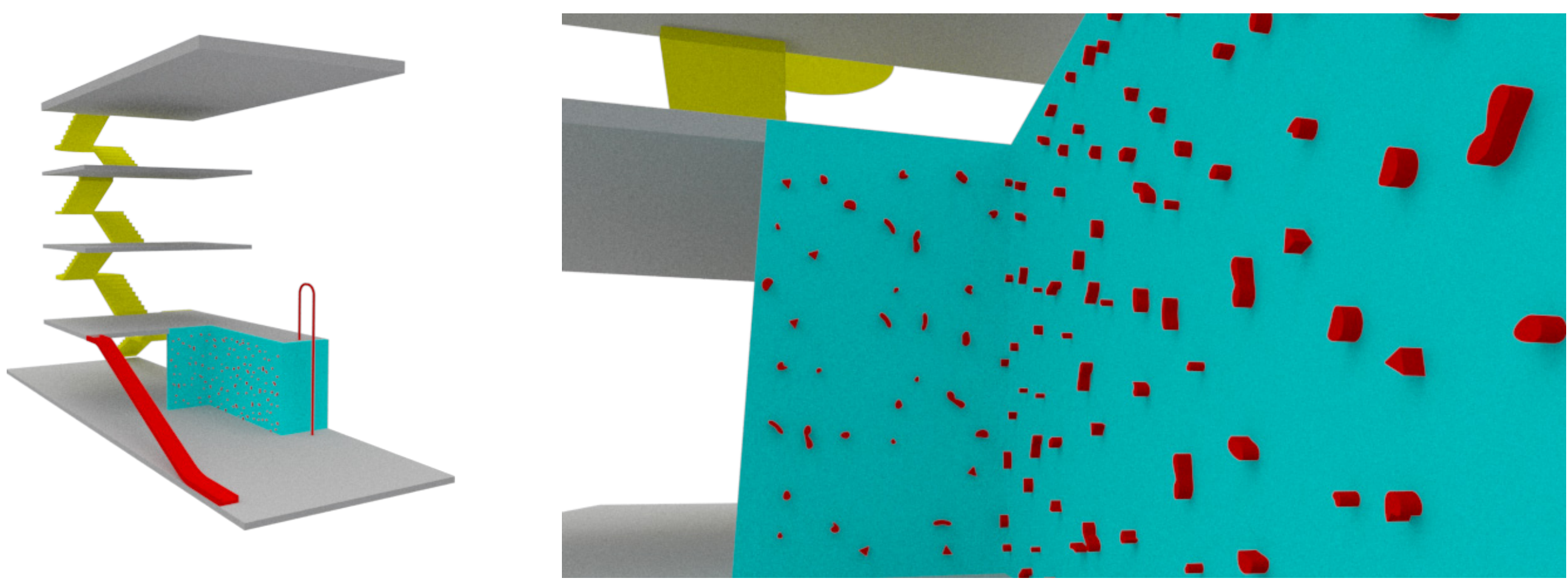

Figure 3.90. Slide, climbing wall and pole in stairwell. 


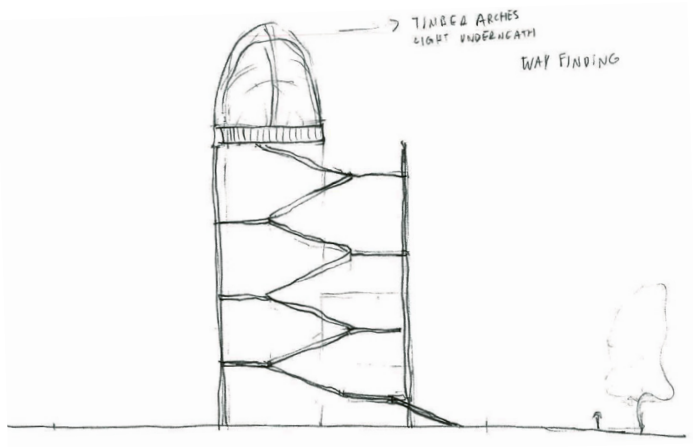

Figure 3.93. Section of stair and observatory.

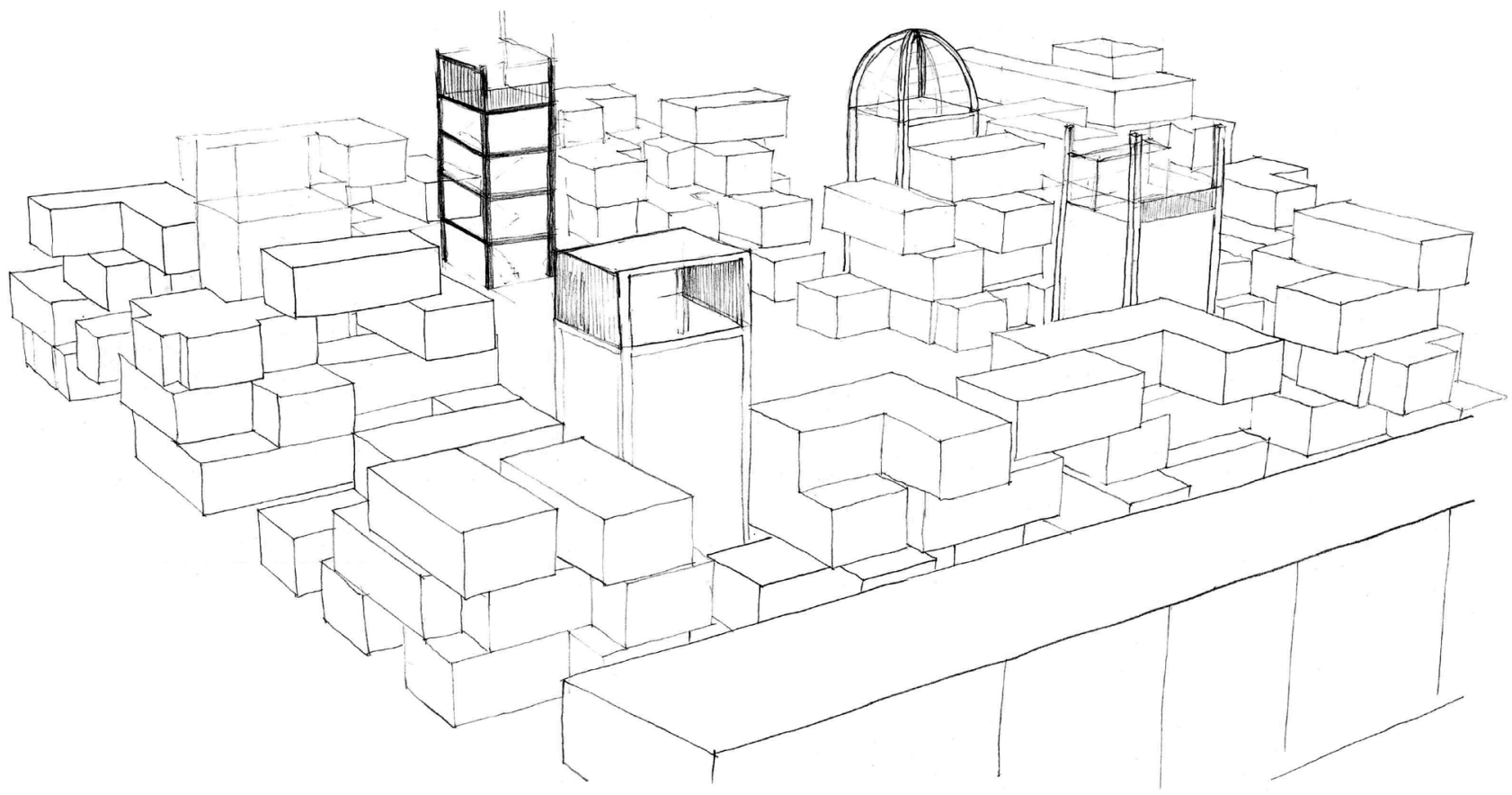

Figure 3.92. Top of stairwell as a lookouts and way-finding.

\section{Concept: Lookout}

Adding another level to the top of the stair, above the roofline of the apartments, meant that it could have a look-out at the top. This gives equal opportunities to residents in ground floor apartments to have an elevated vantage point from the top. One essential purpose for this was to give residents a visual connection to the city, thus meeting criterion 2. Another purpose was to create a tower at the top of the stair building. The towers across the Lichfield Street site create a sense of order distinguished by each tower in the centre of its dwellings. 


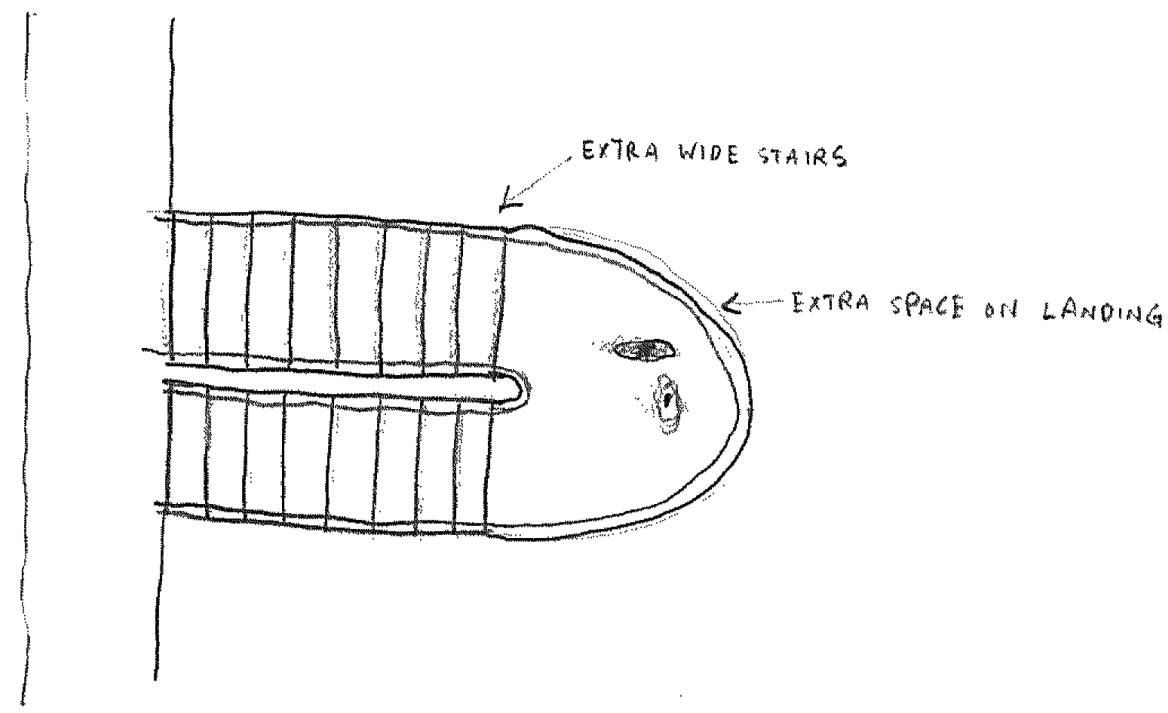

Figure 3.94. Rounded stair landing.

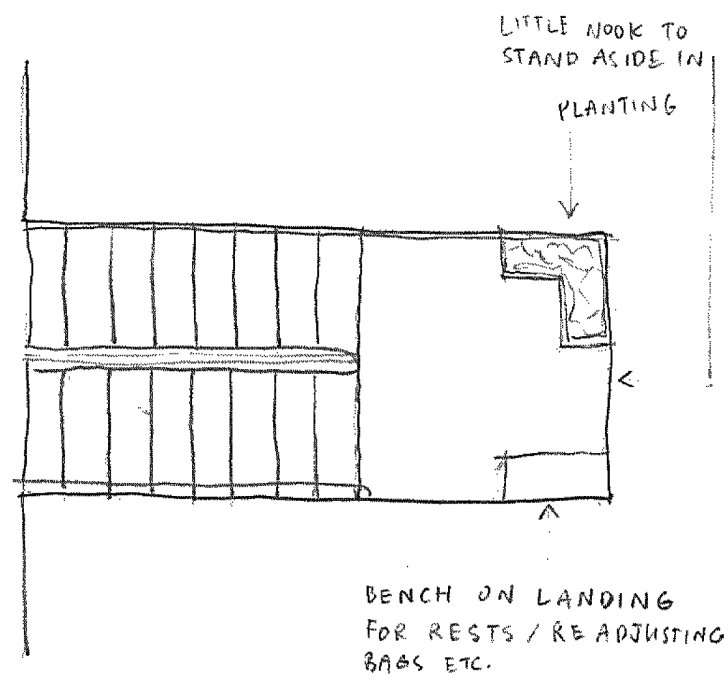

Figure 3.95. Square stair landing with rest and planting.
Concept: How to encourage people to stop and talk to each other

Allowing space for people to stop on the landing of the stair and providing amenities such as planting and a seat to take a rest or reshuffle grocery bags, might encourage people to stop in these spaces to talk. Also, a deeper tread and a shallower riser lower the intensity of the angle of the stair and can make it seem more accessible and desirable to use. It can also slow the pace of user down.

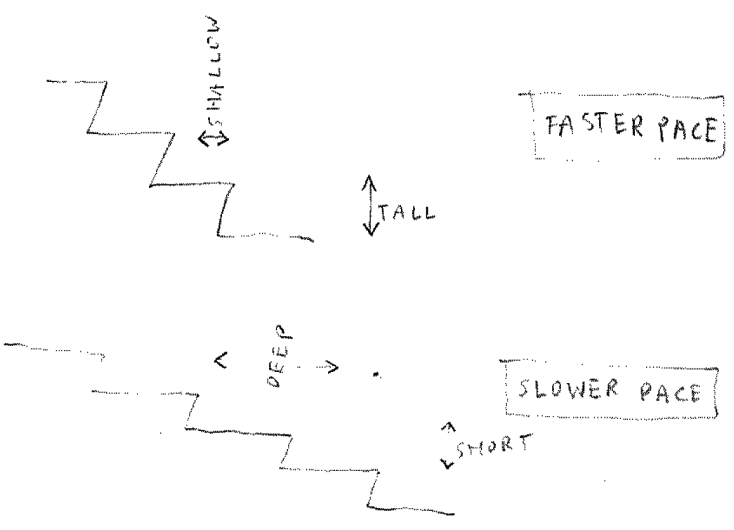

Figure 3.97. Faster pace vs. Slower pace. 
Concept: Incorporating colour

Colour could be incorporated either in the façade as coloured glass or coloured polycarbonate. This would make the inside of the stairwell building colourful during the

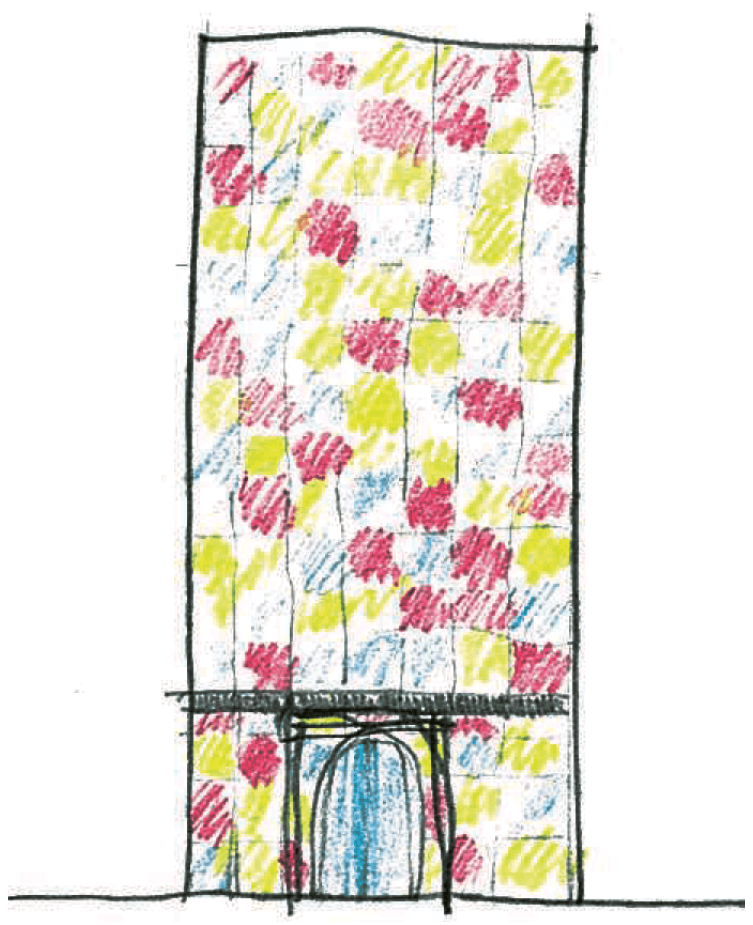

Figure 3.98. Coloured facade stairwell building. day, and it would emanate a soft, colourful glow to the outside at night. Additionally, each stairwell could have its own colour palette, furthering the concept of each tower having its own identity. Alternatively, the underside of the stairs could be painted pop colours to introduce an element of difference and fun rather than the tread and riser to not be dizzying or confusing for those with vision impairments.

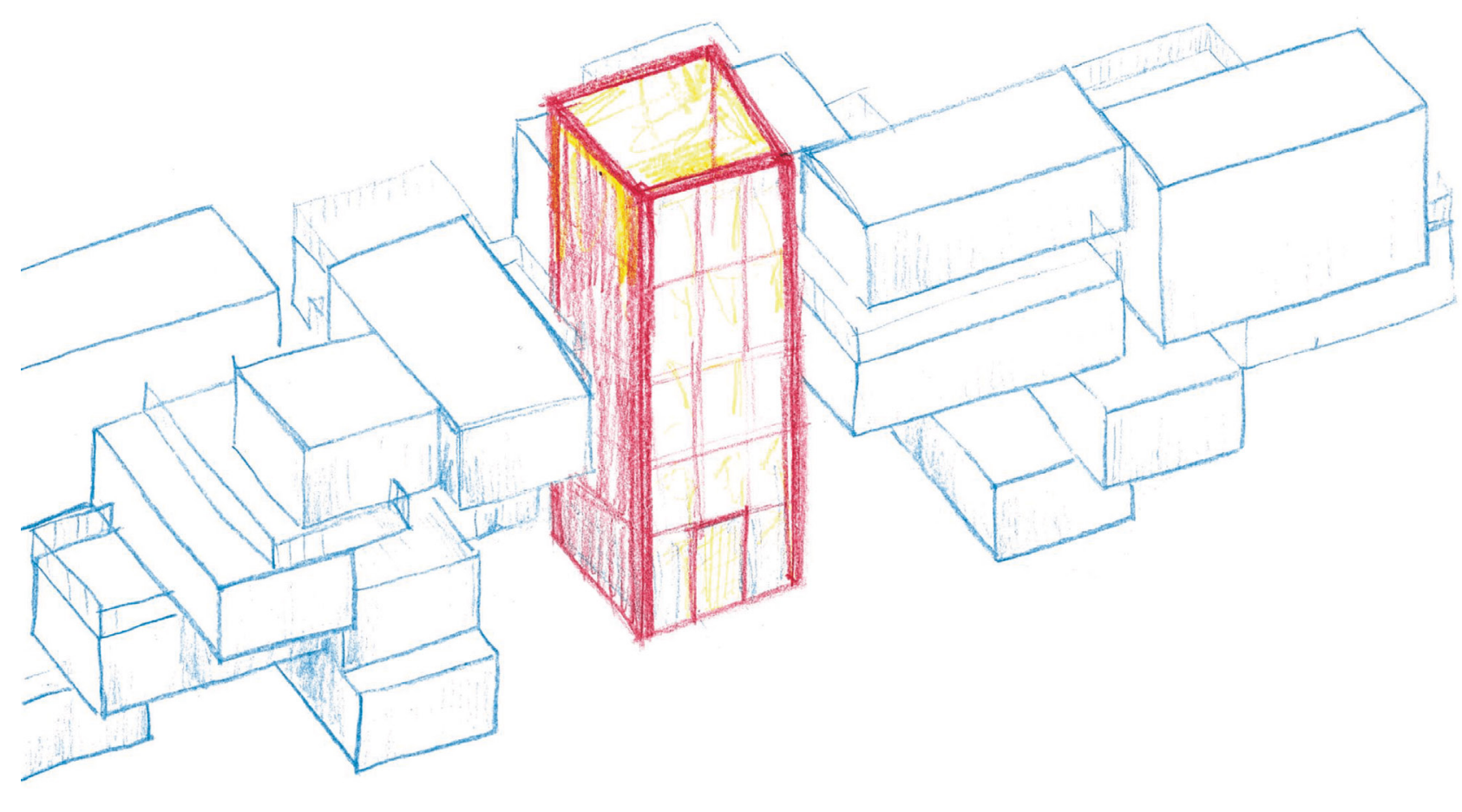

Figure 3.99. Coloured and illuminated stairwell building. 
To avoid the stairwell becoming a place of crime, views from outside of the stairwell building will be visible from the street as well as adjacent units. Jane Jacobs (1961) coined the phrase "eyes on the street", as mentioned in the discussion of the first criterion of the framework in section 2.3.2. Thus, safety, a lower-level needs on Maslow's Hierarchy, is maintained. However, this brings about another challenge: the privacy of the occupants of those units becomes vulnerable. It is proposed that the more public spaces within the dwellings, such as the kitchens and not bedrooms and bathrooms, face in toward the stair to mitigate this vulnerability. If this project is expanded upon on in the future, the light qualities in the stairwell could be studied to give the best outcome to the dwellings facing in toward it.

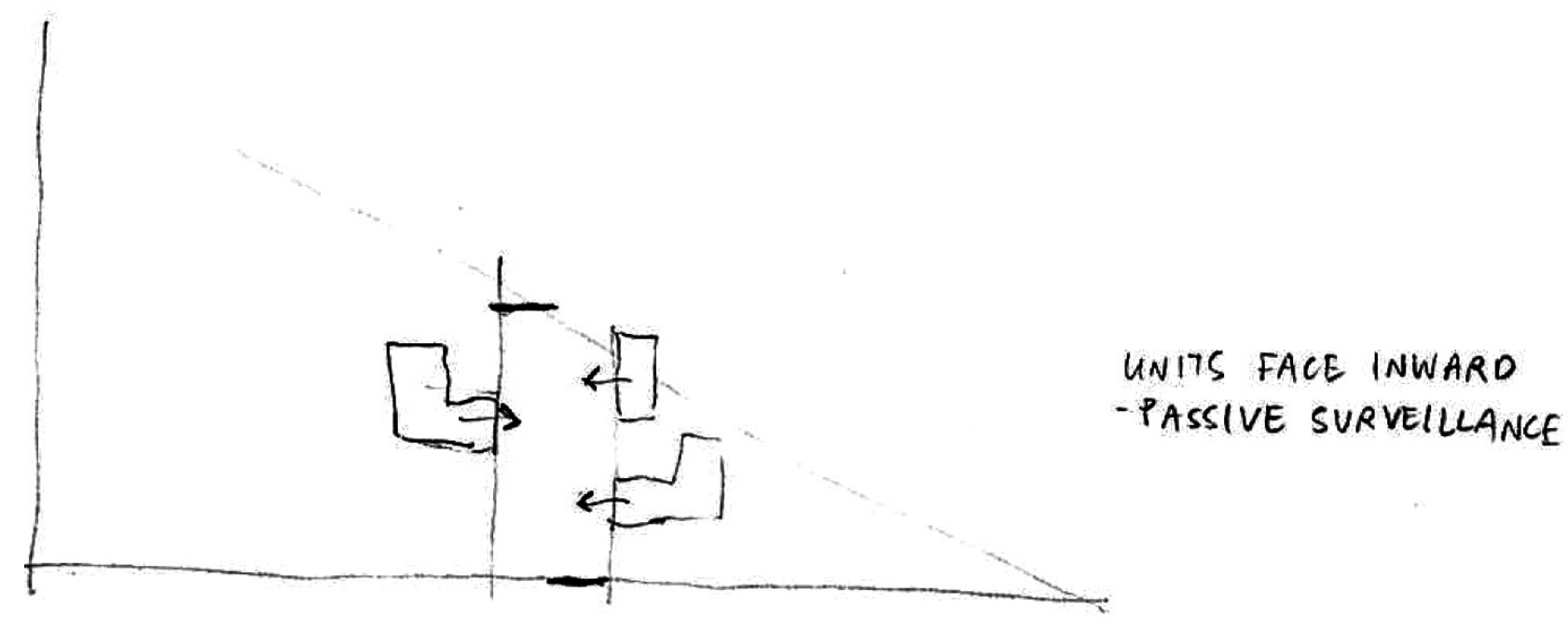

Figure 3.100. Coloured and illuminated stairwell building. 


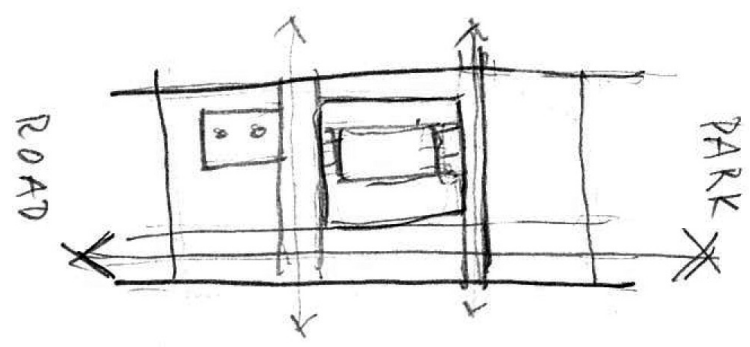

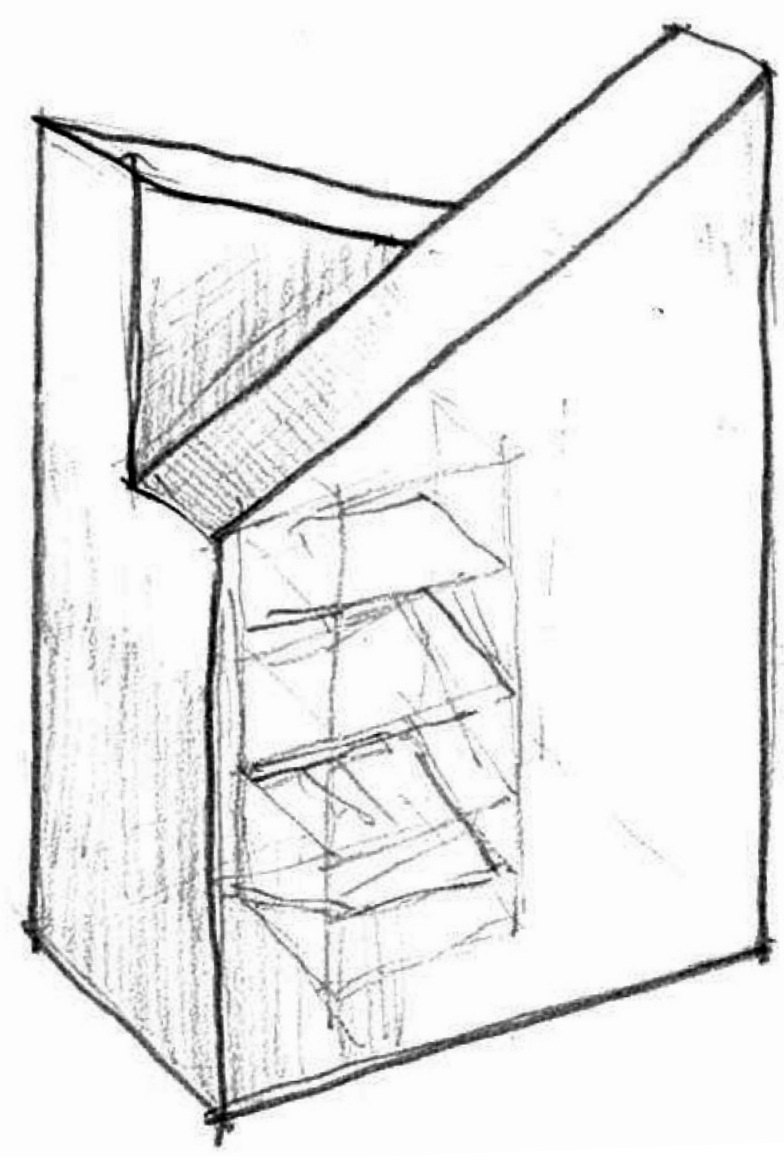

Figure 3.101. Angled roof form perspective.
Figure 3.103. Stairwell building layout plan.

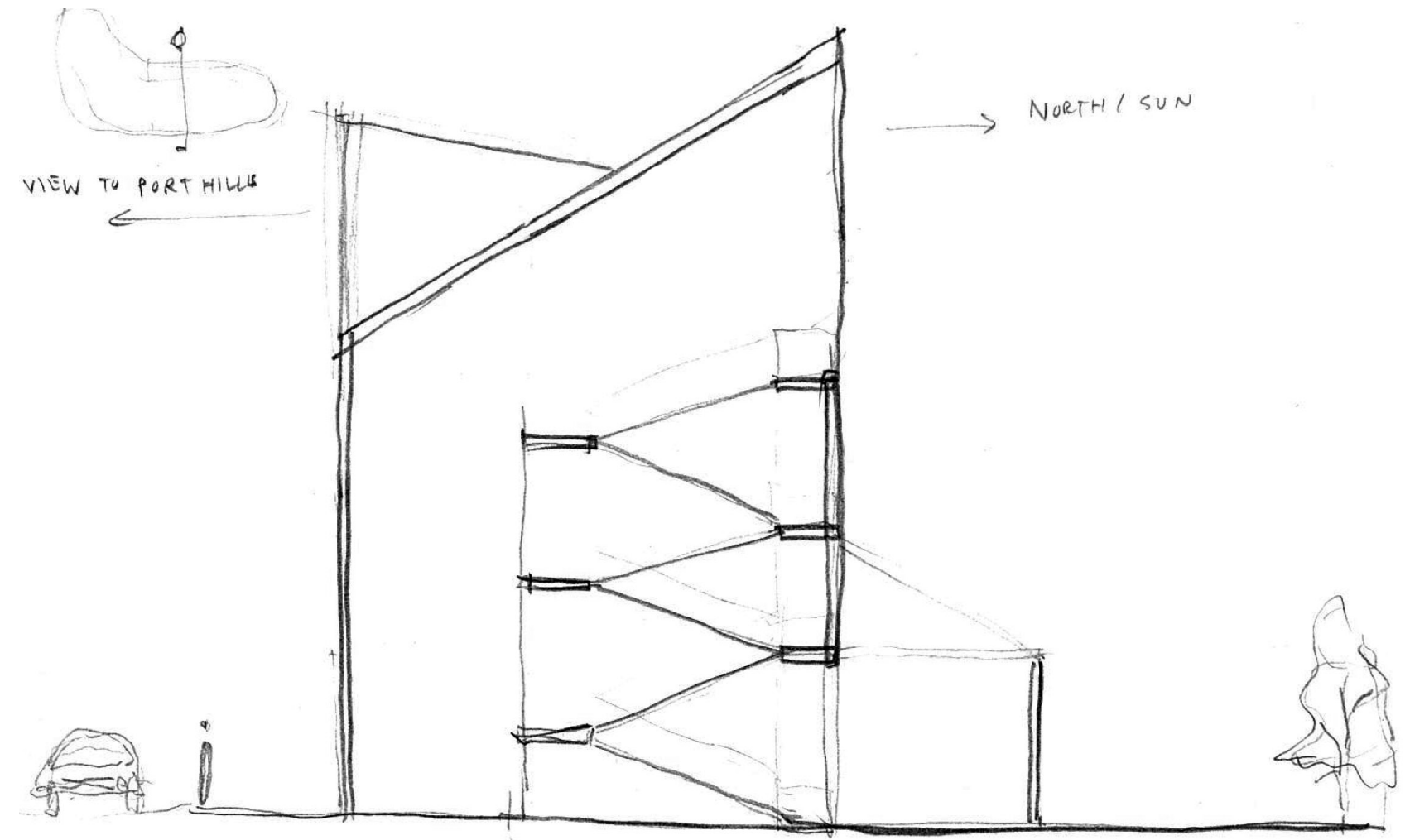

Figure 3.102. Angled roof form section. 


\subsubsection{REFLECTION}

The dwellings aimed to support its occupants' self-actualisation needs, and the stairwell aimed to support the occupants' social needs. The dwellings did so as per the framework described in section 2.3.5, by making all dwellings different from each other to provide a range of floor plans. The criterion was achieved, as the dwellings give residents the autonomy to buy or rent a home that is better suited to them.

The stairwell itself achieves both criteria relating to social needs. The height and use of the roof of the stairs also serve as central points and attractive circulation spaces that will engage residents in its use and encourage them to talk and play with each other, thus achieving Connection with Neighbours.

If the project had been longer than a one year master's thesis, the stair could have been developed to a higher level of detail. For example, the connections between dwellings could be investigated in terms of the balance between privacy and relatedness. Further, the play amenities on the ground floor of the stair could be advanced. The climbing wall is not limited to one storey. With the right research into the matter, the climbing wall could extend beyond the first storey.

The stairwells not only achieved the social needs criteria, which was the goal, but they subsequently met both criteria under the psychological need Esteem, namely, Pride and Competence. Residents can take pride in taking their guests to the top to show off the vantage point that is not

\subsubsection{TECHNIQUES AND IDEAS IMPORTED FROM ANOTHER DESIGN EXPERIMENT TO LICHFIELD}

From Hereford: The treatment of cars on site was dealt with well in the design of the Hereford Street houses, where cars are hidden from the street when parked. If this project were to be extended, the idea from the Hereford Street design could be used in the Lichfield Street apartments when designing the car parking. The challenge remains for the Lichfield St design to provide space for parking cars, but at the same time hide the parked cars and make the ground floor accessible and safe for pedestrians.

\subsubsection{TECHNIQUES AND IDEAS THAT HAVE BEEN EXPORTED FROM LICHFIELD}

To Masterplan: Through the design of the stairwells, it was noted that they perform best when they are accessible from both the street/ laneway and from the communal garden. This was only learned while working at a smaller scale. Connecting the stairwells to the street and the garden was incorporated in 
available to the public. The stairwell buildings have consequently added to the sense of competence in the users of the site. They have done so by acting as way-finding devices to navigate people through the many pathways on the site. Each stairwell building having its own visual identity, furthers their ability to act as a tool for way-finding.

The stairwell concepts were a successful design experiment and left an opportunity to be developed further. This could be a master's thesis project on its own.

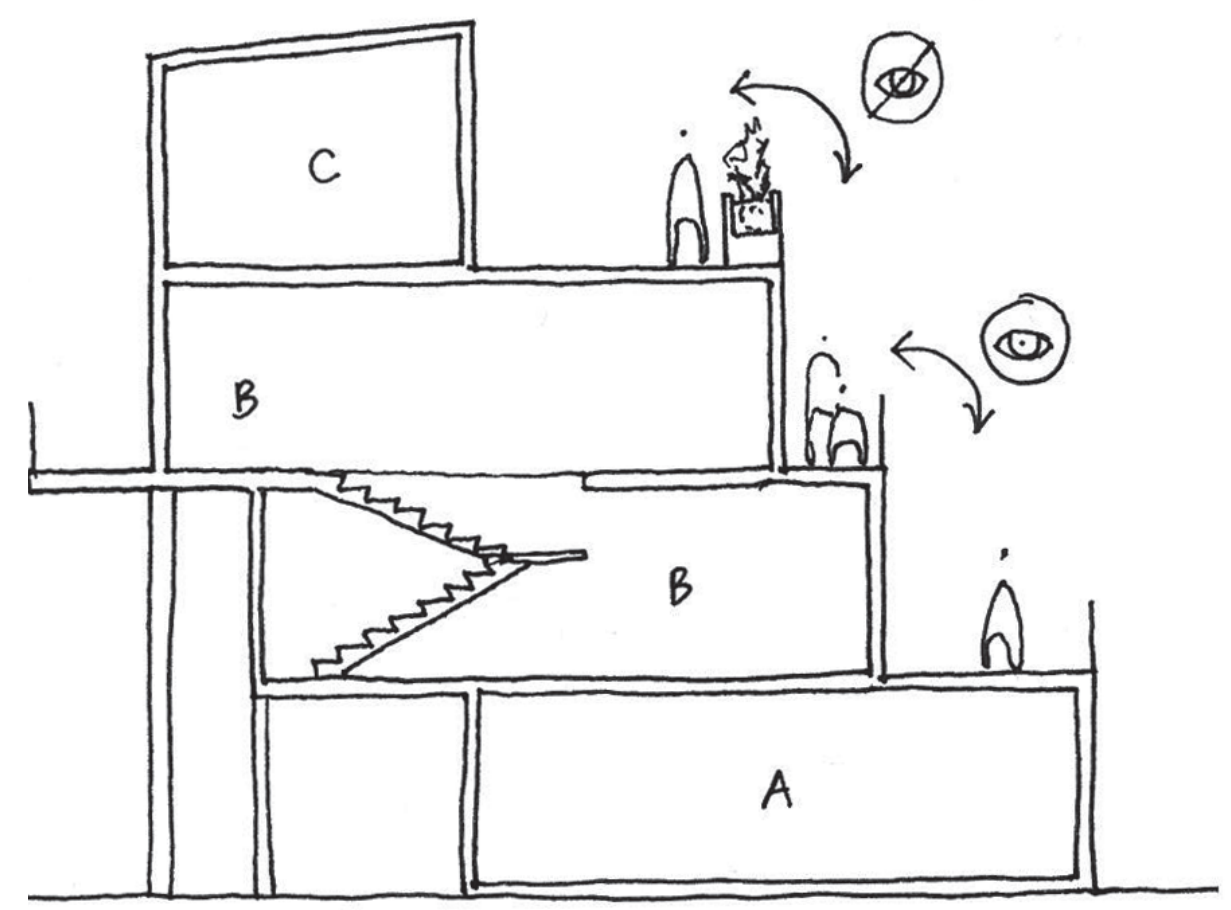

Figure 3.104. Privacy between dwellings. the master planning. The idea was to orient and place as many stairwells to access both points. Thus, by working at a smaller scale, the Masterplan was benefitted.

To Hereford: Maintaining privacy between dwellings was achieved in the Lichfield Street apartments. Therefore, the balcony is stopped before the end of the roof that it sits on, and thus the tenancy underneath is not directly looked over by the one above. Designing a separation between terraces creates a lower perceived density, which is desirable, as occupants feel a sense of spaciousness. This technique was carried over to the Hereford Street housing where houses share a narrow lane and privacy is threatened (see figure opposite).

To Cashel: As previously explained, during this design iteration, various sizes of 'boxes' were tested with arrangements of furniture, rooms and areas. These tests were used to inform the size of the apartments on the Cashel Street site. 
THIS PAGE IS INTENTIONALLY LEFT BLANK. 


\subsection{HEREFORD STREET}

\subsubsection{INTRODUCTION}

Single-detached houses, when clustered and have small private outdoor spaces, can qualify as medium-density. The Masterplan set out to provide a variety of $\mathrm{MDH}$ types, including single-detached houses. Many people are still resistant to $\mathrm{MDH}$ because of a desire to be fully independent, private and disconnected with others. However, this design iteration is a way of working with their preferences, and at the same time, prove that $\mathrm{MDH}$ can provide what they want and need. The clustered housing on Hereford Street aimed to achieve four of the six criteria. These were 1 . Connection with neighbours; 3 . Pride; 5 . Autonomy in the dwelling; 6 . Autonomy on site. The design process, from massing out the buildings in a $3 \mathrm{D}$ software, to crafting laneways, individual facades and interior spaces, followed an iterative process and critical reflections along the way. All of the houses' footprints and property boundaries were outlined and extruded in the master plan to ensure that there was a diverse range of sizes of footprints of single-detached houses on the site. From these 24, nine were chosen to study at a smaller scale. Specifically, these nine were chosen as they offer the opportunity from the designer's perspective to work out the relationship between dwellings across the lane from each other, the relationship between the backs of the houses and the relationship between two dwellings next-door to each other.

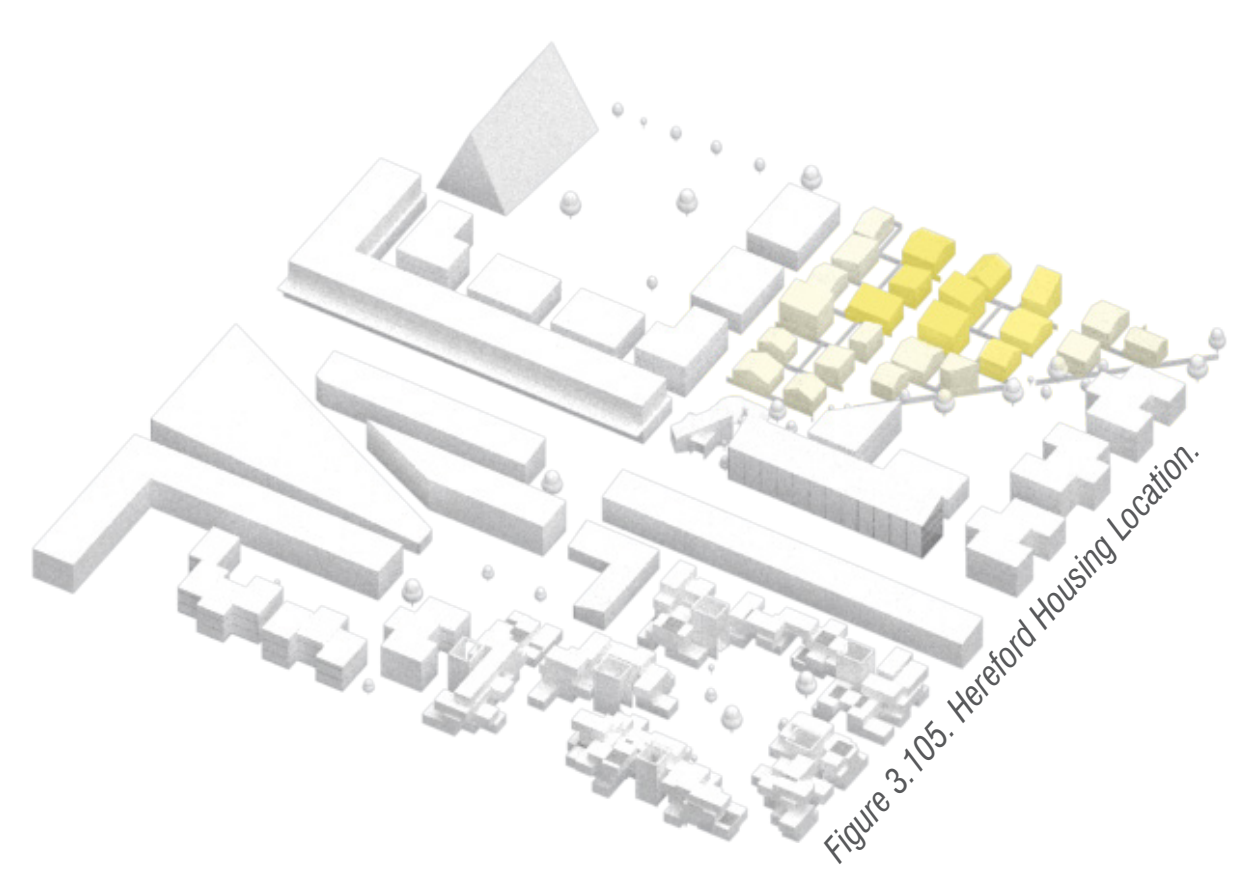




\subsubsection{DESIGN PROCESS}

The private outdoor space allotted to each house is relatively small. Thus, all of the houses were placed on the southern boundary to allow for the maximum usable space possible on the north side of the property.

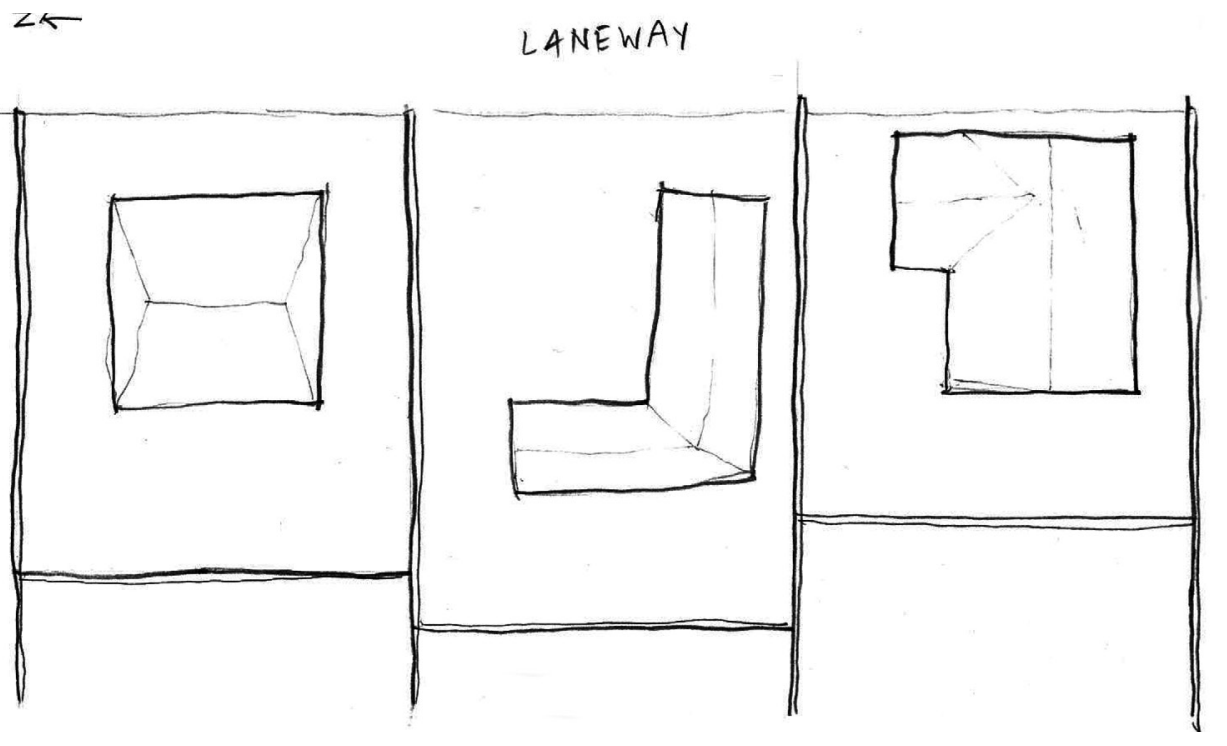

Figure 3.106. Housing centre of site, minimal outdoor space.

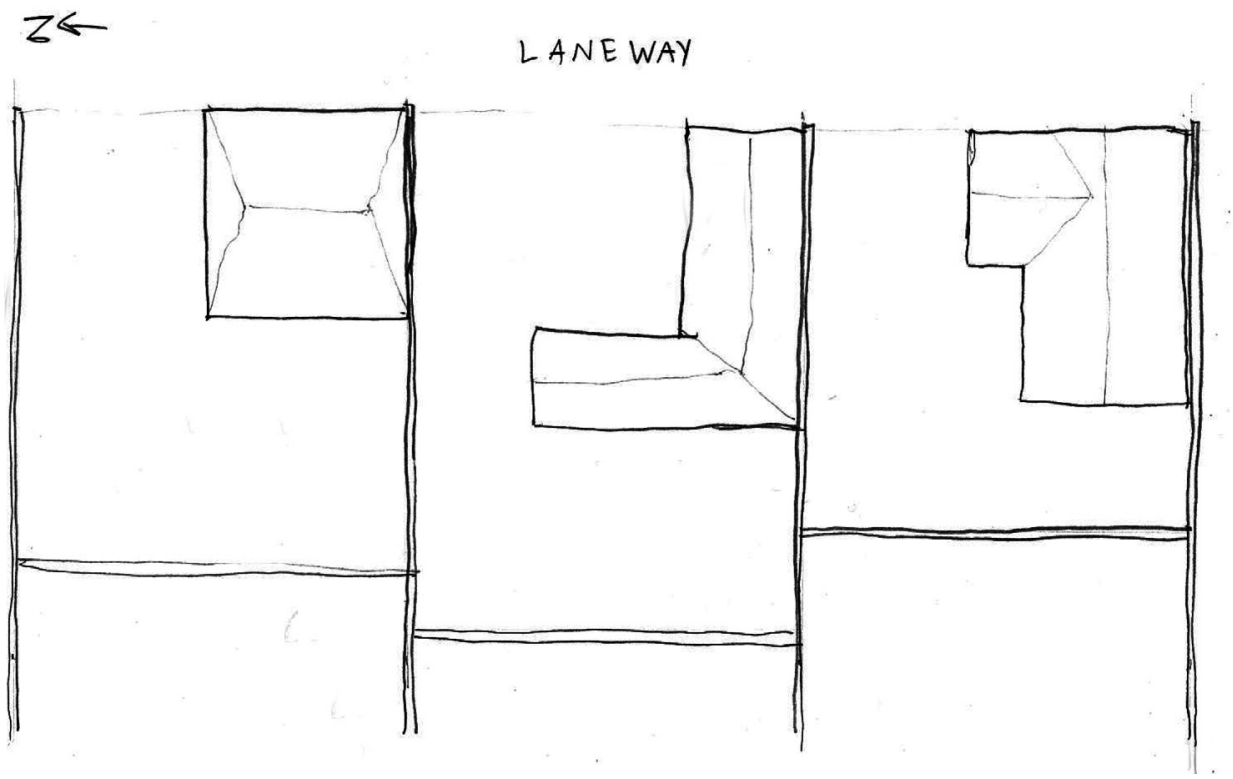

Figure 3.107. Housing on boundary, maximum outdoor space. 
The southern facade of each house is unpenetrated, addressing potential privacy issues between houses. Brick was chosen as the material of the southern facade, as it is at more human scale than a monotonous, blank wall. There is an opportunity for creeper plants to climb the wall and enhance the southern neighbour's northern edge. The bricks are also a nod to Christchurch's pre-earthquake built environment, as bricks were abundant in the city's urban fabric.

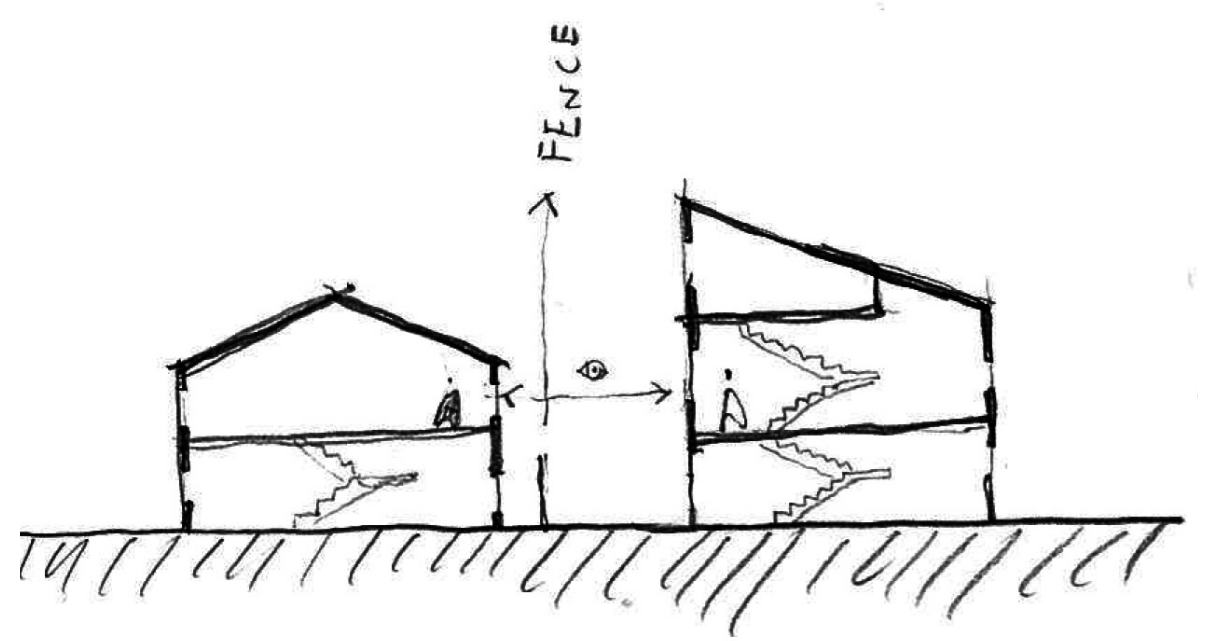

Figure 3.108. Privacy between next-door neighbours problem - section.

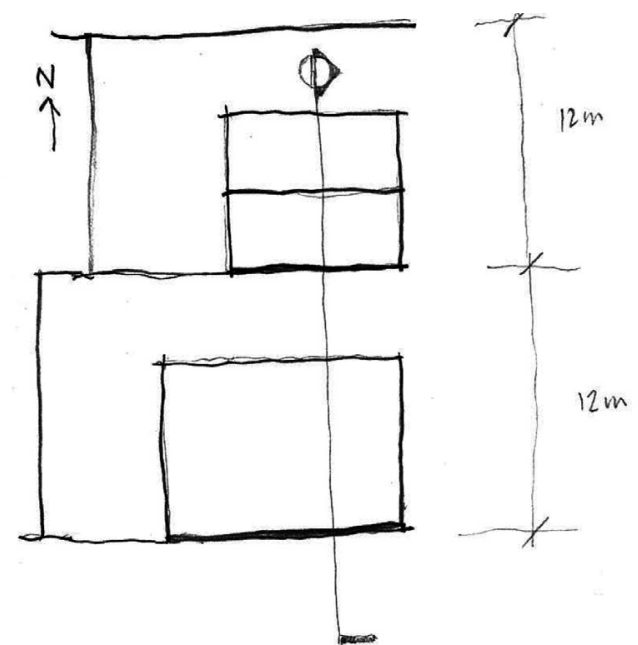

Figure 3.109. Privacy between next-door neighbours reference plan.

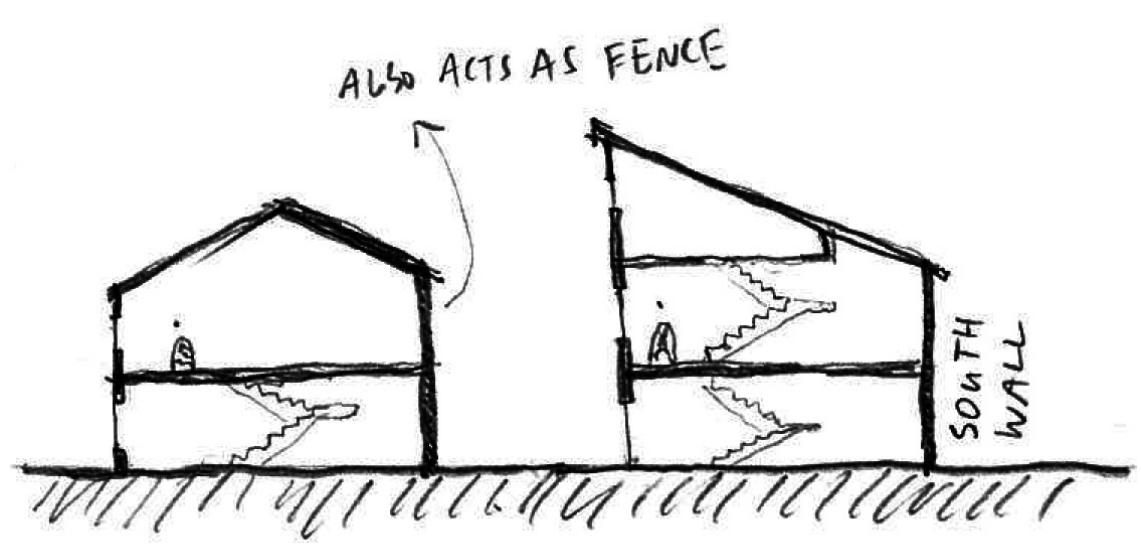

Figure 3.110. Privacy between next-door neighbours solution - section. 
The laneways were made narrow to slow down cars and encourage pedestrian activity. As a result, more land space was awarded to the houses. A consequence of having a narrow and social laneway is a lack of privacy in the fronts of people's homes. Therefore, each house will have a public-to-private gradient inside it, with the more public areas, such as kitchens, and lounges closest to the street.

One strategy that was used to combat privacy issues was raising the east side of the street by half a level and adding a veranda to the street side. This move obstructs views from the inside of one dwelling to another (see figure below).

Car parking was ramped down from the laneway to semi-underground garages, which utilise the half storey above ground and diminishes the presence of garages and cars on the street edge. This helps with the integrity of the streetscape as large garages do not overburden it. In turn, this could add to the residents' sense of pride (criterion no.3, Pride) as the relationships between the houses and the laneway were carefully considered.

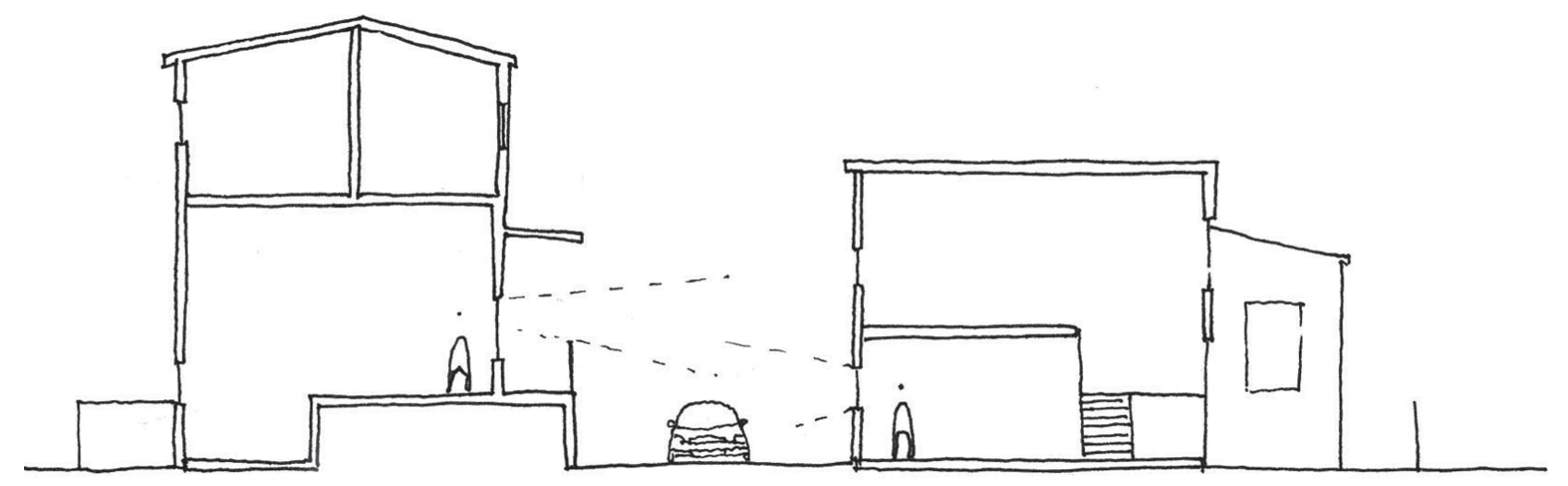

Figure 3.111. Privacy across lane. 


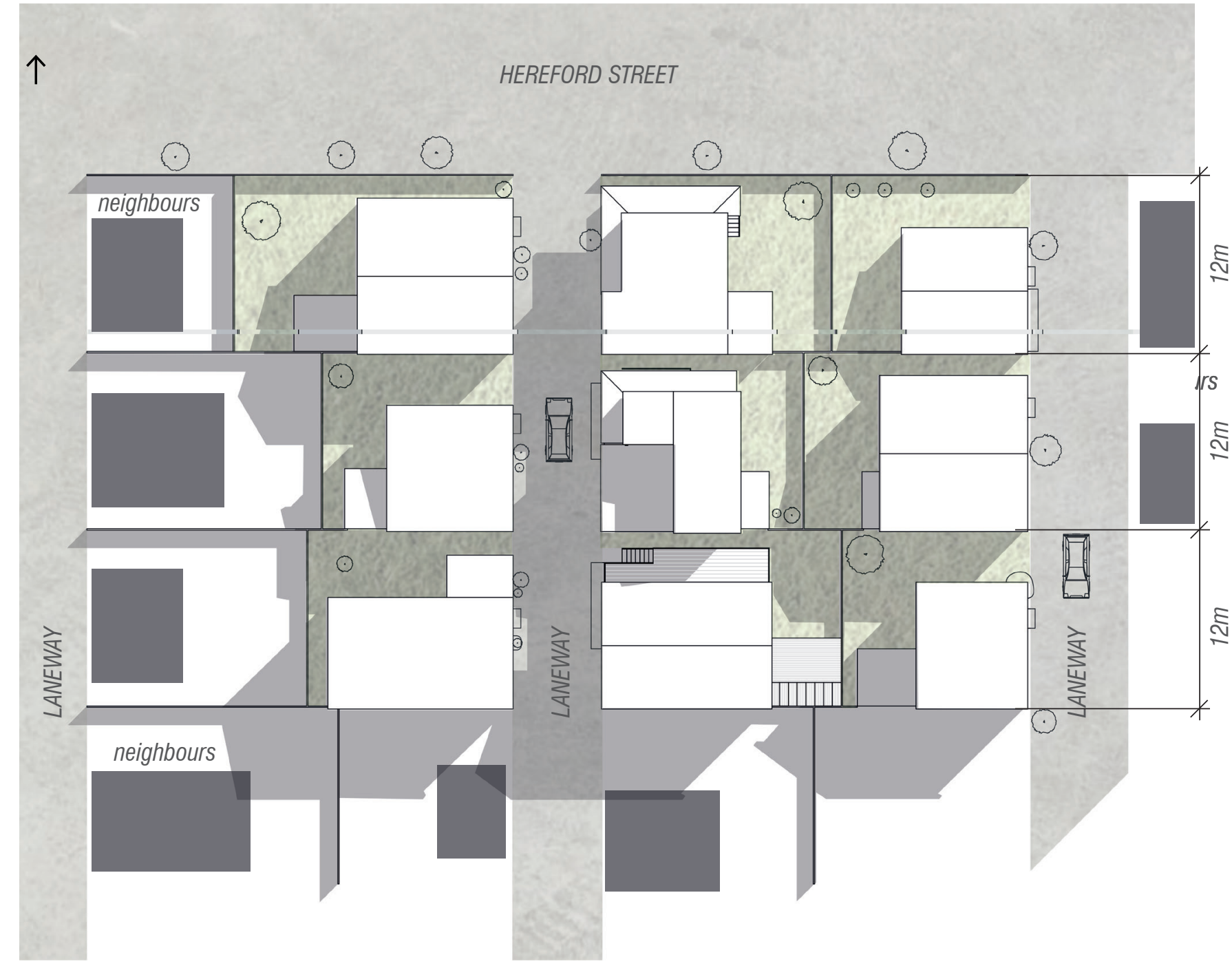

Figure 3.112. Hereford Housing site plan.
All of the houses are three storeys or less and therefore fall inside the scope of NZS3604. All houses will be timber-framed. However, the semi-underground garages in each of the houses may require specific engineering.

Solar power and rainwater collection are added to each house, giving occupants autonomy and freedom from having to rely on an external source, especially after a natural disaster. During and for some time after natural disasters, these amenities that are often taken for granted can be cut-off for an unknown period of time.

After the previous considerations had been made, each house was designed to be different from each other. Not only were they different in size and number of bedrooms, but some houses had the emphasis of space given to lounges and communal areas, while others had emphasis given to private areas of the house. Additionally, each 


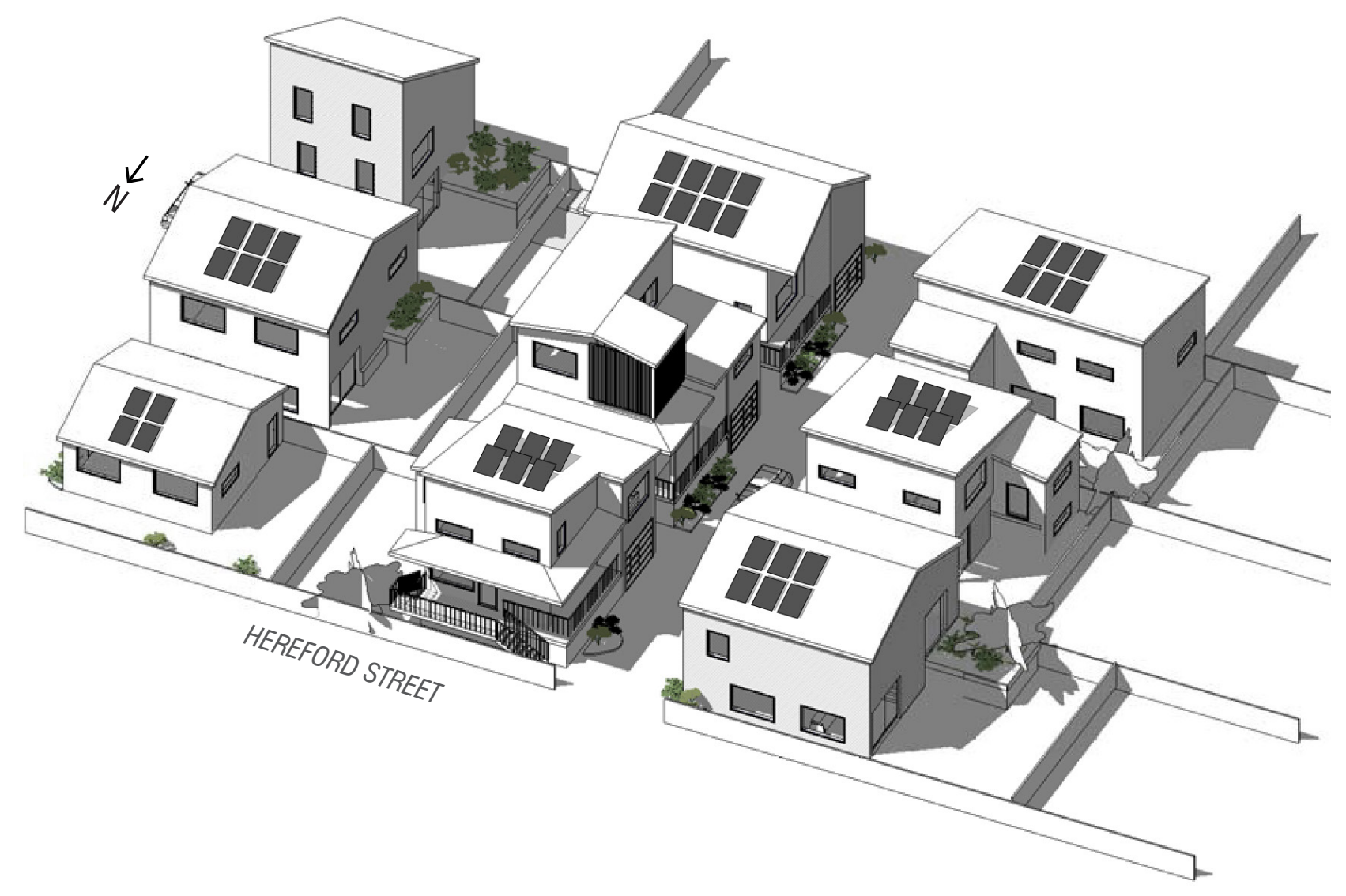

house looks different from each other from the outside in both form and materiality. Fences between dwellings were left low so that neighbours can decide between them whether to build a taller fence, grow plants along with it, or leave it as it is. This means that next-door neighbours must speak to each other if they wish to change it. The idea behind this was to invite interactions and connections between neighbours and to give the residents autonomy to change the elements (i.e. the fences) on the site.

Figure 3.113. Hereford Housing from north/ west corner. 


\subsubsection{REFLECTION}

Naturally, single-detached houses will afford more autonomy to the inhabitants than duplex housing, terraced housing and apartments. However, this example of medium-density, clustered housing invites its occupants to 'take ownership' of the treatment of the site. For example, through the fences, and through rainwater collection, and harvesting solar power.

Christchurch has had multiple earthquakes in its past, so power generation and rainwater collection may be appealing to those who in February 2011, after the earthquake, had them cut-off.

If the project had allowed for more time, the details could have been worked out to a higher standard, and perhaps more opportunities could have come up to provide more autonomy to residents. Due to the time restraints of the project, it was not possible to delve deeply into the design of the smaller details. The design process gave attention to the overall materials in the façade and streetscape, and some of the interior spaces within the houses. The generality of the design process gives an overall impression of the site, rather than smaller details within the houses.

Criterion number three, pride, was achieved by the craft of not only the houses, but the spaces between as well, but again, if there was more time for the research project, these spaces could have been further enhanced.

\subsubsection{TECHNIQUES AND IDEAS IMPORTED FROM ANOTHER DESIGN EXPERIMENT TO HEREFORD}

From Lichfield: Creating privacy between dwellings that sit across the narrow lanes from each other was achieved by adopting a technique from the Lichfield Street apartments, as explained in section 3.4.5. This technique was adapted for the stand-alone houses by giving all of the houses on the east side of the street a veranda on the west side of the house, and by offsetting the ground floor by half of a storey. Doing this obstructs views between dwellings across the lane from each other. This also helps to reinforce property boundaries which are important for the well-being of occupants (Jacobs, 1961) as it helps to keep lower-level needs satisfied (security/safety) by giving a good foundation for meeting higher-level needs (Maslow, 1943). 


\subsubsection{TECHNIQUES AND IDEAS THAT HAVE BEEN EXPORTED FROM HEREFORD}

To Lichfield: How cars were treated in the Hereford Street housing development inspired a similar treatment in the Lichfield Street design. Here, the laneway is too narrow to park cars on it; therefore, the houses were adapted to fit cars semi-under them. Having the car parking semi-underground means that the garage has a smaller presence on the street. 


\subsection{CASHEL STREET}

\subsubsection{INTRODUCTION}

For the final design experiment, the research tested one criterion from each level of need. The criteria were a connection to the city, competence and autonomy on the site.

Going beyond the housing and stepping into the commercial and community part of the site, this design experiment devised two apartments above commercial spaces (representative of all in the same building), and a community building, in the middle of the entire site.

Their respective and relevant axes and paths informed the form of the gallery and apartments-above-commercial building. The commercial and apartment building stands along the edge of Cashel Street, and the gallery faces the direction of the diagonal desire line. The purpose of the diagonal path was to draw people into the site, and it is enhanced by the

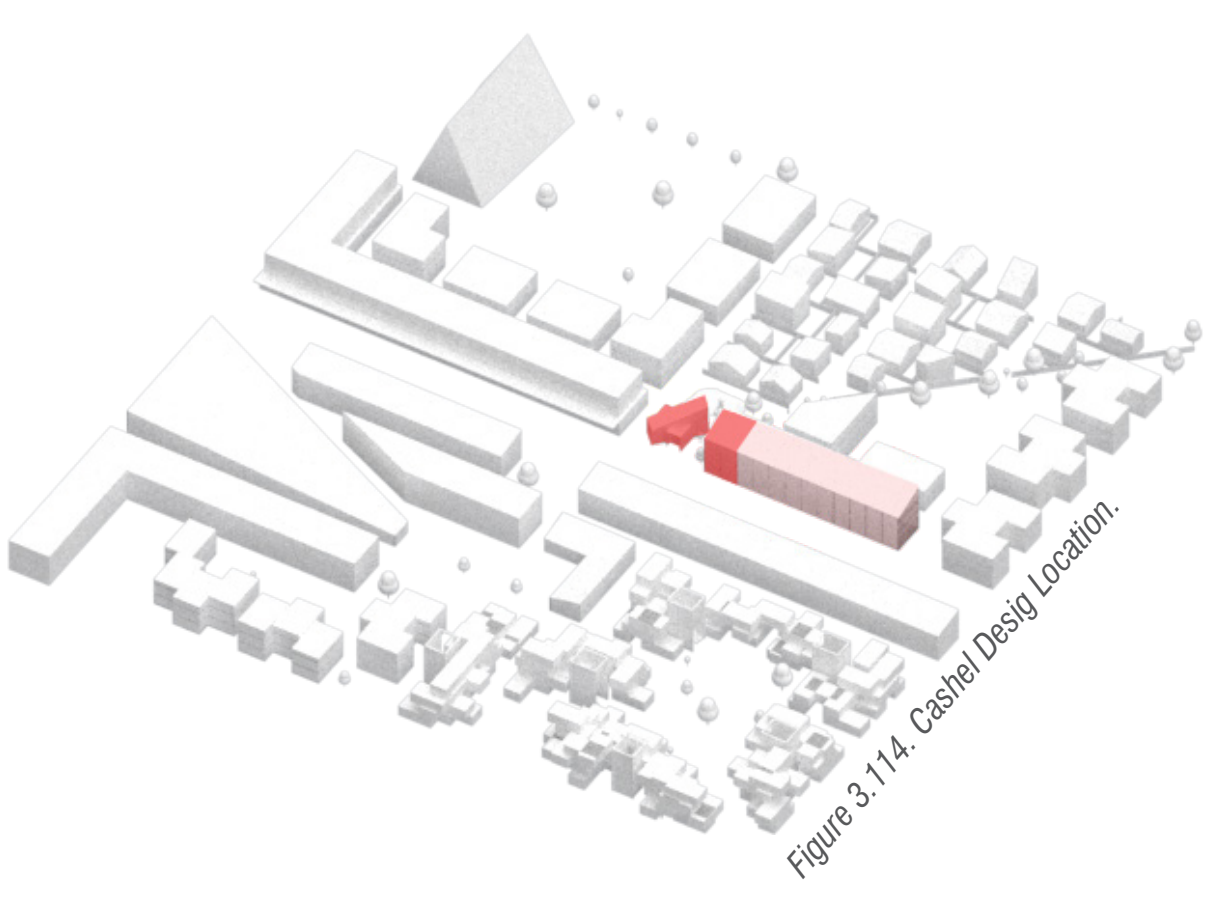
gallery facing this direction. 


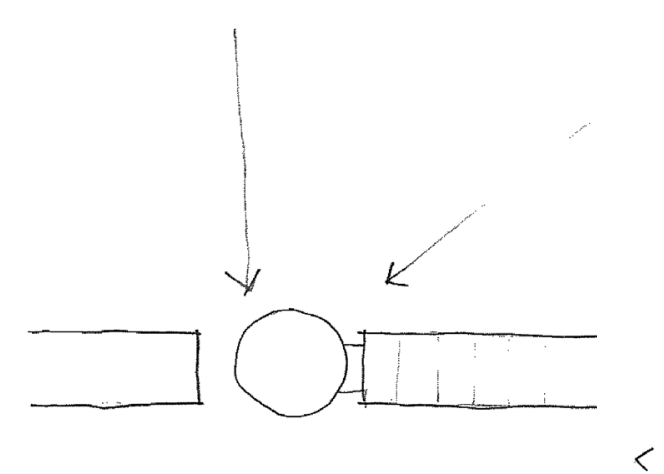

1 $\lambda$

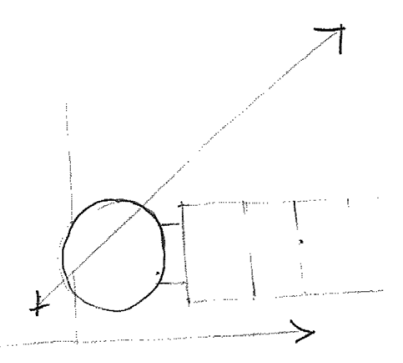

2

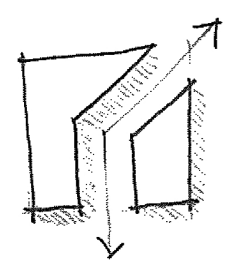

6

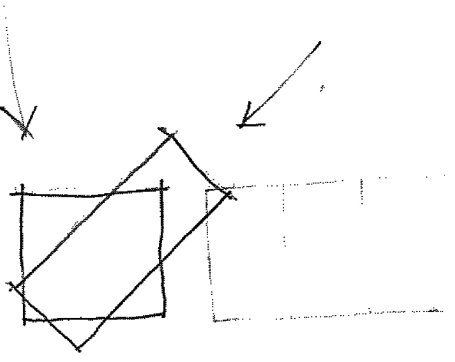

9

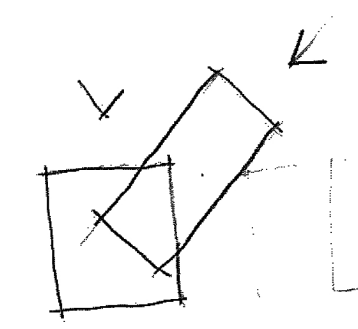

3

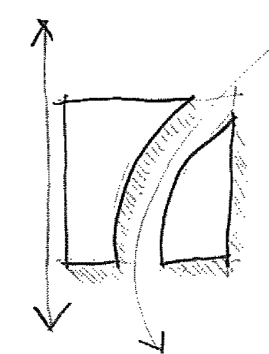

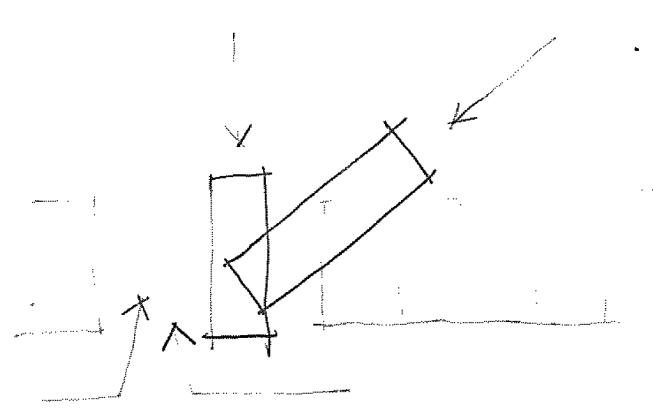

8

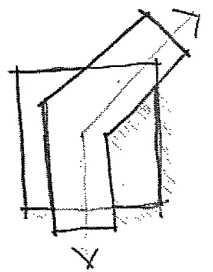

5

Figure 3.115. Parti Diagrams for Gallery.

\subsubsection{DESIGN PROCESS}

\subsubsection{Gallery}

The plan of the gallery was developed through parti diagrams. At first, the gallery was connected to the commercial building, but it was separated and given outdoor space on its east side. The separation gave the building more purpose and stature and removed restrictions to the form that it would have had if the two structures remain connected. When they were separated, part of the gallery was rotated to match the desire line pathway running diagonally through the site.

$x$

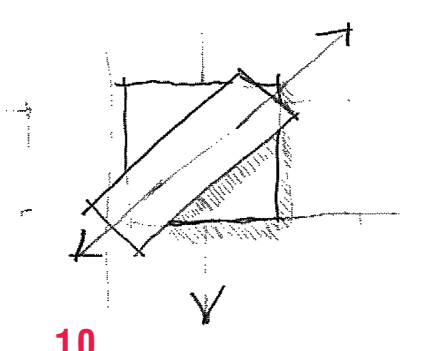




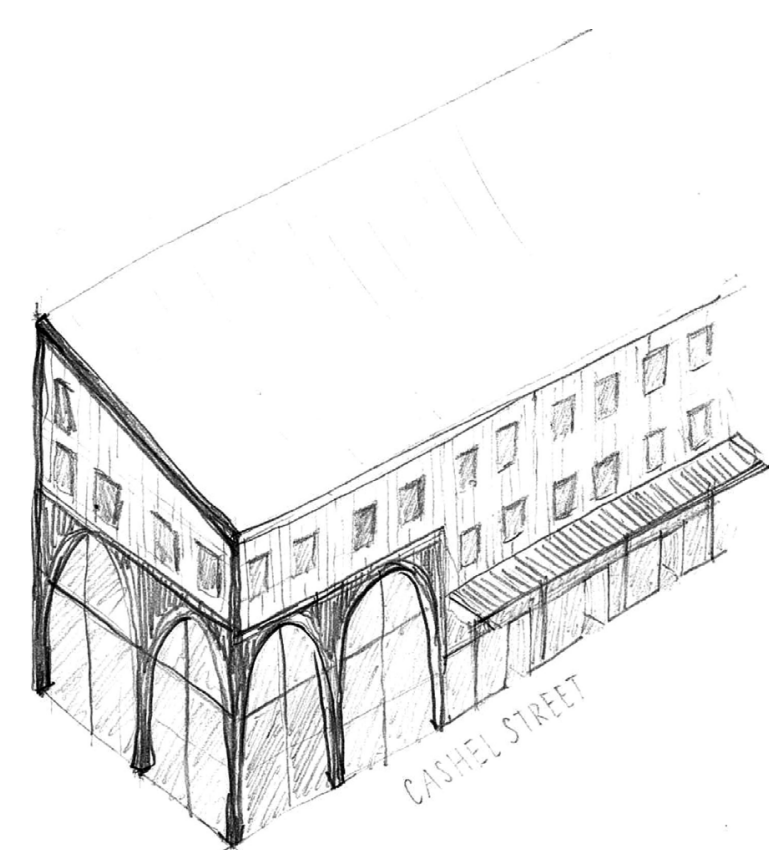

Figure 3.116. Conceptual Gallery, Commercial and Apartment form 1.

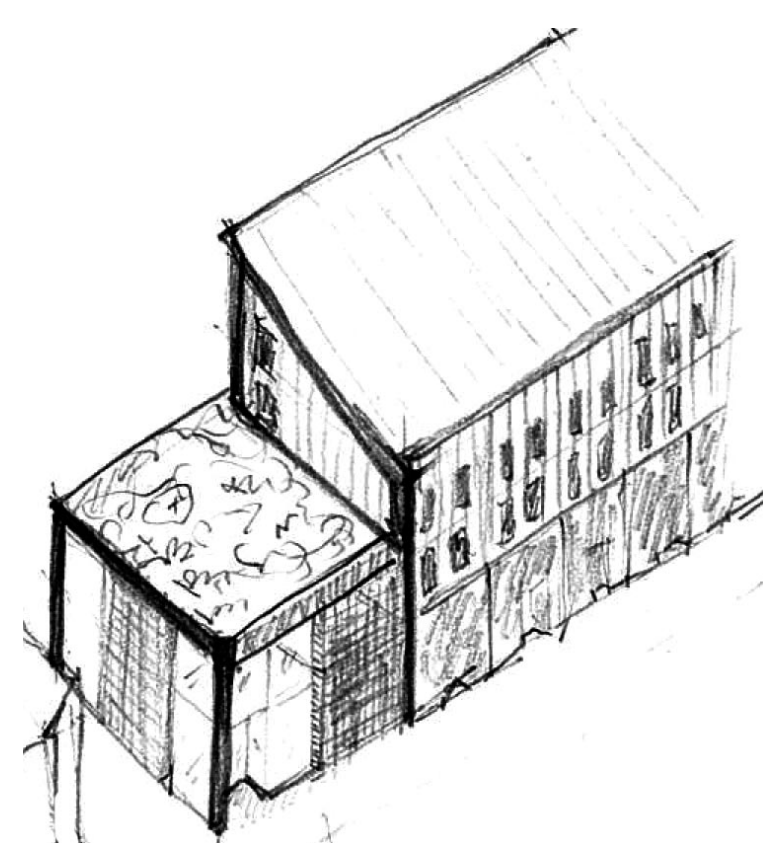

Figure 3.117. Conceptual Gallery, Commercial and Apartment form 2.

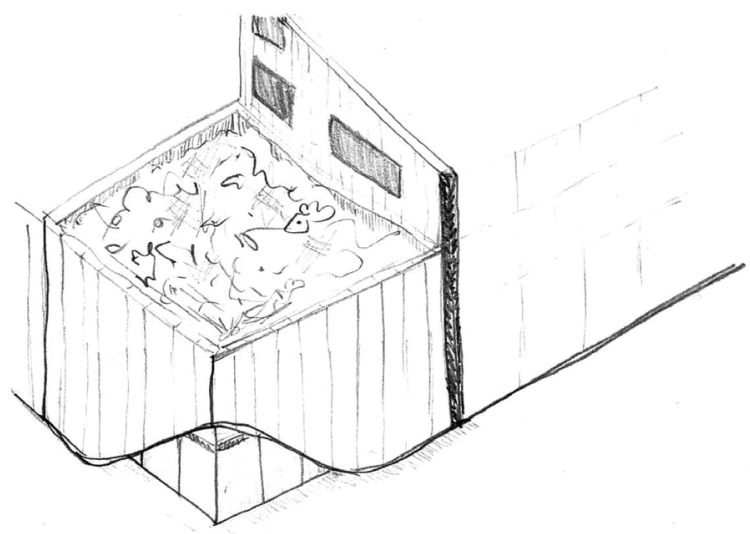

Figure 3.118. Conceptual Gallery, Commercial and Apartment form 3.

From there, the $3 \mathrm{D}$ form was created. This project has prescribed the building's function to be a gallery, but the space is for the residents to use as they collectively choose. A gallery is the suggested function of the building as it might directly relate to one achieving self-actualisation through their artworks. However, the building is designed to double-up as a community hall and function space. 

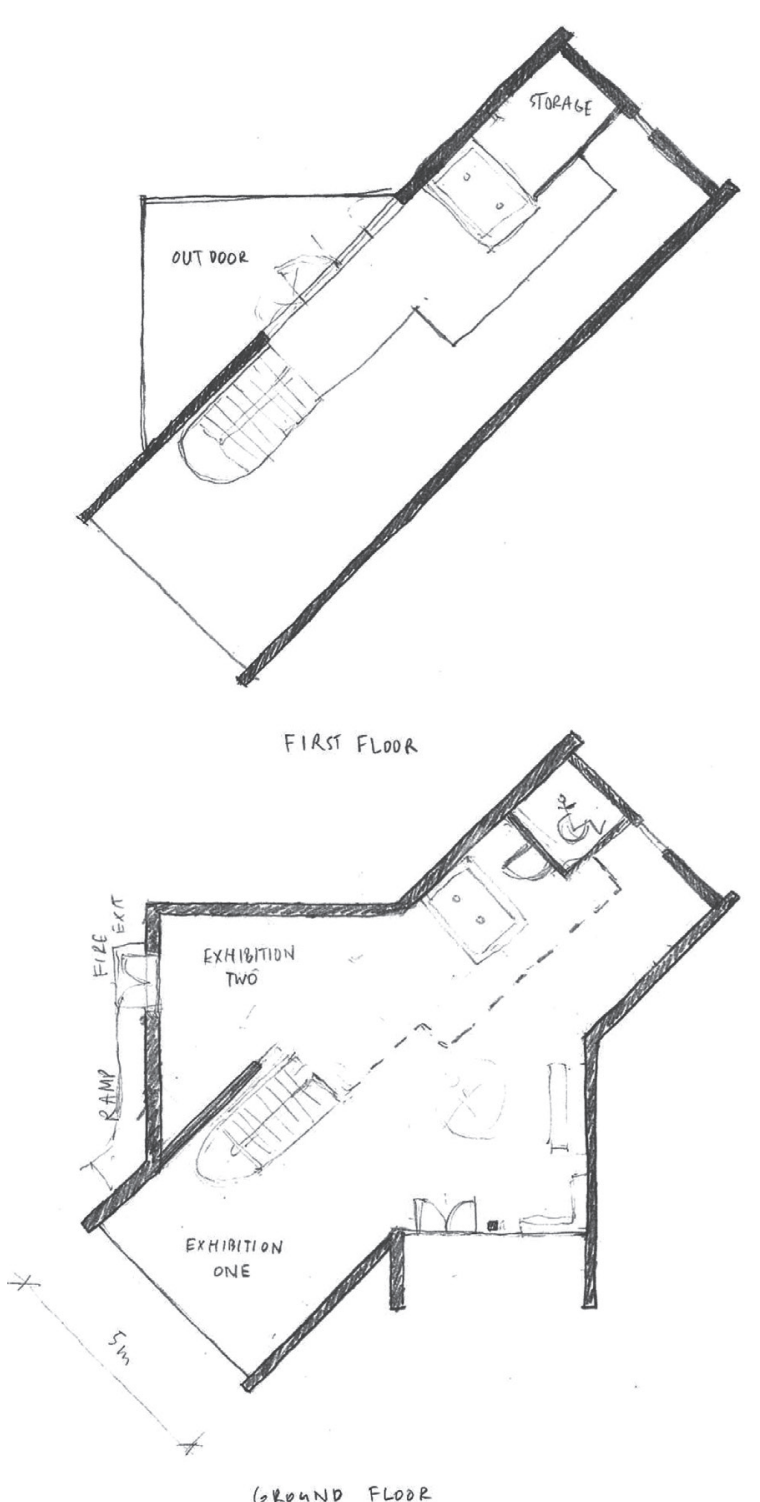

GROUND FLOOR

Figure 3.119. Conceptual plans of Gallery.

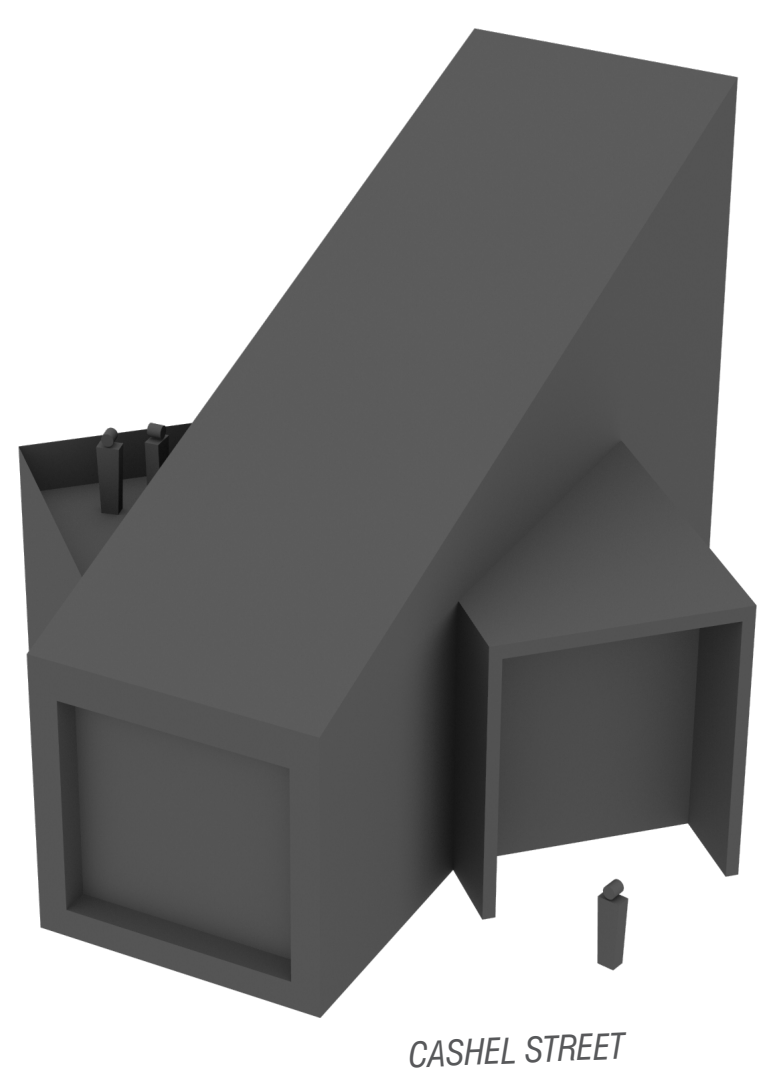

Figure 3.120. Conceptual plans of Gallery.
The form is read from the outside as three pieces: one strong, grounded centre piece seemingly contradicting the two main axes that Cashel Street and the north-south path run along; an entrance piece facing Cashel Street; and a north-facing piece with a terrace on it. When one walks around to the public space on the north side of the building, the path leading diagonally out to the corner of Hereford and Barbadoes Streets is revealed. Conversely, the tall structure draws people from the corner, through the site toward the gallery. Inside the gallery, a tall double-height space is revealed after the entrance-way. A mezzanine floor gives a different perspective to visitors of taller art pieces and gives access to the terrace on the north-west side. The public outdoor space on the north side of the gallery is an amenity to the nearby housing and commercial spaces and could be used as seating space for cafes 


\subsubsection{Commercial}

The commercial spaces along Cashel Street were designed with permeability and access to the back laneway in mind. Every third commercial space is transparent, meaning that someone walking along Cashel Street can see through the building to the laneway. These spaces would be best as cafés with seating in the laneway, on the north side of the building. The visual connection strengthens the connection from the site to the city and reinforces safety needs; a lower-level need, but an important one, nevertheless.

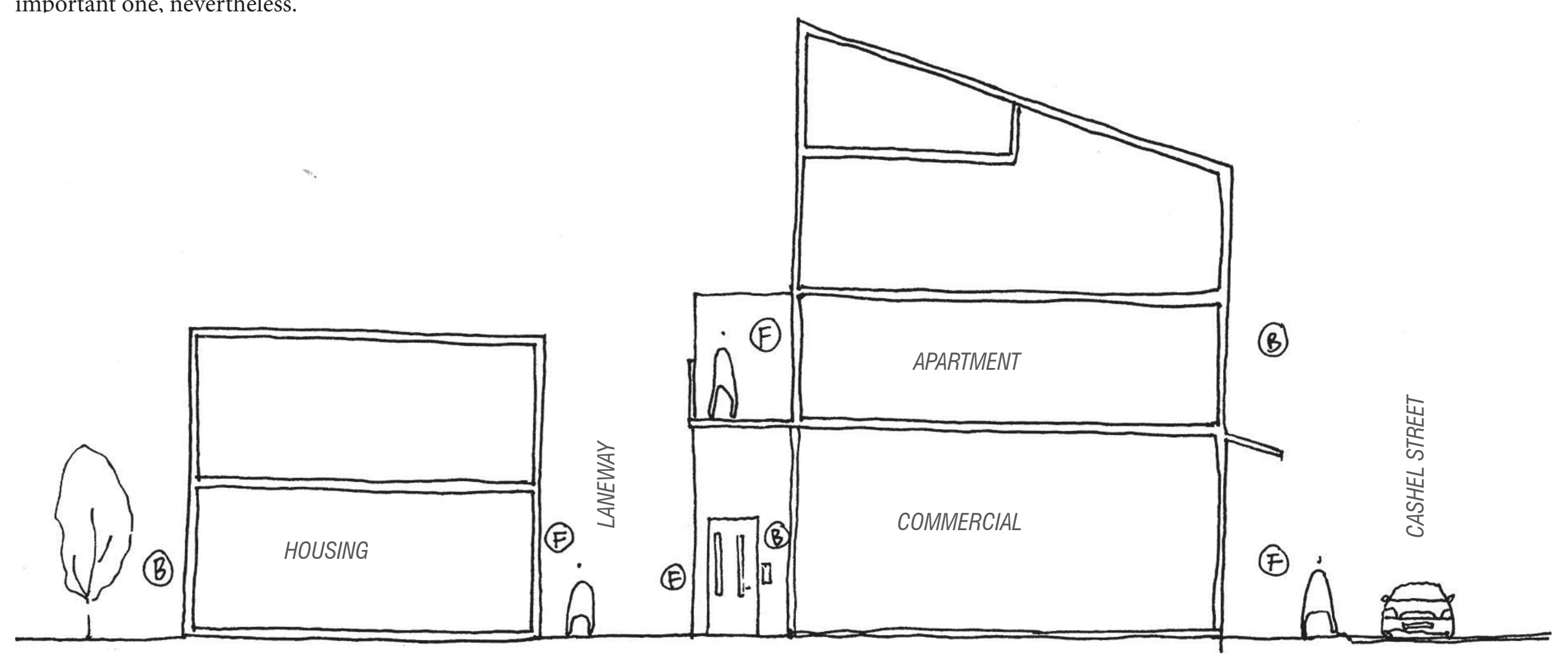

Figure 3.121. Fronts-of-house vs.back-of-house. 


\subsubsection{Apartments}

The apartments above the commercial spaces are accessed from stairwells via the laneway on the north side. Pairs of apartments share a common stairwell from the laneway. As discussed in the Masterplan development, appropriately addressing the fronts and backs of houses is crucial. The laneway access to the apartments challenged this notion. This was solved, as shown in the section drawing below.

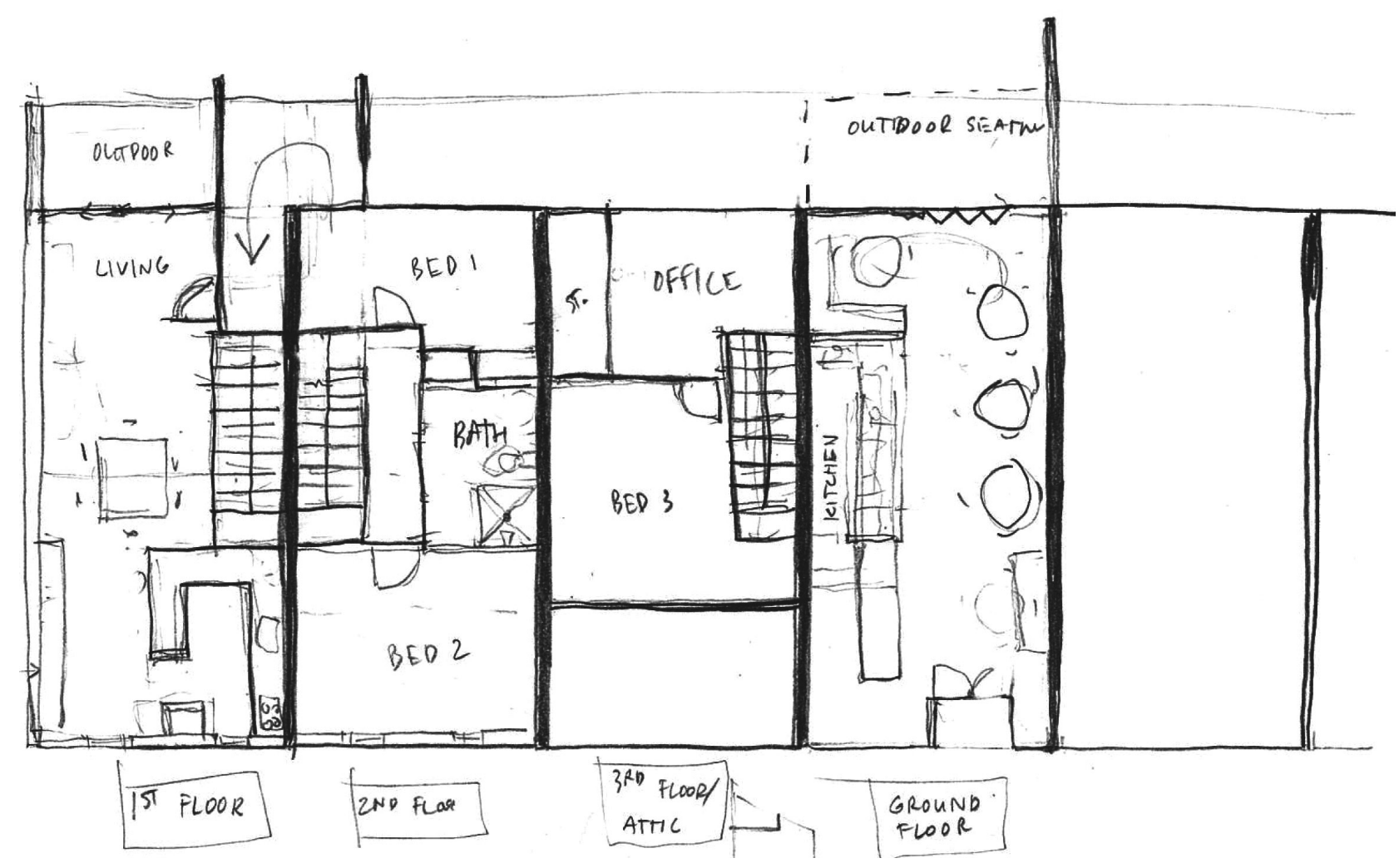

Figure 3.122. Conceptual plans of apartments and commercial. 
The apartments have two storeys facing Cashel Street, the building then sweeps up to the north to reveal a third half-story/ attic space. This was done to let more light onto Cashel Street in the winter. Also, the east and west ends of the building have a dramatic mono-pitched roof which tells the public it is residential. Tall windows on the south façade, facing Cashel Street, give people of all mobility and size (e.g. small children) inside the apartments the opportunity to watch the street. The windows were also a 'nod' to the neo-gothic architecture that was once a lot more prevalent in Christchurch.

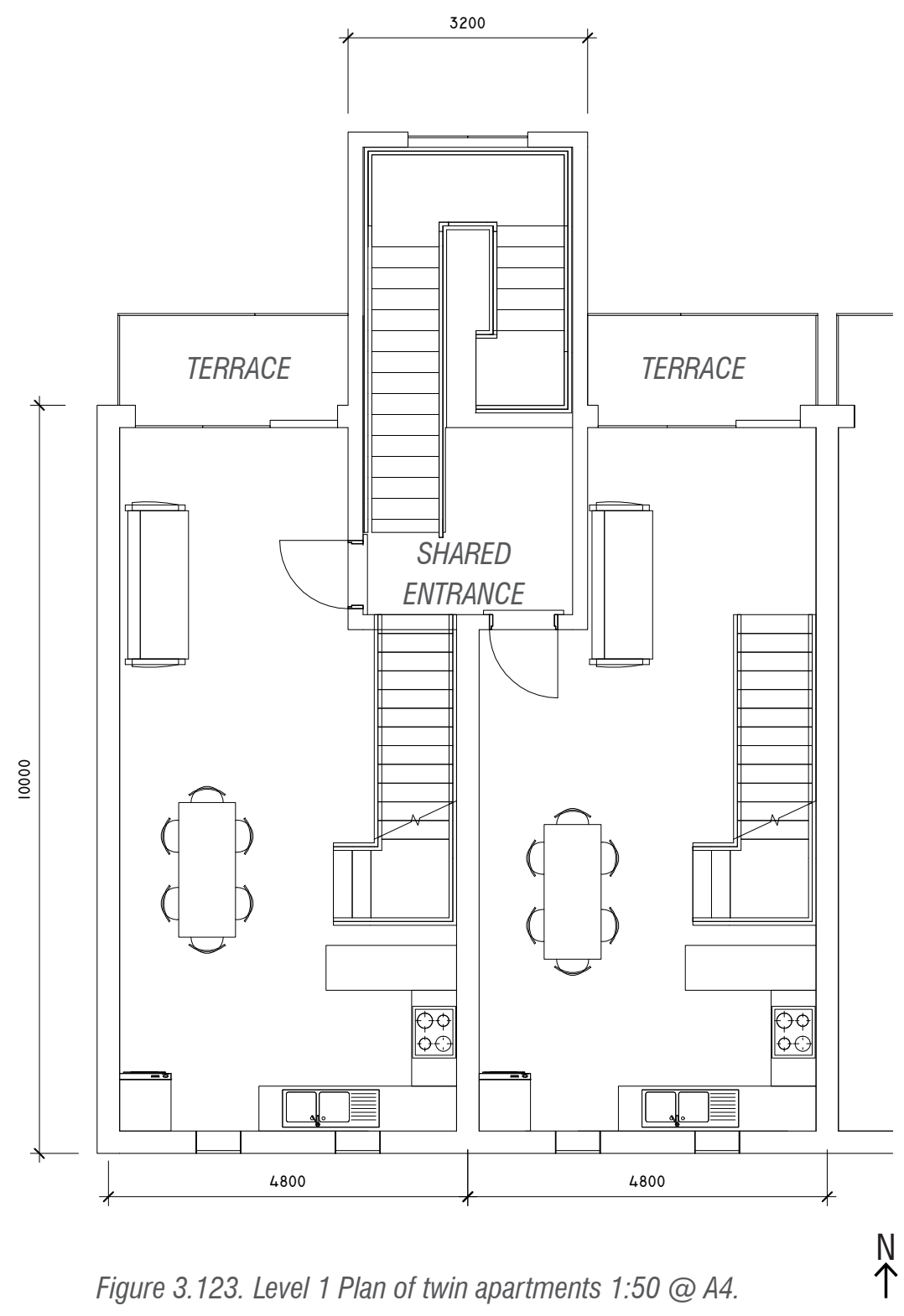




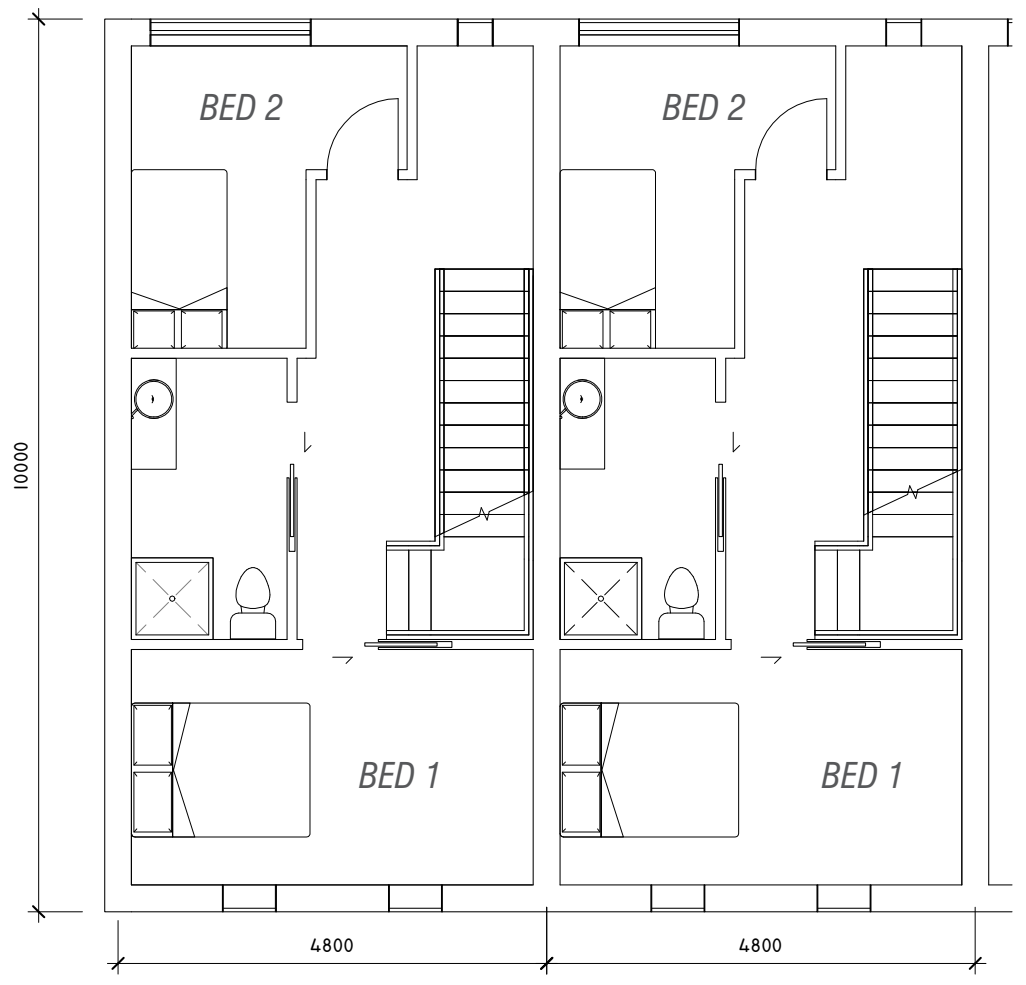

Figure 3.124. Level 2 Plan of twin apartments 1:50@ A4.

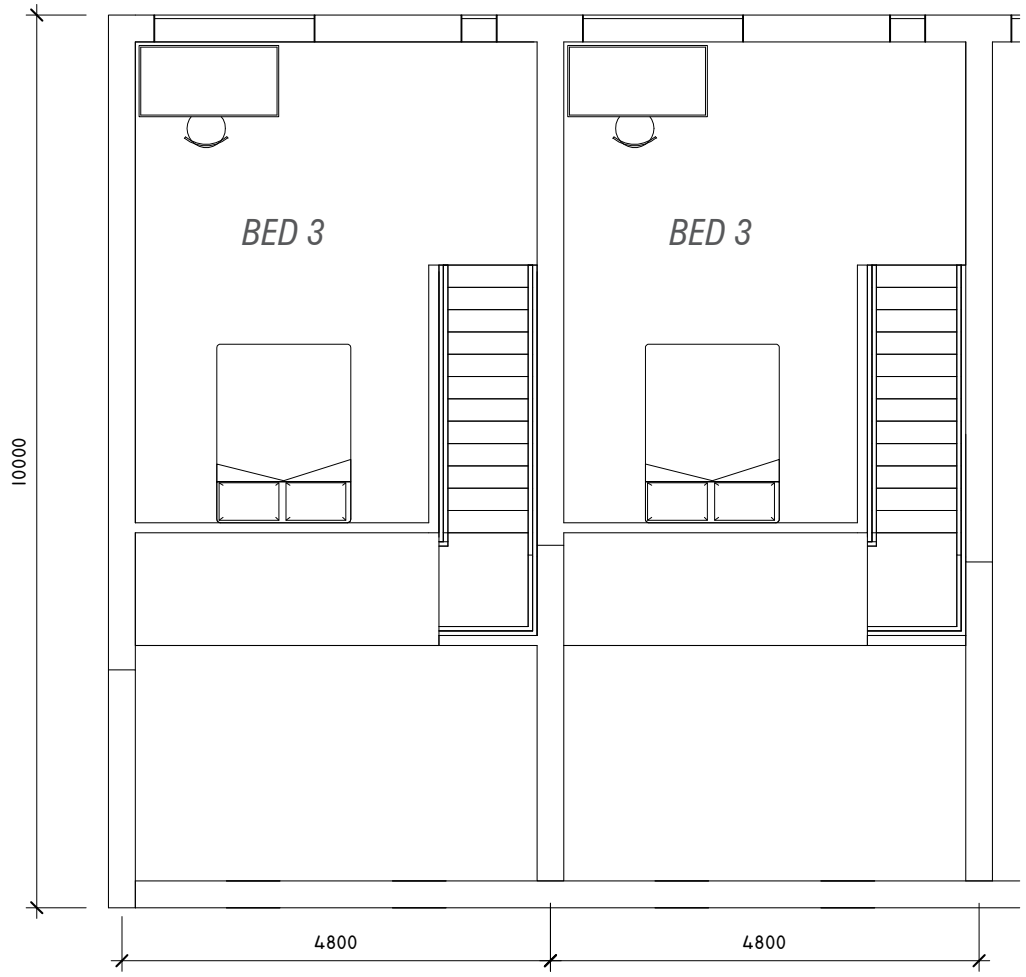

Figure 3.125. Level 3 Plan of twin apartments 1:50 @ A4. $\quad \stackrel{\uparrow}{\uparrow}$ 


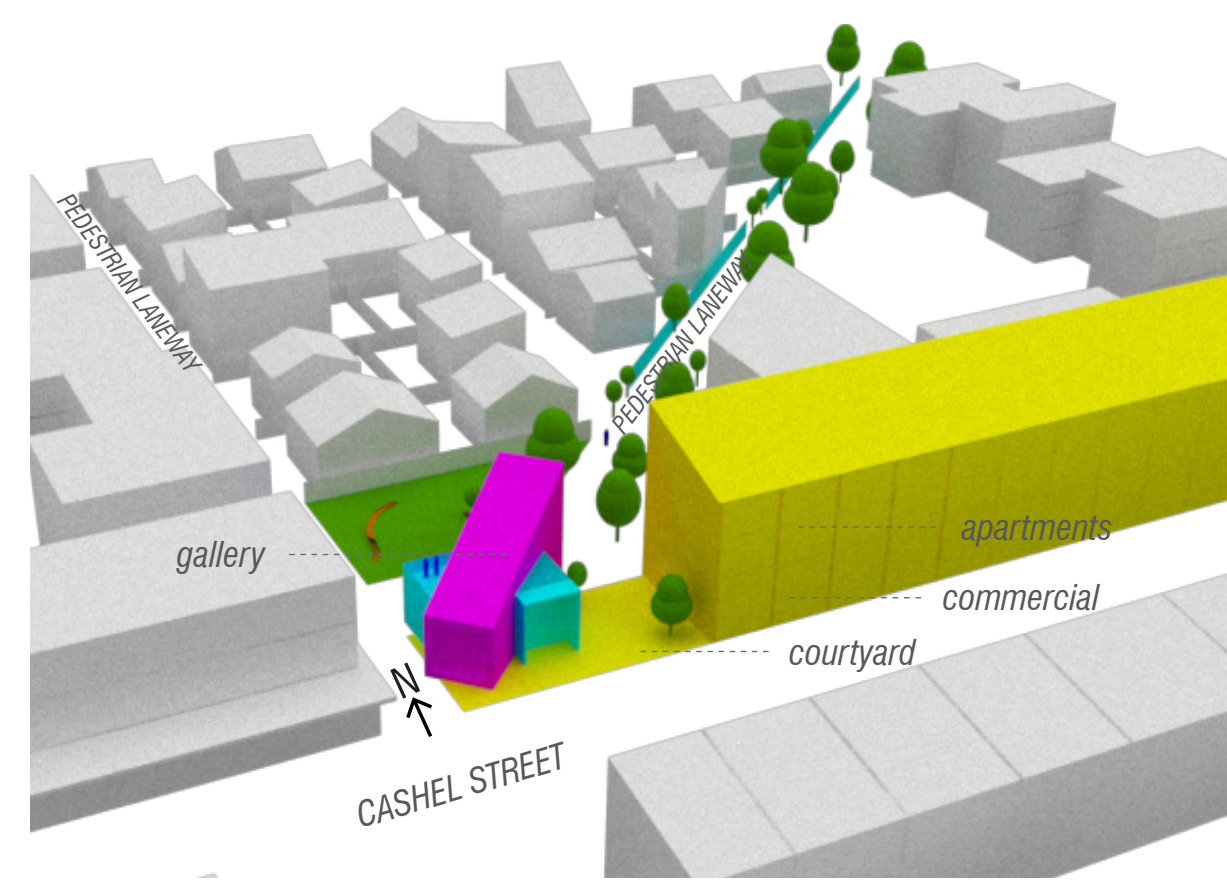

Figure 3.126. Gallery, Commercial and Apartments basic forms .

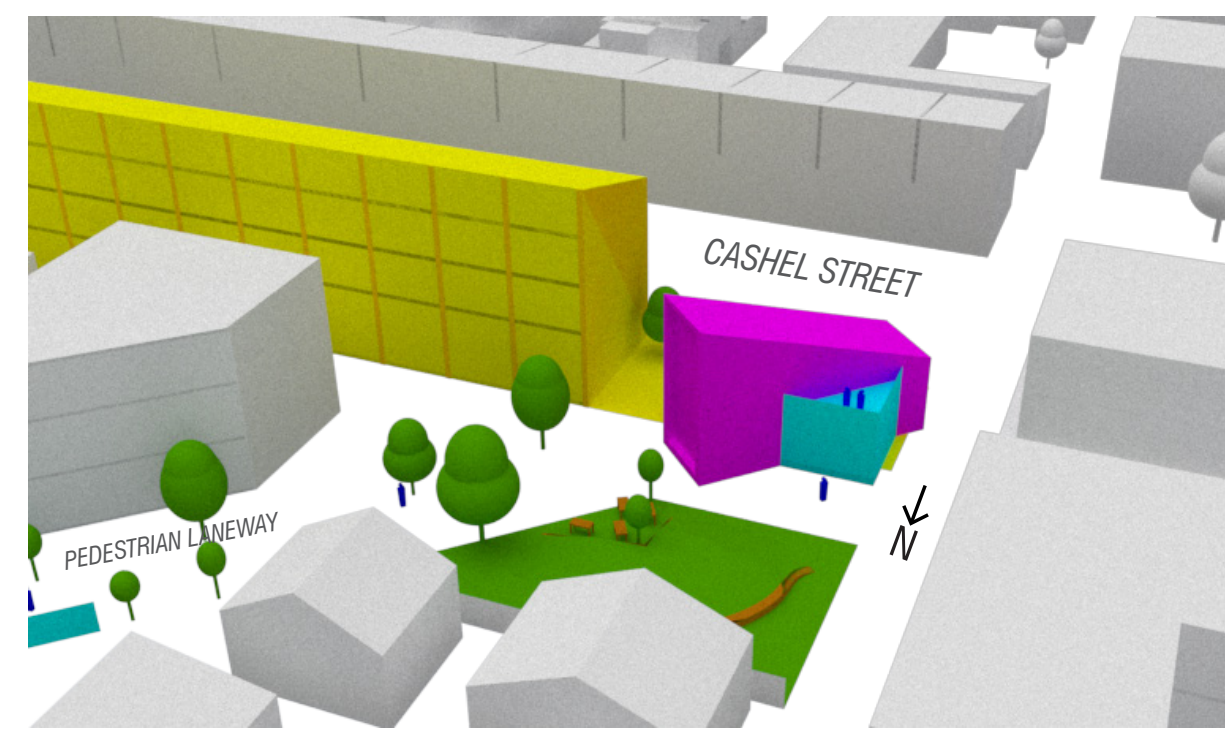

Figure 3.127. Outdoor space by Gallery .

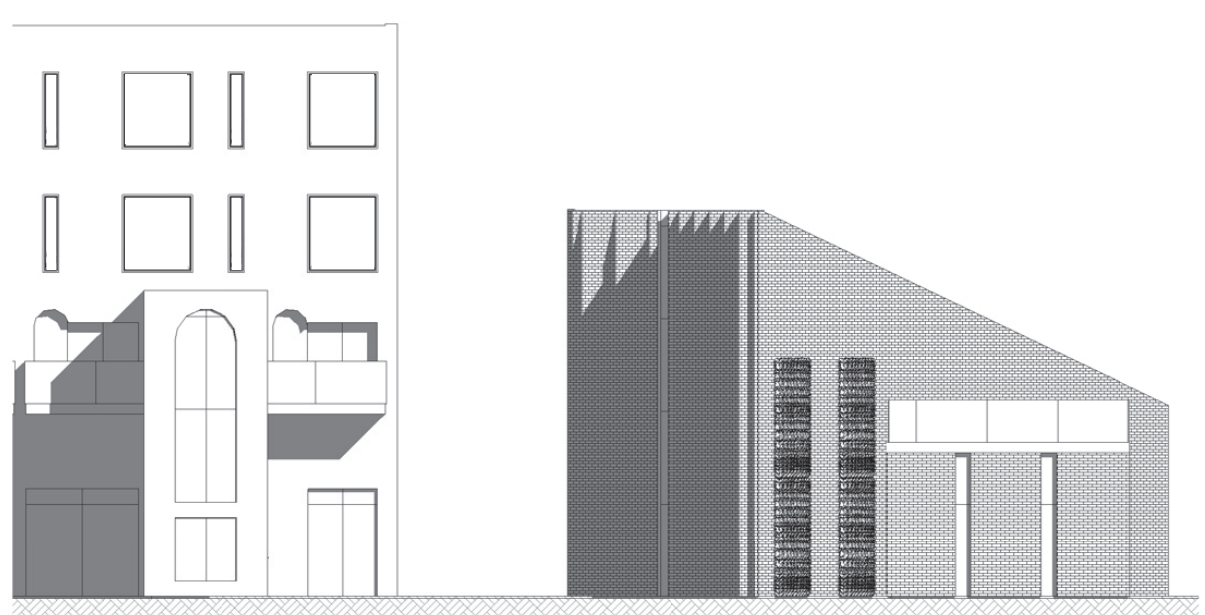

Figure 3.129. North elevation of Commercial, Apartments and Gallery .

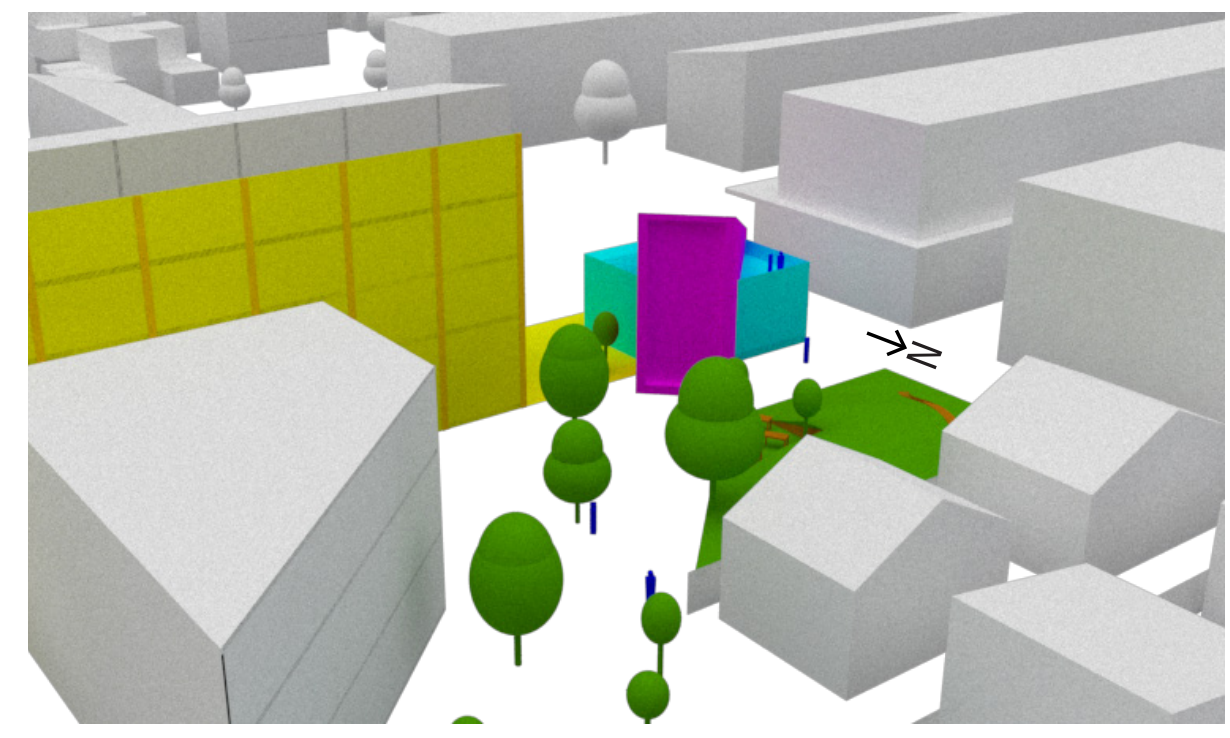

Figure 3.128. Laneway to Gallery . 


\subsubsection{REFLECTION}

Separating the gallery from the commercial and apartment building was a successful move as it enabled the gallery to have its own architectural identity. The form of the building addresses Cashel Street and the two paths well. Additionally, the gallery invites members of the public to enter the building and view local artworks. This achieves the second criterion: connection to the city in a more intimate way than other design experiments, as visitors can be inside of a building and get a snippet of the lives of some of the residents through the medium of their artwork.

Although the gallery/ community building is not technically $\mathrm{MDH}$, it is an integral part of the overall housing design. Residents of the site (not just in the apartments) can use the gallery in the way that they decide to as a community, meeting psychological needs at all levels; connection with the community, competence to voice opinions and self-actualisation to be autonomous with the space.

Having apartments above commercial spaces gives residents the opportunity to rent a shop/ office space and have a live-above-work lifestyle and potentially support their self-actualisation needs.

From the beginning, this design experiment promised to be more complex than Lichfield and Hereford, as it has three building typologies. Therefore, attempting to achieve one criterion from each of the three psychological human needs made the goal clearer.

\subsubsection{TECHNIQUES AND IDEAS IMPORTED FROM ANOTHER DESIGN EXPERIMENT TO} CASHEL

From the Masterplan: As discussed previously, the first iteration of the Masterplan showed the fronts of some houses facing the backs of others. The attention of this issue was brought to the apartments above commercial spaces and their relationship to the alleyway behind them in the Cashel Street design. This has been mitigated by the design shown in the illustration below.

From the Masterplan: As discussed in section 3.3.7, the form of the gallery building on Cashel Street was informed by the diagonal path on the masterplan. The form and the path aim to invite passers-by into the site, thus meeting criterion no. 2: Connection to City.

From Lichfield: Various 'box' sizes tested as part of the development of the Lichfield Street dwellings were used to inform an appropriate size and layout of the apartments on the Cashel Street site. The allocated space for the apartments provided from the Masterplan was a maximum length of $10 \mathrm{~m}$. Testing sizes in the Lichfield design experiments proved that 
Future research could look into addressing cars in a situation that is tight for space like this design experiment was. A challenging aspect of this site is that the commercial occupancies under the apartments have their backs facing the laneway. If cars were parked here, then that connection would not be so strong. If the project allowed for more time, lessons from the Hereford Street houses could be applied to car parking under the apartments. this length was long enough and that apartments could afford to be narrow $(4.8 \mathrm{~m})$ and still functionally work.

\subsubsection{TECHNIQUES AND IDEAS THAT HAVE BEEN EXPORTED FROM CASHEL}

To the Masterplan: Having transparency through every third ground-level commercial space strengthens the connection between the site and the city as passers-by can see through to the spaces beyond. This also reinforces lower-level needs on Maslow's hierarchy: safety. This technique was used in advancing the Masterplan. The terrace houses along Barbadoes and Lichfield Streets were broken up to allow light and views in and out of the site boundary. 


\subsection{SUMMARY OF DESIGN}

It is common, as seen on the east end of Cashel

Street, for housing to be dense and not have spaces or spatial relationships that foster interneighbour relationships. This project has, however, demonstrated in a number of ways how it is possible to design housing at higher densities and at the same time, encourage relationships between residents through the design of communal spaces. This proves to designers, developers and communities who are interested in adopting this framework for design, that there are multiple ways to achieve the criteria and that it is robust and universal for different housing types. The design followed the process of developing a site in the industrial/ car park zone of Cashel Street, incorporating commercial and residential spaces along a gradient. The first two iterations of the Masterplan failed to blend the commercial and residential zones; however, upon critical reflection, this was amended in the third iteration with the development of a more holistic design. From the Masterplan, three spaces within the site were chosen for further development. A staggered apartment structure, clustered single-detached houses, and a gallery and commercial spaces with apartments above them were used as the architectural medium for testing the design framework. Lessons from each area were cross-referenced to other design areas to make educated decisions. The cluster of apartments explored in the Lichfield design experiment is representative of all of the apartments on Lichfield. Similarly, the cluster of houses on Hereford is representative of all the houses in that area. The one-year time limit for this project did not allow for all of the sites to be finished to this level of detail.
Instead, a few close-ups of the site allowed enough investigation through design to answer the research question thoughtfully. Overall, the design brief was followed, and every one of the criteria from the framework was tested at least once in at least one design exploration. This proved that the framework is robust and applicable to many different housing types. 
4.1 REFLECTIONS

4.2 CONCLUSION 


\subsection{REFLECTIONS}

This design-led research project worked within a framework for design based on Maslow's Hierarchy of Needs. The framework brings relevance to having psychological well-being as an integral part of the design of medium-density housing. The research was undertaken in the context of research through architectural design and has provided a platform for design. The design itself demonstrated an example of how the framework may be interpreted into the built form.

The project used Cashel Street, a central street in Christchurch, to test and evaluate the framework through an iterative architectural design process. After the framework was produced, there was an opportunity to either test it on a single, highly detailed design or, to test it on multiple designs. It was necessary to choose either quantity or detail due to the time limit of the twelve-month project. The breadth of the framework would have made it difficult to test all the criteria on one design. Thus, four design solutions for the site, namely the overall Masterplan, and three smaller sites within it, were iteratively worked out while cross-referencing each other and drawing lessons to help the design process of each. Further, laneways through the site might encourage future developments on adjacent sites to continue the path and bring more connection to the city.

As Maslow explains, there is some fluidity between the needs; they are not so linear. Therefore, some of the architectural responses to the framework can relate to multiple criteria. Competence and autonomy outcomes were an example of this. Residents choosing a home that suits them best from a range of different layouts may not only give them a sense of autonomy but competence as well.

When adopted by others, the specificities outlined in the framework will not all be relevant, as they were tailored to the specific site. It is therefore encouraged that designers, architects, communities and developers who are developing housing adopt the principles of each criterion, and alter the details to suit their project. For example, they might collaboratively rewrite the "Means to Achieve Desired Outcome" and "Role of Design/ Designer" sections of the framework (see section 2.3.8, a summary of the design framework).

Focus groups would have been an ideal way to legitimately test the 6th criterion: the resident's autonomy on-site. However, the one-year time limit of the project made 
this impossible. For future research in this field, focus groups with residents who live within a few blocks of the site could provide the project with valuable inside knowledge of the subjective qualities and the day to day happenings of the place. Alternatively, a focus group could be conducted after the majority of the design work is completed to provide feedback on its function and aesthetics before the completion of the final design. 


\subsection{CONCLUSION}

\subsubsection{ANSWER TO THE RESEARCH QUESTION:}

How can the design of medium-density housing support its occupants to meet their psychological needs?

Naturally, housing should support its occupants' basic needs; shelter, warmth, water, safety and protection. The three higher-level needs, social, esteem and selfactualisation are not always supported by one's housing. However, housing can support its occupants to meet these higher-level needs in two different ways for each need.

Socially, occupants can be connected to both their

SOCLAL neighbours and the rest of the city. Crafting the shared

and communal spaces to encourage occupants to slow down and talk to each

other can help occupants to connect with their neighbours. Additionally, visual and physical connections to the broader context of the place will help residents to have a sense of belonging. In this project's case, it was Christchurch city.

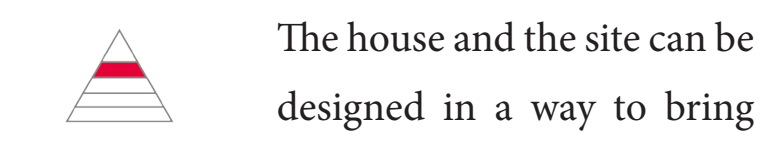

ESTEEM about the esteem of the residents. Firstly, the house can be good quality and have visual differences to all other houses so that people feel proud of their home. Secondly, when a site is designed with many ways to get from one side to another, people can feel competent while navigating their own way through the site.

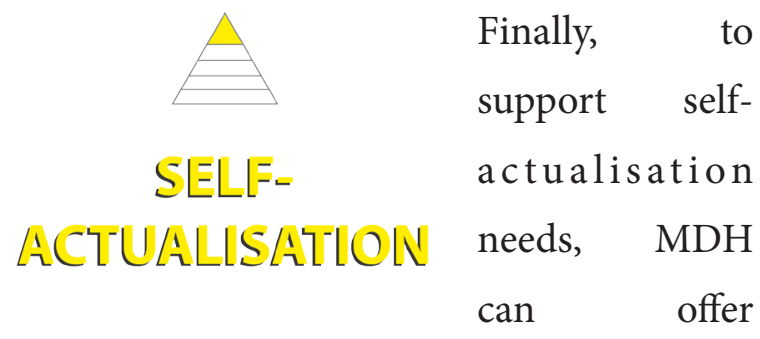

residents autonomy within the dwelling, and throughout the site as a whole. Residents can choose a home that suits their wants and needs from a range of different shapes and sizes rather than having to choose a generic house, giving them autonomy at the scale of the dwelling. Secondly, residents having autonomy at the scale of the site means that they can use the site to live autonomously day to day by growing food in a communal garden or generating electricity. Further, future residents could be included in the design phase of the project to ascertain what spaces they want or need. 


\subsubsection{LIMITATIONS}

The time limit of a master's thesis and the nature of the project made it impossible to conduct research involving humans. This research would have benefitted from consultation with relevant people in the conceptual stage of the design to provide a basis for the design. It would have also been advantageous to consult residents from the area at the end of the project to give qualitative feedback on the outcome. There are limitations to testing architecture's effect on people, primarily how the home affects its occupants. This left a qualitative gap in the findings. However, the approach taken in this project was to test multiple urban housing typologies against a robust framework that bridges the disparity between the abstract Hierarchy of Needs, and more pragmatic needs of housing. In doing so, the research project concluded that it is possible, and recommended, that housing at higher densities can support its occupants to fulfil their psychological needs.

Additionally, to manage the scope of the project, costs and cost analyses were excluded from the research. Bringing a monetary aspect to the research could have made the conclusions more realistic, but if time had been spent on it, the outcomes of the project would have been underdeveloped.

\subsubsection{FUTURE RESEARCH}

It would have been advantageous to the research to test out another area of the Masterplan with a different housing type again, for example, the terraced housing on the south-west corner of the site. Therefore, further research could pick up from this project and demonstrate how housing around a community garden performs while being so close to the adjacent commercial part of the site.
Other future research in this field might consider alternative ways of addressing the housing crisis. One answer might not be just to build more housing but to improve the housing that already exists. Instead of demolishing buildings, an act which is disturbing to the environment, and building new ones in their place, what if existing housing is adapted to support its occupants to meet their psychological needs?

\subsubsection{FINAL REMARKS}

"Design cannot cause behaviour, but it can offer the possibility of certain activities taking place" (Cooper Marcus and Sarkissian, 1986).

Conversely, when a design is executed poorly, it can constrain behaviour unnecessarily. Therefore, housing alone cannot make one self-actualised. One must do the work if one is to become a self-actualised person truly. However, the spaces we continuously surround ourselves with do have effects on 
us; thus if one has a good foundation at home, it will support them in their psychological growth. This design-led research project has demonstrated how this is possible. 


\section{BIBLIOGRAPHY}

Bratt, R G. (2002) 'Housing and Family Well-Being'. Housing Studies 17 (1): 13-26.

Campos-Andrade, C. Hernández-Fernaud, E. and Lima, M. (2013) 'A Better Physical Environment in the Workplace Means Higher Well-Being? A Study with Healthcare Professionals'. PsyEcology 4 (1): 89-110.

Christchurch City Council. (2013) Intersection Count Search. Available from: Open Source Repository < https://ccc.govt.nz/transport/transport-projects/ traffic-count-data/intersection-count-search/> (accessed 25 January 2020).

Cooper Marcus, C. (1983) The Medium-Density Housing Kit: Guidelines and Resources for Designing Better Housing at Higher Densities. Milsons Point, N.S.W.: Milsons Point, N.S.W. : Social Impacts Publications.

Cooper Marcus, C. and Sarkissian, W. (1986) Housing as If People Mattered: Site Design Guidlines for Medium-Density Family Housing. Edited by Peter Hall and Peter Marris. University of California Press.

Després, C. (1991) 'The Meaning of Home: Literature Review and Directions for Future Research and Theoretical Development'. Journal of Architectural and Planning Research 8 (2): 96-115.

Dudding, A., Hoffman, T. and Hastings, A. (2018) 'Quality of Life Survey 2018: Topline Report'. Prepared on behalf of Auckland Council, Wellington City Council, Christchurch City Council, and Dunedin City Council. Wellington, New Zealand.
Evans, G W., Wells, N.M. and Moch, A. (2003) 'Housing and Mental Health: A Review of the Evidence and a Methodological and Conceptual Critique.' Journal of Social Issues 59 (3): 475-500.

Grimes, A. (2019) 'Well-Being at the Local Level'. Policy Quarterly; Vol 15 No 2 (2019): Special Issue: Localism and DevolutionD0 - 10.26686/Pq.V15i2.5369, May.

"Habitat 67" (2015) Available from: Open Source Repository < http://www. habitat67.com/en/homage/> (accessed 8 October 2019).

Hickey, B. (2019). Two Cents' Worth: The Park Mews effect. Available from: Open Source Repository <https://www.newsroom.co.nz/2019/02/23/458752/twocents-worth-the-park-mews-effect $>$ (accessed 20 January 2020).

Jacobs, J. 1961. The Death and Life of Great American Cities.

Jansen, S. (2013) Different Values, Different Housing? Can Underlying Value Orientations Predict Residential Preference and Choice? Vol. 31.

Johnson, A., Howden-Chapman, P. and Eaqub, S. (2018). 'A Stocktake of New Zealand's Housing'. New Zealand Government. Available from: Open Source Repository <https://www.beehive.govt.nz/sites/default/files/2018-02/A\%20 Stocktake\%200f\%20New\%20Zealand\%27s\%2OHousing.pdf.> (accessed 20 July 2019). 
Kearns, A., Hiscock, R., Ellaway, A. and MaCintyre, S. (2000) "Beyond Four Walls". The Psycho-Social Benefits of Home: Evidence from West Central Scotland'. Housing Studies 15 (3): 387-410.

MacPherson, L. (2016) "National Population Projections: 2016(Base)-2068." Stats NZ. October. Available from: Open Source Repository <http://archive. stats.govt.nz/browse_for_stats/population/estimates_and_projections/ NationalPopulationProjections_HOTP2016.aspx> (accessed 11 July 2019).

Maslow, A.H. (1943) 'A Theory of Human Motivation'. Psychological Review 50: 370-96.

Morrison, P.S. (2019) 'Measuring Local Well-Being'. Policy Quarterly; Vol 15 No 2 (2019): Special Issue: Localism and DevolutionD0 - 10.26686/Pq.V15i2.5370,

May.

Ryan, R.M., and Deci, E.L. (2000) 'Self-Determination Theory and the Facilitation of Intrinsic Motivation, Social Development, and Well-Being.' The American Psychologist 55 (1): 68-78.

Seligman, M.E.P., and Csikszentmihalyi, M. (2000) 'Positive Psychology: An Introduction.' The American Psychologist 55 (1): 5-14.

Shostrom, E. (1968) Abraham Maslow and Self Actualization Interview. Available from: Open Source Repository <https://www.youtube.com/ watch?v=7DOKZzbuJQA\&t=1734s $>$ (accessed 8 April 2019)

“The Sustainable Development Goals Report”. (2019) New York: 2019 United Nations. Available from: Open Source Repository <https://unstats.un.org/sdgs/ report/2019/The-Sustainable-Development-Goals-Report-2019.pdf. >
"United Nations Population Division | Department of Economic and Social Affairs." (2019). United Nations. Available from: Open Source Repository <https://www. un.org/en/development/desa/population/index.asp > (Accessed 22 July 2019)

Walker, R. (2018). The Pertinence of Park Mews. Available from: Open Source Repository <http://www.rogerwalker.co.nz/2018/05/the-pertinence-of-parkmews/> (accessed 20 January 2020). 


\section{LIST OF FIGURES}

Figure 2.1. Abraham Maslow. Source: https://www.verywellmind.com/biography-of-abraham-maslow-1908-1970-2795524

Figure 2.2. Maslow's Hierarchy of Needs. Source: Author, after Maslow, 1943

Figure 2.3. Antisocial housing 353 Cashel Street. Source: Author

Figure 2.4. Antisocial housing 533 Cashel Street. Source: Author

Figure 2.5. A 2017 aerial view of the residential red zone in Christchurch.

Source: https://www.stuff.co.nz/the-press/news/99097784/government-asks-christchurch-red-zone-stayers-about-their-plans

Figure 2.6. Christchurch Avon River. Source: https://www.stuff.co.nz/thepress/news/95661149/the-future-isnt-going-anywhere-so-why-didchristchurch-rebuild-the-city-of-yesterday

Figure 2.7. Antisocial housing 491 Cashel Street. Source: Author

Figure 2.8. Red zone. Source: https://www.nzgeo.com/issue/124/

Figure 2.9. Christchurch from above. Source: https://www.stuff.co.nz/thepress/news/95661149/the-future-isnt-going-anywhere-so-why-didchristchurch-rebuild-the-city-of-yesterday

Figure 2.10. Habitat 67. https://www.archdaily.com/772632/living-anatomy-an-exhibition-about-housing-at-harvard-graduate-school-ofdesign/55df7580e58ece77 ef0000e8-living-anatomy-an-exhibitionabout-housing-at-harvard-graduate-school-of-design-image

Figure 2.11. Construction of Habitat 67. Source: https://www.vintag.es/2019/05/ habitat-67-construction.html

Figure 2.12. Architect Moshe Safdie with the model for Habitat 67. Source: https://www.vintag.es/2019/05/habitat-67-construction.html

Figure 2.13. Habitat 67 Circulation. Source: https://www.mtl.org/en/experience/ revolutionary-montreal-icon-habitat-67

Figure 2.14. Park Mews. Iconic 30 unit development in Hataitai, Wellington. Source: http://www.rogerwalker.co.nz/multi-unit-houses/

Figure 2.15. Park Mews Terrace. Source: https://nz.raywhite.com/wellington-city/hataitai/2064015/

Figure 2.16. Park Mews. Iconic 30 unit development in Hataitai, Wellington. Source: http://www.rogerwalker.co.nz/multi-unit-houses/

Figure 2.17. Stranges Lane. Source: author
Figure 2.18. Lichfield Courtyard. Source: author

Figure 2.19. Stranges Lane. Source: author

Figure 2.20. Lichfield Courtyard. Source: author

Figure 2.21. Stranges Lane. Source: author

Figure 2.22. High St Laneway. Source: author

Figure 2.23. Lichfield St Laneway. Source: author

Figure 2.24. Habitat 67. https://www.archdaily.com/772632/living-anatomy-an-exhibition-about-housing-at-harvard-graduate-school-ofdesign/55df7580e58ece77ef0000e8-living-anatomy-an-exhibitionabout-housing-at-harvard-graduate-school-of-design-image

Figure 2.25. Park Mews. Iconic 30 unit development in Hataitai, Wellington. Source: http://www.rogerwalker.co.nz/multi-unit-houses/

Figure 2.26. Stranges Lane. Source: author

Figure 3.1. Aerial view looking towards Latimer Square. Source: https://discoverywall.nz/media/45151

Figure 3.2. Site Location Plan. Source: Author, after http://www. arcgis.com/home/webmap/viewer.html?webmap $=7$ baec8e1cf1b439bb6644bd4ba64bf11

Figure 3.3. Site Location Plan 2. Source: Author

Figure 3.4. Zones and Thresholds. Source: Author after https://koordinates. $\mathrm{com} /$ search/global/oceania/new-zealand/?q=building + outlines Figure 3.5. House on Cashel Street. Source: Author

Figure 3.6. Section sketch of Cashel Street Residential Zone. Source: Author Figure 3.7. Building on Cashel Street. Source: Author

Figure 3.8. Elevation Sketch "Very tall all of a sudden". Source: Author

Figure 3.9. Avon River from Bridge of Remembrance. Source: Author

Figure 3.10. Section Sketch over Avon River. Source: Author

Figure 3.11. Cashel Mall. Source: Author

Figure 3.12. "Street is Social Space". Source: Author

Figure 3.13. Bike Parks on Cashel. Source: Author

Figure 3.14. Section Sketch "Park open and engaging". Source: Author

Figure 3.15. Car Parking Sign on Cashel. Source: Author

Figure 3.16. Section Sketch through barren car parking. Source: Author 
Figure 3.17. Abandoned building on Cashel Street. Source: Author

Figure 3.18. Sketch of fence abandoned building Source: Author

Figure 3.19. Prominent driveway. Source: Author

Figure 3.20. Speculative section sketch of house. Source: Author

Figure 3.21. Prominent driveway 2. Source: Author

Figure 3.22. Plan sketch of house and driveway Source: Author

Figure 3.23. Footpath on Cashel Street. Source: Author

Figure 3.24. Plan sketch "Monotonous housing". Source: Author

Figure 3.25. Heavy fence, missing gate. Source: Author

Figure 3.26. Plan Sketch "Heavy fence, missing gate". Source: Author

Figure 3.27. Hierarchy of Needs Speculation. Source: Author after https://koordinates.com/search/global/oceania/new-zealand/?q=building + outlines

Figure 3.28. Block Lengths. Source: Author after https://koordinates.com/ search/global/oceania/new-zealand/?q=building + outlines

Figure 3.29. Nearby Destinations. Source: Author after https://koordinates.com/ search/global/oceania/new-zealand/?q=building + outlines

Figure 3.30. Traffic Volume. Source: Author after https://koordinates.com/ search/global/oceania/new-zealand/?q=building + outlines

Figure 3.31. Birds eye view site location. Source: Author after https:// www.google.com/maps/place/Christchurch/@43.5378419,172.6303002,377a,35y,61.31h,69.87t/data$=! 3 \mathrm{~m} 1 ! 1 \mathrm{e} 3 ! 4 \mathrm{~m} 5 ! 3 \mathrm{~m} 4 ! 1 \mathrm{~s} 0 \times 6 \mathrm{~d} 322 \mathrm{f} 4863 \mathrm{c} 5 \mathrm{ed} 01: 0 \times 500 \mathrm{ef} 86847999$ 45!8m2!3d-43.5320544!4d172.6362254

Figure 3.32. Masterplan brainstorm. Source: Author.

Figure 3.33. Space Outlines Masterplan Iteration 1. Source: Author.

Figure 3.34. Negative Space as Positive Object Masterplan Iteration 1. Source: Author.

Figure 3.35. Positive Space Masterplan Iteration 1. Source: Author.

Figure 3.36. Colour-coded Masterplan Iteration 1. Source: Author.

Figure 3.37. Space Outlines Masterplan Iteration 2. Source: Author.

Figure 3.38. Negative Space as Positive Object Masterplan Iteration 2. Source: Author.
Figure 3.39. Positive Space Masterplan Iteration 2. Source: Author.

Figure 3.40. Digital Model of Masterplan Iteration 2. Source: Author.

Figure 3.41. Masterplan Iteration 2 sketch. Source: Author.

Figure 3.42. Masterplan 2 with Context. Source: Author after https://www.google.com/maps/@-43.5369601,172.6475064,418a,35y,322.69h,50. $58 \mathrm{t} / \mathrm{data}=! 3 \mathrm{~m} 1 ! 1 \mathrm{e} 3$

Figure 3.43. Masterplan 3 initial site plan sketch. Source: Author after https:// www.google.com/maps/@-43.5369601,172.6475064,418a,35y,3 $22.69 \mathrm{~h}, 50.58 \mathrm{t} /$ data $=! 3 \mathrm{~m} 1 ! 1 \mathrm{e} 3$

Figure 3.44. Masterplan 3 initial site plan sketch. Source: Author after https:// www.google.com/maps/@-43.5369601,172.6475064,418a,35y,3 $22.69 \mathrm{~h}, 50.58 \mathrm{t} / \mathrm{data}=! 3 \mathrm{~m} 1 ! 1 \mathrm{e} 3$

Figure 3.45. Masterplan 3 refined site plan sketch. Source: Author after https:// www.google.com/maps/@-43.5369601,172.6475064,418a,35y,3 $22.69 \mathrm{~h}, 50.58 \mathrm{t} / \mathrm{data}=! 3 \mathrm{~m} 1 ! 1 \mathrm{e} 3$

Figure 3.46. Masterplan Iteration 3 Development 1. Source: Author

Figure 3.47. Masterplan Iteration 3 Development 2. Source: Author.

Figure 3.48. Masterplan Iteration 3 Development 3. Source: Author.

Figure 3.49. Masterplan Iteration 3 Development 4. Source: Author.

Figure 3.50. Masterplan Iteration 3 Development 5. Source: Author.

Figure 3.51. Masterplan Iteration 3 Development 6. Source: Author.

Figure 3.52. Masterplan Iteration 3 Development 7. Source: Author.

Figure 3.53. Masterplan Iteration 3 Development 8. Source: Author.

Figure 3.54. Masterplan Iteration 3 Development 9. Source: Author.

Figure 3.55. Masterplan Iteration 3 Colour-coded. Source: Author.

Figure 3.56. Masterplan Iteration 3 with context. Source: Author.

Figure 3.57. Masterplan with design experiement sites identified. Source: Author

Figure 3.58. Lichfield Housing Location. Source: Author.

Figure 3.59. Box test: $3.6 \mathrm{~m} \times 7.2 \mathrm{~m}$. Source: Author.

Figure 3.60. Box test: $4.2 \mathrm{~m} \times 8.4 \mathrm{~m}$. Source: Author.

Figure 3.61. Box test: $4.2 \mathrm{~m} \times 8.4 \mathrm{~m}$. Source: Author.

Figure 3.62. Box test: $4.8 \mathrm{~m} \times 9.6 \mathrm{~m}$. Source: Author.

Figure 3.63. Box test: $5 \mathrm{~m} \times 10 \mathrm{~m}$. Source: Author. 
Figure 3.64. Box test: $6 \mathrm{~m} \times 12 \mathrm{~m}$. Source: Author.

Figure 3.65. Chosen box: $4.8 \mathrm{~m} \times 9.6 \mathrm{~m}$. Source: Author.

Figure 3.66. Paper box arrangement 1. Source: Author.

Figure 3.67. Digital box arrangement view 1. Source: Author.

Figure 3.68. Digital box arrangement view 2. Source: Author.

Figure 3.69. Paper box arrangement 2. Source: Author

Figure 3.70. Dwelling cluster arrangement cladding identities. Source: Author

Figure 3.71. Stair parti diagram 1. Source: Author.

Figure 3.72. Stair parti diagram 2. Source: Author.

Figure 3.73. Stair parti diagram 3. Source: Author.

Figure 3.74. Two stair landings, multiple runs. Source: Author.

Figure 3.75. Circular stair and walkways Source: Author.

Figure 3.77. Digital model circular stair 1. Source: Author.

Figure 3.76. Circular stair with observatoires Source: Author.

Figure 3.78. Digital model circular stair 2. Source: Author.

Figure 3.79. Digital model square stair. Source: Author.

Figure 3.80. Two stairs with central lobby. Source: Author.

Figure 3.81. Winding stair with central landing. Source: Author.

Figure 3.82. Outdoor stair elevation. Source: Author.

Figure 3.83. Outdoor stair plan. Source: Author.

Figure 3.84. Zipline/ Flying fox. Source: Author.

Figure 3.85. Climbing wall. Source: Author.

Figure 3.86. Slide 1. Source: Author.

Figure 3.87. Slide 2. Source: Author.

Figure 3.88. Ladder. Source: Author.

Figure 3.89. Fireman's pole. Source: Author.

Figure 3.90. Slide, climbing wall and pole in stairwell. Source: Author.

Figure 3.91. climbing wall close-up. Source: Author.

Figure 3.92. Top of stairwell as a lookouts and way-finding. Source: Author.

Figure 3.93. Section of stair and observatory. Source: Author.

Figure 3.94. Rounded stair landing. Source: Author.

Figure 3.95. Square stair landing with rest and planting. Source: Author.

Figure 3.96. Central walkway plan. Source: Author.
Figure 3.97. Faster pace vs. Slower pace. Source: Author

Figure 3.98. Coloured facade stairwell building. Source: Author.

Figure 3.99. Coloured and illuminated stairwell building. Source: Author.

Figure 3.100. Coloured and illuminated stairwell building. Source: Author.

Figure 3.101. Angled roof form perspective. Source: Author.

Figure 3.102. Angled roof form section. Source: Author.

Figure 3.103. Stairwell building layout plan. Source: Author.

Figure 3.104. Privacy between dwellings. Source: Author.

Figure 3.105. Hereford Housing Location. Source: Author.

Figure 3.106. Housing centre of site, minimal outdoor space. Source: Author.

Figure 3.107. Housing on boundary, maximum outdoor space. Source: Author.

Figure 3.108. Privacy between next-door neighbours problem - section.

Figure 3.109. Privacy between next-door neighbours reference plan. Source: Author.

Figure 3.110. Privacy between next-door neighbours solution - section. Source: Author.

Figure 3.111. Privacy across lane. Source: Author.

Figure 3.112. Hereford Housing site plan. Source: Author.

Figure 3.113. Hereford Housing from north/ west corner. Source: Author.

Figure 3.114. Cashel Desig Location. Source: Author.

Figure 3.115. Parti Diagrams for Gallery. Source: Author.

Figure 3.116. Conceptual Gallery, Commercial and Apartment form 1. Source: Author.

Figure 3.117. Conceptual Gallery, Commercial and Apartment form 2. Source: Author.

Figure 3.118. Conceptual Gallery, Commercial and Apartment form 3. Source: Author.

Figure 3.119. Conceptual plans of Gallery. Source: Author.

Figure 3.120. Conceptual plans of Gallery. Source: Author.

Figure 3.121. Fronts-of-house vs.back-of-house. Source: Author.

Figure 3.122. Conceptual plans of apartments and commercial. Source: Author.

Figure 3.123. Level 1 Plan of twin apartments 1:50 @ A4. Source: Author.

Figure 3.124. Level 2 Plan of twin apartments 1:50 @ A4. Source: Author. 
Figure 3.125. Level 3 Plan of twin apartments 1:50 @ A4. Source: Author.

Figure 3.126. Gallery, Commercial and Apartments basic forms . Source: Author.

Figure 3.127. Outdoor space by Gallery . Source: Author.

Figure 3.129. North elevation of Commercial, Apartments and Gallery . Source: Author.

Figure 3.128. Laneway to Gallery . Source: Author. 


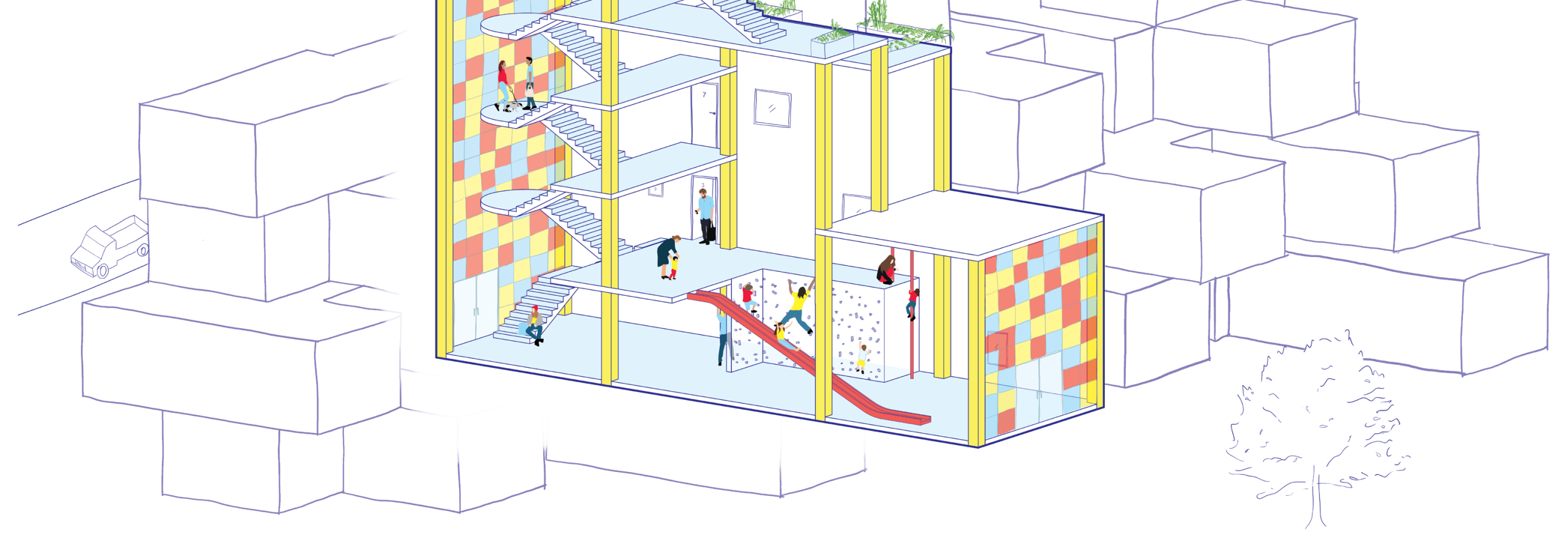

CENTRAL STAIRWELL RENDER 

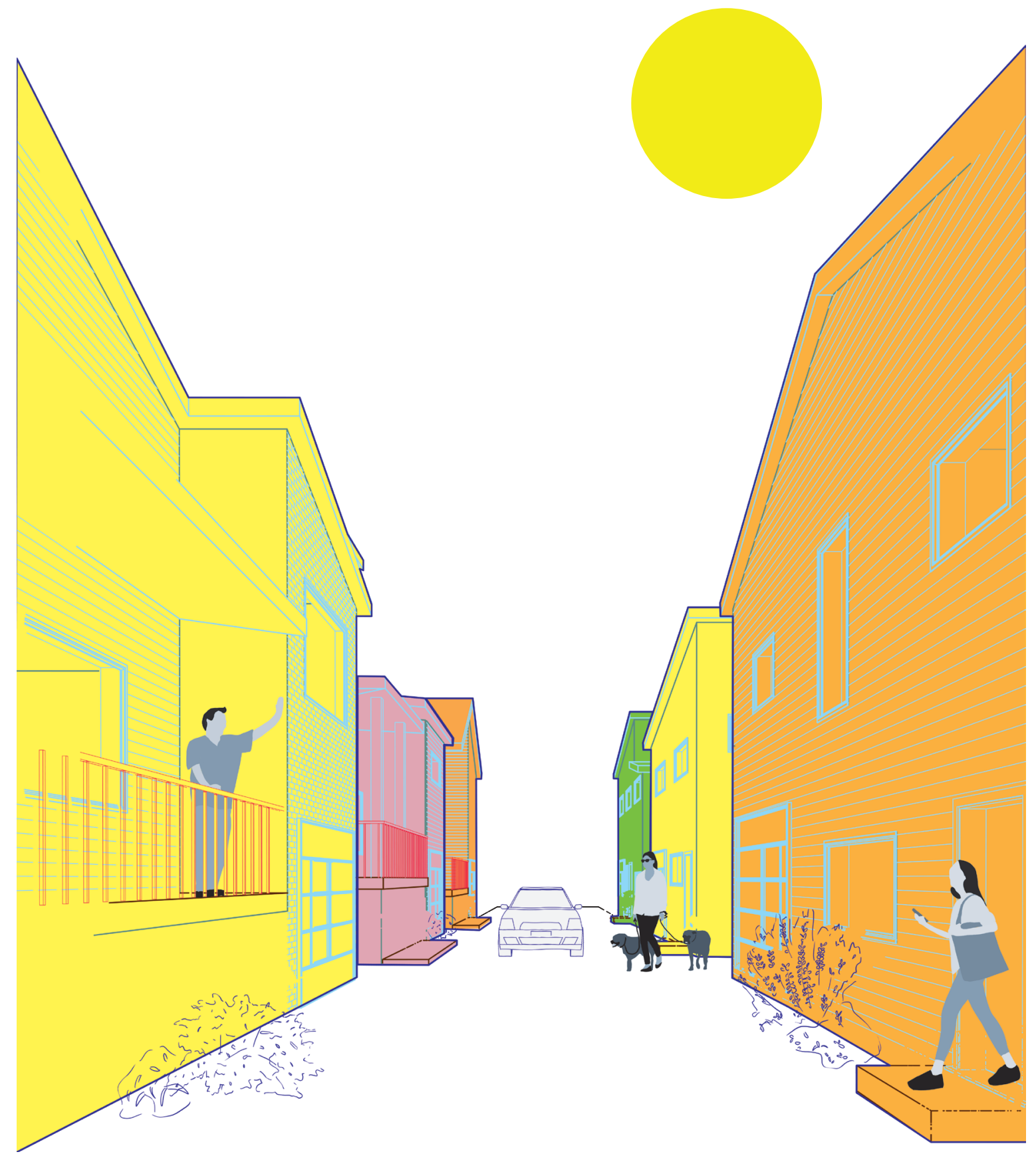


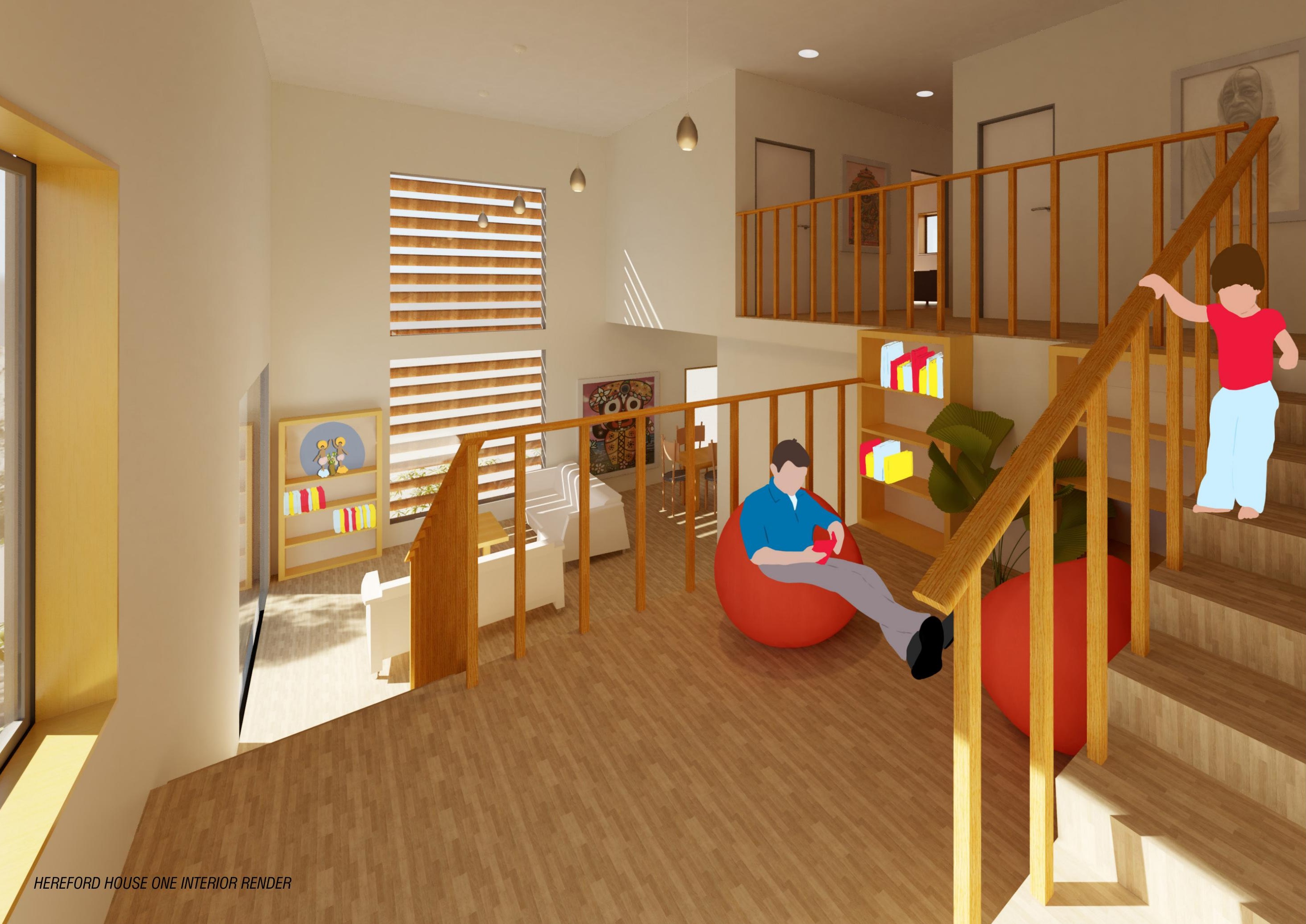




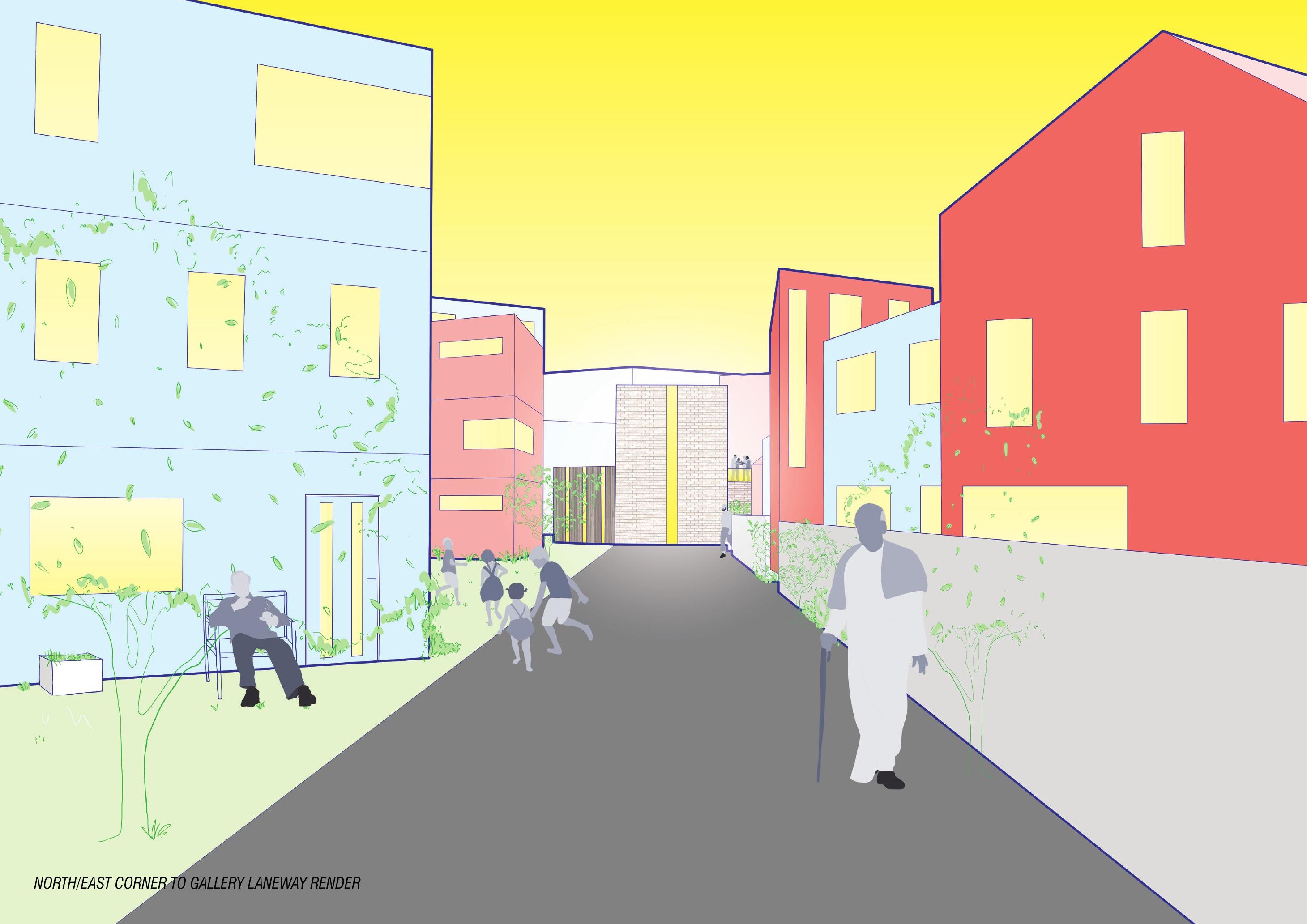




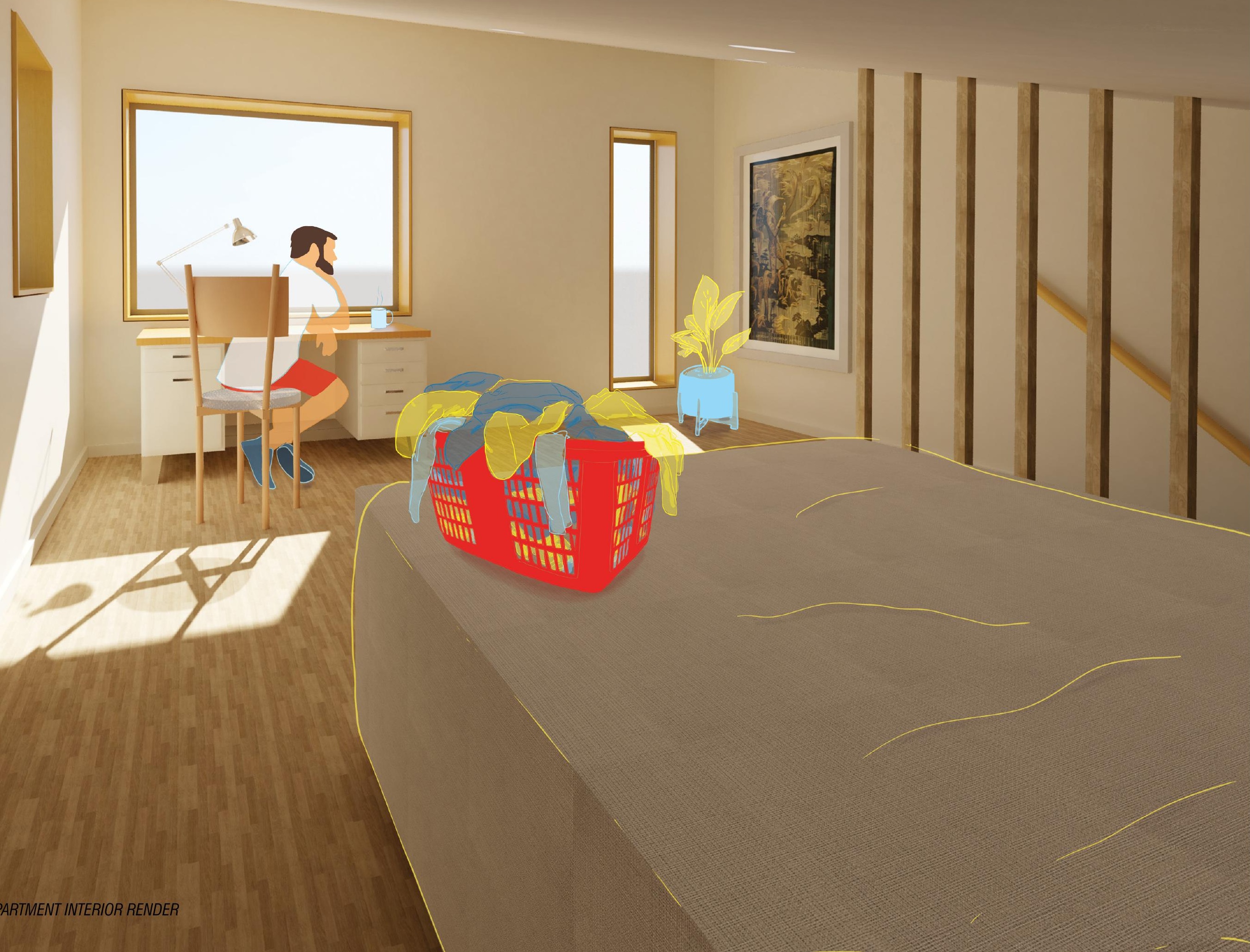

